\title{
Cranial anatomy of Bellusaurus sui (Dinosauria: Eusauropoda) from the Middle-Late Jurassic Shishugou Formation of northwest China and a review of sauropod cranial ontogeny
}

${ }^{3}$ Key Laboratory of Vertebrate Evolution and Human Origins, Institute of Vertebrate Paleontology and Paleoanthropology, Chinese Academy of Sciences, Beijing, China
\end{abstract}

Corresponding Author: Andrew J Moore

Email address: djmoore@gwmail.gwu.edu

Bellusaurus sui is an enigmatic sauropod dinosaur from the Middle-Late Jurassic Shishugou Formation of northwest China. Bellusaurus is known from a monospecific bonebed preserving elements from more than a dozen juvenile individuals, including numerous bones of the skull, providing rare insight into the cranial anatomy of juvenile sauropods. Here, we present a comprehensive description of the cranial anatomy of Bellusaurus, supplementing the holotypic cranial material with additional elements recovered from recent joint Sino-American field expeditions. Bellusaurus is diagnosed by several unique autapomorphies, including a neurovascular foramen piercing the ascending process of the maxilla at midheight, the frontal process of the nasal extending farther posteriorly onto the frontal than the prefrontal, and U-shaped medial and lateral notches in the posterior margin of the ventral process of the squamosal. Several features identified here, including a preantorbital opening in the maxilla, a stepped dorsal margin of the vomerine process of the pterygoid, and the partitioning of the dorsal midline endocranial fossae associated with the dural venous sinuses into anterior and posterior components by a transverse ridge of the parietal, are consistent with recent phylogenetic hypotheses that recover Bellusaurus as a basal macronarian or close relative of Neosauropoda. We review the current state of knowledge of sauropod cranial ontogeny, placing several aspects of the cranial anatomy of Bellusaurus in an ontogenetic context and providing explicit hypotheses of ontogenetic transformations that can be tested by future discoveries of ontogenetic variants of sauropod skulls. While scoring ontogenetically variable characters as unknown may help to alleviate the biasing effects of ontogeny on the phylogenetic position of juvenile specimens, we caution that this approach may remove phylogenetically informative character information, and argue that inference methods that are known to be less sensitive to homoplasy than equal weights parsimony (i.e., implied weights parsimony; 
Bayesian approaches) should also be employed. 
1 Cranial anatomy of Bellusaurus sui (Dinosauria: Eusauropoda) from the 2 Middle-Late Jurassic Shishugou Formation of northwest China and a 3 review of sauropod cranial ontogeny 4

Andrew J Moore ${ }^{1}$, Jinyou $\mathrm{Mo}^{2}$, James M Clark ${ }^{1}$, Xing Xu

${ }^{1}$ Department of Biological Sciences, George Washington University, Washington, DC, United States

${ }^{2}$ Natural History Museum of Guangxi Zhuang Autonomous Region, Nanning, China

${ }^{3}$ Key Laboratory of Vertebrate Evolution and Human Origins, Institute of Vertebrate Paleontology and Paleoanthropology, Chinese Academy of Sciences, Beijing, China

Corresponding author:

Andrew J Moore ${ }^{1}$

Email address: djmoore@gwmail.gwu.edu 
ABSTRACT: Bellusaurus sui is an enigmatic sauropod dinosaur from the Middle-Late Jurassic Shishugou Formation of northwest China. Bellusaurus is known from a monospecific bonebed preserving elements from more than a dozen juvenile individuals, including numerous bones of the skull, providing rare insight into the cranial anatomy of juvenile sauropods. Here, we present a comprehensive description of the cranial anatomy of Bellusaurus, supplementing the holotypic cranial material with additional elements recovered from recent joint Sino-American field expeditions. Bellusaurus is diagnosed by several unique autapomorphies, including a neurovascular foramen piercing the ascending process of the maxilla at midheight, the frontal process of the nasal extending farther posteriorly onto the frontal than the prefrontal, and Ushaped medial and lateral notches in the posterior margin of the ventral process of the squamosal. Several features identified here, including a preantorbital opening in the maxilla, a stepped dorsal margin of the vomerine process of the pterygoid, and the partitioning of the dorsal midline endocranial fossae associated with the dural venous sinuses into anterior and posterior components by a transverse ridge of the parietal, are consistent with recent phylogenetic hypotheses that recover Bellusaurus as a basal macronarian or close relative of Neosauropoda. We review the current state of knowledge of sauropod cranial ontogeny, placing several aspects of the cranial anatomy of Bellusaurus in an ontogenetic context and providing explicit hypotheses of ontogenetic transformations that can be tested by future discoveries of ontogenetic variants of sauropod skulls. While scoring ontogenetically variable characters as unknown may help to alleviate the biasing effects of ontogeny on the phylogenetic position of juvenile specimens, we caution that this approach may remove phylogenetically informative character information, and argue that inference methods that are known to be less sensitive to homoplasy than equal weights parsimony (i.e., implied weights parsimony; Bayesian approaches) should also be employed.

\section{INTRODUCTION}

Sauropod dinosaurs are among the most diverse and abundant members of Mesozoic vertebrate faunas (Wilson, 2002) and reached their acme globally in the Late Jurassic (Mannion et al., 2011), with more than 20 species having been described from the North American Morrison Formation alone (Ikejiri, 2005; Harris, 2006; Tschopp, Mateus \& Benson, 2015). Although an apparently comparable diversity of sauropods has been described from Middle-Late Jurassic localities in China (Dong, Zhou \& Zhang, 1983; Martin-Rolland, 1993; Li et al., 2011; Xing et al., 2015b), these specimens have generally not received the scrutiny that has attended the study of North American sauropods (but see He, Li \& Cai, 1988; Ouyang \& Ye, 2000). Emblematic of this general dearth of taxonomic and anatomical interrogation, no fewer than 14 genera have been named from Middle-Late Jurassic strata of the Junggar and Sichuan Basins of China; despite lacking apomorphy-based diagnoses, two of these genera, Mamenchisaurus and Omeisaurus, currently comprise at least six species each, and are very likely catch-all "waste basket" taxa in need of taxonomic revision. As a result, it is unclear whether the alpha taxonomy of sauropods from Middle-Late Jurassic deposits in China mirrors that of Late Jurassic sauropods from western North America, or whether this diversity is instead an artifact of the lack of specimen-level phylogenetic and comparative analyses.

Recent studies of newly discovered specimens (Sekiya, 2011; Xing et al., 2015a; Xing et al., $2015 \mathrm{~b}$ ) are providing fresh insight on the anatomy and evolutionary relationships of Middle-Late Jurassic Chinese sauropods; however, untangling the taxonomy and systematics of Chinese sauropods will ultimately require redescription of historically and taxonomically important 
67 specimens in concert with discovery and description of new exemplars from across the Junggar

68 and Sichuan Basins. To that end, we thoroughly redescribe the cranial material of the enigmatic

69 taxon Bellusaurus sui Dong, 1990, one of four sauropod taxa recognized from the Middle-Late

70 Jurassic Shishugou Formation of northwest China, supplementing the material described by

71 Dong (1990) with new elements recovered in the course of joint Sino-American field expeditions

72 of the Institute of Vertebrate Paleontology and Paleoanthropology of the Chinese Academy of

73 Sciences and The George Washington University. We differentiate Bellusaurus from other

74 sauropods of the Shishugou Formation and provide an apomorphy-based diagnosis and extensive

75 morphological comparisons that indicate that Bellusaurus, despite being known solely from

76 juvenile material, can be distinguished from other Middle-Late Jurassic Chinese sauropods.

77 Lastly, we review the current state of knowledge of sauropod cranial ontogeny, and place several noteworthy cranial characters observed in Bellusaurus in their appropriate ontogenetic and phylogenetic contexts.

Institutional abbreviations - BP: Bernard Price Institute, Johannesburg, South Africa; BYU: Brigham Young University Museum of Paleontology, Provo, UT, USA; CM: Carnegie Museum of Natural History, Pittsburgh, PA, USA; FCPT-D: Fundación Conjunto Paleontológico de Teruel-Dinópolis, Teruel, Spain (plus CPT for the fossil material deposited in the museum [Museo Fundación Conjunto Paleontológico de Teruel]); DFMMh: DinosaurierFreilichtmuseum Münchehagen/Verein zur Förderung der Niedersächsischen Paläontologie e.V., Rehburg - Loccum, OT Münchehagen, Germany; DINO: Dinosaur National Monument; DMNH: Denver Museum of Natural History, Denver, USA; IVPP: Institute of Vertebrate Paleontology and Paleoanthropology, Beijing, China; MCNV: Museo de Ciencias Naturales, Valencia, Spain; MB.R.: Museum für Naturkunde, Berlin, Germany; MNBH: Musée National Boubou Hama, Niamey, Niger; UMNH: Natural History Museum of Utah, Salt Lake City, UT, USA; USNM: Smithsonian National Museum of Natural History, Washington, DC, USA; ZDM: Zigong Dinosaur Museum, Dashanpu, China

\section{METHODS}

\section{Descriptions, comparisons, and skull reconstruction}

All descriptions were made directly from the holotype and referred cranial material of Bellusaurus. Comparisons with other taxa were made from direct observations of specimens or with published descriptions, illustrations and photographs. Measurements of key dimensions of the skeletal elements were taken with Fowler electronic calipers to the nearest tenth of a millimeter and are presented in Table 1. We provide a hypothetical skull reconstruction of Bellusaurus sui based on the holotypic and referred material in Figure 1.

102

103

104

\section{Three-dimensional rendering of maxillae and parabasisphenoid}

106

107

108

109

110

111

112
To produce three-dimensional reconstructions of two maxillae (IVPP V17768.1 and IVPP V17768.3) and the parabasisphenoid (IVPP 8299.2), the specimens were subjected to microcomputed tomography (CT) scanning using a Nikon XT H 225 micro-computed tomography scanner with slice thicknesses of $62.8 \mu \mathrm{m}$ for the maxillae and $31.4 \mu \mathrm{m}$ for the parabasisphenoid. Data were output in .raw file format and imported into Mimics v.15.0 for viewing, analysis, and visualization. Poor or ambiguous preservation of portions of the maxillary neurovasculature, especially in IVPP V17768.3, required interpolation of endocast volumes between areas where these channels were better preserved. Raw CT scan data (TIFF file stacks) are reposited on 
113 MorphoBank (http://morphobank.org/permalink/?P3122). Further details of CT scanning 114 protocol are available from the Key Laboratory of Vertebrate Evolution and Human Origins of 115 the Chinese Academy of Sciences.

116

117

118

119

120

121

122

123

124

125

126

127

128

129

130

131

132

133

134

135

136

137

138

139

140

141

142

143

144

145

146

147

148

149

150

151

152

153

154

155

156

157

158

\section{SYSTEMATIC PALEONTOLOGY}

SAURISCHIA Seeley, 1887

SAUROPODOMORPHA Huene, 1932

SAUROPODA Marsh, 1878

EUSAUROPODA Upchurch, 1995

BELLUSAURUS Dong, 1990

\section{Type Species-Bellusaurus sui (by monotypy).}

Diagnosis-As for type and only species (see below).

Occurrence and Age - Konglonggou area, Junggar Basin, Xinjiang Uyghur Autonomous Region, northwest China. The vertebrate locality producing Bellusaurus was discovered in 1954 by a Kelameili regional petroleum exploration team of the Xinjiang Petroleum Administrative Office. In 1983, the Xinjiang Paleontological Expedition of the Institute of Vertebrate Paleontology and Paleoanthropology (IVPP) collected hundreds of bones from an assemblage of mostly disarticulated, juvenile skeletons, from which Dong (1990) erected Bellusaurus sui. In 2003, a Sino-American field expedition comprising the Institute of Vertebrate Paleontology and Paleoanthropology of the Chinese Academy of Sciences and The George Washington University re-opened the quarry at the area informally called Dinosaur Valley (Konglonggou), approximately 10 kilometers northeast of the town of Huoshaoshan, and collected hundreds of additional specimens referable to Bellusaurus, including new cranial elements (Clark et al., 2006; Mo, 2013). The presence of 17 left scapulae among the material collected by the Xinjiang Paleontological Expedition and the 7 additional left scapulae recovered in 2003 together indicate that at least 24 individuals are preserved in the quarry, a greater number than can be confidently inferred from any other element. No other taxa are known from the quarry.

The Bellusaurus quarry is situated at the base of the upper beds of the Shishugou Formation in a succession of tan-colored calcareous mudstones and fine-grained sandstones, near the type locality of the mammaliaform Klamelia zhaopengi Chow \& Rich, 1984. The lower contact of the Shishugou Formation with the Xishanyao Formation in this area has not been located precisely, but the quarry lies 80 meters stratigraphically above a coal bed in the uppermost Xishanyao Formation (D. Eberth, pers. comm. 2014). The Shishugou Formation is poorly exposed in this area but the transition from lower beds (variegated redbeds and coarser-grained sandstones) into upper beds (finer-grained, tuffaceous and tan colored mudstones and sandstones) matches a similar transition that is present in all areas where the formation is better exposed (e.g., Jiangjunmiao; Wucaiwan). At Wucaiwan - 25 kilometers to the northwest of Dinosaur Valley — the Shishugou Formation is 378 meters thick (Eberth et al., 2010). Lithostratigraphic correlation indicates that the upper part of the formation is thicker and the lower part thinner at Dinosaur Valley than at Wucaiwan, and places the Bellusaurus quarry at the level of the lowest horizons of the upper beds of the Shishugou Formation at Wucaiwan (D. Eberth, pers. comm. 2014), between two tuffs - one in the middle beds (Tuff T-1) and one in the upper beds (Tuff TBW) (Figure 2). Radiometric dating at Wucaiwan provides ages of $162.2 \pm 0.2 \mathrm{Ma}$ and $159.7 \pm$ 0.3 Ma for the T-1 and T-BW tuffs, respectively (Choiniere et al., 2013; Han et al., 2015), 
159 placing the Bellusaurus quarry, and much of the Shishugou Formation, within the earliest

160 Oxfordian (early Late Jurassic) (Figure 2).

161 The stratigraphic positions of other Shishugou sauropods are somewhat less well-

162 constrained (Figure 2). Mamenchisaurus sinocanadorum was recovered from a coarse, rusty-red

163 channel sandstone in the upper portion of Shishugou Formation, near Jiangjunmiao, and

164 Tienshanosaurus chitaiensis Young, 1937 was excavated from an unknown stratigraphic level in

165 roughly the same area (Russell \& Zheng, 1993), while Klamelisaurus gobiensis was found in

166 gray-brown to purple red sandy mudstones near Jiangjunmiao at the top of what was formerly

167 called the "Wucaiwan Formation" (Zhao, 1993; Clark et al., 2006) and is now considered to

168 constitute the lower beds of the Shishugou Formation (Clark et al., 2006).

169

170

171

172

173

174

175

176

177

178

179

180

181

182

183

184

185

186

187

188

189

190

191

192

193

194

195

196

197

198

199

200

201

202

203

204
BELLUSAURUS SUI Dong, 1990

(Figs. 3-19)

Holotype-IVPP V8299.1-7, fragmentary cranial elements including a nearly complete right otoccipital, partial parabasisphenoid, partial left maxilla, and four isolated teeth. Dong (1990) also described an isolated supraoccipital, but this element was not figured in the original description and could not be located for study.

Referred material-IVPP V8300, a composite skeleton lacking cranial elements, described by Dong (1990).

IVPP V17768.1-21, three incomplete right maxillae, a partial right nasal, an articulated left frontal and parietal, two articulated right frontals and parietals, a nearly complete right squamosal, a right quadrate, a right pterygoid, an incomplete left dentary, a nearly complete right angular, ten isolated teeth, and postcranial elements from numerous individuals (Mo, 2013). Although none of the new elements, with the exception of an articulated sacrum, were preserved in articulation, morphological overlap among the elements described by Dong (1990) and the new material, as well as the high concentration of morphologically-consistent juvenile sauropod bones within a narrow layer of the Shishugou Formation, indicate that these elements come from a single taxon and are referable to Bellusaurus sui. The presence of three right maxillae indicates that at least three individuals are represented by cranial material; there is no evidence that multiple elements came from any one individual.

Emended Diagnosis - (Cranial features only.) A non-neosauropod eusauropod near the origin of Neosauropoda (Wilson \& Upchurch, 2009; Royo-Torres \& Upchurch, 2012; Mo, 2013) or early-branching macronarian (Upchurch, Barrett \& Dodson, 2004; Carballido \& Sander, 2014) diagnosed by the following unique autapomorphies: neurovascular foramen piercing ascending process of the maxilla at midheight; frontal process of the nasal extends farther posteriorly onto the frontal than the prefrontal; U-shaped medial and lateral notches in the posterior margin of the ventral process of the squamosal, near its base; a shallow, anteromedially-facing concavity on the ventral articular process of the quadrate, extending from the medial condyle to the anteroventral edge of the pterygoid wing; and a pronounced, trough-like structure on the dorsal margin of the pterygoid at the union of the vomerine, transverse, and quadrate processes.

Differential diagnosis-Here we present differentiation of Bellusaurus sui to show that this taxon is not a juvenile specimen of other named Shishugou Formation sauropods.

Klamelisaurus gobiensis has been hypothesized to be the adult form of Bellusaurus (Paul, 2010), presumably on the basis of the co-occurrence of these taxa in the Shishugou Formation and the juvenile status of all known Bellusaurus material. Klamelisaurus is from the lower beds 
205

of the Shishugou Formation and is thus stratigraphically older than Bellusaurus, falling within the late Callovian (latest Middle Jurassic) portion of the Shishugou Formation (Figure 2). With the exception of teeth that could not be located for study, the holotype and only specimen of Klamelisaurus gobiensis (IVPP V9492; Zhao, 1993) does not preserve cranial elements. However, there is substantial morphological overlap between the postcranial skeletons of Klamelisaurus and Bellusaurus specimens, and Bellusaurus can be readily distinguished from Klamelisaurus in: lacking presacral neural spine bifurcation (this character may be ontogenetically variable: Woodruff \& Fowler, 2012, Wedel \& Taylor, 2013); having cervical vertebrae with lateral pneumatic excavations subdivided by two or more oblique accessory laminae (cervical and dorsal pneumatic excavations of the centrum are generally deeper and more extensively subdivided in Bellusaurus than they are in Klamelisaurus; this is the opposite of what would be expected if the Bellusaurus quarry were comprised of juvenile specimens of Klamelisaurus, given that pneumatic structures in sauropods progress ontogenetically from simple fossae to deeper and more extensively subdivided pneumatic recesses: Wedel, 2003, Schwarz et al., 2007, Carballido \& Sander, 2014; Tschopp \& Mateus, 2017); lacking cervical vertebrae with ventral surfaces that are mediolaterally concave in the anterior half; lacking posterior projections of the transverse processes of the cervical vertebrae; having a tab-like process on the prezygodiapophyseal lamina, below the pre-epipophysis, in middle-posterior cervical vertebrae; lacking sheet-like extensions of the spinoprezygapophyseal lamina of middleposterior cervical vertebrae; having an accessory, subvertical lamina in the postzygapophyseal centrodiapophyseal fossa of posterior cervical vertebrae; having lateral pneumatic foramina of the dorsal centra with margins that are flush with the lateral surface of the centrum; having camerate dorsal centra; having dorsal vertebrae with transverse processes whose distal ends curve smoothly onto the dorsal surface of the process; having dorsolaterally directed transverse processes in middle-posterior dorsal vertebrae; lacking a posterior centroparapophyseal lamina in middle-posterior dorsal centra; having vertically oriented rod-like struts dividing the lateral pneumatic excavation of middle and posterior dorsal vertebrae; having ventral bifurcation of posterior centrodiapophyseal laminae of posterior dorsal vertebrae; having ventral bifurcation of the medial centropostzygapophyseal lamina in posterior dorsal vertebrae (likely a postcranial autapomorphy of Bellusaurus); having a divided centropostzygapophyseal lamina in middle and posterior dorsal neural arches, with the lateral branch connecting to the posterior centrodiapophyseal lamina; having middle and posterior dorsal neural spines with anteroposterior widths that are approximately constant throughout the height of the spine; lacking aliform processes that project farther laterally than the postzygapophyses in middle and posterior dorsal vertebrae (this feature may vary ontogenetically: Carballido \& Sander, 2014); lacking posterior offset of neural spines in middle and posterior dorsal vertebrae; having a subtriangular lateral pneumatic foramen in the centrum of posterior dorsal vertebrae; having lateral pneumatic excavations in the sacral vertebral centra; having well-developed spinodiapophyseal lamina on sacral neural spines; having a nearly orthogonal orientation between the scapular blade and coracoid articulation; having a smoothly rounded anterodorsal coracoid margin; having a coracoid with a distinct infraglenoid lip and notch; having a humeral head with a prominent subcircular process on the posterior surface of the proximal end; lacking a distally expanded deltopectoral crest of the humerus; having a strongly proximolaterally beveled distal condyle of the radius; having a stepped ventral surface of the femoral head; and having a posterolateral projection on the distal condyle of metatarsal I.

Bellusaurus differs from Mamenchisaurus sinocanadorum - the only species of 
251 Mamenchisaurus named from the Shishugou Formation, the holotype and only specimen of 252 which was recovered from the upper part of the Shishugou Formation at Jiangjunmiao (Russell 253 \& Zheng, 1993) - in: having a stepped, rather than essentially straight, vomerine process of the 254 pterygoid; lacking a lingual boss near the distal edge of the teeth; having deep, subdivided lateral structure in cervical vertebrae.

Distinguishing Bellusaurus from Tienshanosaurus chitaiensis — one of the first sauropods discovered in China (Young, 1937), likely from approximately the same locality as Mamenchisaurus sinocanadorum (Russell \& Zheng, 1993) - is more difficult, owing to limited morphological overlap, apparent loss of some of the holotypic material of Tienshanosaurus, and incomplete preservation of existing Tienshanosaurus material. Based on the available material (IVPP RV 37089) and the original description, Bellusaurus can be differentiated from Tienshanosaurus in: lacking presacral neural spine bifurcation; having strongly procoelous anterior caudal vertebrae; having a relatively elongate scapular blade; and having greater distal expansion of the scapular blade.

\section{DESCRIPTION}

\section{General Comments}

We use Romerian orientational descriptors (i.e., anterior, posterior) rather than standardized terms (i.e., cranial, caudal). Given the lack of a standardized terminology for sauropod skull bones and their various processes, we follow Wilson, Pol \& Zaher (2016) in employing morphological and orientational descriptors for cranial element processes, favoring morphological descriptors where it is convenient to do so.

Preservation of the holotype material is generally poorer than that of the referred material. The cranial elements of the holotypic and referred specimens were not discovered in articulation, as is also true for the vast majority of the postcranial material, and portions of at least 24 individuals were preserved in the quarry (Dong, 1990; Mo, 2013). All known Bellusaurus specimens are clearly juvenile. Among the five long bones of the newly referred material that have been sectioned for histological analysis, there is little or no secondary remodeling of bone tissue (Mo, 2013). Two elements display evidence indicative of periods of slowed or arrested growth - an apparent annulus in a fibula (IVPP V17768.283) and a single line of arrested growth (LAG) in an ulna (IVPP V17768.240) (Mo, 2013) - suggesting death within the first two years post-hatching. Sauropods are typically characterized by continuous deposition of highly vascularized fibrolamellar bone throughout most of ontogeny, with growth marks only appearing near adult size (Curry, 1999; Sander, 2000; Curry Rogers \& Erickson, 2005; Sander et al., 2011; Cerda et al., 2017), though cyclic, zonal organization prior to deposition of an external fundamental system has been noted in the cortices of several taxa, including Patagosaurus (stratification into zones and annuli, and a LAG; Cerda et al., 2017), Apatosaurus (cyclic changes in vascularity; Curry, 1999), Janenschia (polish lines; Sander, 2000), and the island dwarf Europasaurus (LAGs; Sander et al., 2006). The presence of growth marks in some Bellusaurus specimens is thus somewhat unusual, and may reflect high seasonality of the Shishugou Formation (Eberth et al., 2001; Tütken et al., 2004), an acute period of stress (due to, e.g., disease), or taxon-specific growth patterns. In addition to skeletochronological indicators, most cranial elements exhibit the porous and striated cortical surface typical of fast-growing, juvenile bone (Varricchio, 1997; Benton et al., 2010; Marpmann et al., 2014). The preponderance of evidence for young juvenile status of all known Bellusaurus material and the 
297 roughly sub-equal size of duplicate elements in the bone bed (AJM, unpublished data) 298 including the four maxillae and three sutured frontal-parietals (Table 1) — suggest that all 299 Bellusaurus specimens are of approximately the same age, and thus that intraspecific variation

300

301

302

303

304

305

306

307

308

309

310

311

312

313

314

315

316

317

318

319

320

321

322

323

324

325

326

327

328

329

330

331

332

333

334

335

336

337

338

339

340

341

342

may be a greater source of differences between specimens than is ontogenetic variation.

Inferences about sutural contacts with missing elements are based in large part on topological associations observed in Camarasaurus (Madsen, McIntosh \& Berman, 1995; CM 11338, UMNH 5668, UMNH 5669) and other sauropods known from relatively intact skulls.

Maxilla (IVPP V8299.5, IVPP V17768.1-3; Figures 3-7) Although none of the maxillae are preserved fully intact, the three referred elements together preserve most portions of the maxilla and provide a nearly complete picture of its morphology. The maxilla is comprised of a main body and several processes for articulation with the nasal, lacrimal, jugal, and possibly quadratojugal.

The maxilla is the only cranial element of the holotype that overlaps with IVPP V17768. Dong (1990) described the holotype as including a portion of the right maxilla, which we recognize instead as a fragment of the left maxilla. The holotypic maxilla is largely incomplete, lacking the ascending and posterior processes and the anterior and ventral portions of the main body; though fragmentary, the occurrence of the holotypic maxilla within a monospecific bone bed, its size, and its morphological similarity with the referred maxillae all indicate that the holotypic and referred maxillae belong to a single taxon. Unfortunately, the holotype does not preserve the ascending process so the presence of the autapomorphic neurovascular foramen cannot be determined.

An ascending process projects posterodorsally and slightly laterally from the body of the maxilla; though this process is missing in IVPP V8299, its broken base also expands laterally on the maxillary body (Figure 3A, D, E). All three of the referred maxillae preserve portions of the ascending process, though the direction of the process is crushed ventrally in IVPP V17768.1. The distal posterolateral surface of the ascending process was presumably overlapped laterally by the descending lateral process of the nasal and the dorsal portion of the lacrimal. The shaft of the ascending process is pierced by a small foramen at just over mid-height of the process (Figure 5A, B, D). There is a shallow trough dorsal to the foramen on the lateral surface of the process and a pronounced ventral trough on the medial surface of the process, indicating passage of a neurovascular channel between the external and internal surfaces of the ascending process in a line subparallel to the trajectory of the process. This foramen and the associated short, deep trough on the medial surface of the ascending process have not been previously described for other sauropods; a similar feature may be present on the right side of Shunosaurus (ZDM 5009), though in this specimen, there is no evidence of an associated trough and the remainder of the skull exhibits taphonomic or pathological pockmarking of the bone surface that calls into question the validity of the foramen. We thus interpret the presence of a neurovascular foramen and associated trough in the ascending process of the maxilla of Bellusaurus to be an autapomorphy of the taxon.

The ascending process makes up the anterior border of the antorbital fenestra, which lacks an antorbital fossa. The last maxillary tooth is positioned just posterior to the midpoint of the antorbital fenestra; Bellusaurus thus resembles other sauropods in having the tooth row anterior to the orbit, but lacks the condition in diplodocoids and some titanosauriforms wherein the maxillary tooth row is anterior to the antorbital fenestra, though this feature may be ontogenetically variable (see Discussion). 
343

344

345

346

347

348

349

350

351

352

353

354

355

356

357

358

359

360

361

362

363

364

365

366

367

368

369

370

371

372

373

374

375

376

377

378

379

380

381

382

383

384

385

386

387

388

A tapering, tongue-like premaxillary process extends anteriorly from the anteriormost portion of the palatal shelf, and is continuous posterolaterally with the ascending process via a thin sheet of bone - the 'maxillary flange' of Upchurch (1998) - that bounds the narial fossa medially and posteriorly, separating the fossa from the antorbital cavity (Figures 5-6). Only IVPP V17768.2 preserves an essentially complete maxillary flange. A straight, narrow groove for the dorsal maxillary process of the premaxilla extends anteriorly along much of the dorsomedial margin of the maxillary flange until it reaches the base of the premaxillary process (IVPP V17768.2), while a corresponding shallow groove for the ventral maxillary process of the premaxilla extends along the ventromedial aspect of the premaxillary process. The medial surfaces of the maxillary flange and base of the premaxillary process are smooth, and in IVPP V17768.1, this surface is very slightly concave and tapers posteriorly toward the palatal shelf. At the base of the premaxillary process, the anterior surface of the maxilla preserves a dorsally and slightly laterally directed channel that corresponds to the maxillary portion of the subnarial foramen (Figures 3-6). The subnarial foramen is well-removed medially from the gently angled lateral margin of the narial fossa, and is partially obscured in lateral view. The narial fossa is more developed than in Shunosaurus lii (ZDM 5009), where the fossa is only weakly offset from the lateral margin of the maxilla, but shallower than that in most specimens of Camarasaurus (CM 11338, BYU 13743, UMNH 5907, UMNH VP 5959, UMNH VP 11393), Giraffatitan (MB.R.2180.2), and cf. Brachiosaurus (USNM 5370), in which the fossa is a sunken embayment that falls below the angular margin at the juncture of the narial fossa and the lateral surface of the maxilla. The surface of the narial fossa is smooth in IVPP V17768.1 and V17768.3, while that of IVPP V17768.2 exhibits irregular, wart-like tuberosities that extend across the narial fossa, into the subnarial foramen, and onto the anteromedial surface of the palatal shelf, above the tooth row (Figure 5). None of the other maxillae preserve similar structures, and we interpret their presence in IVPP V17768.2 to be pathological.

Posteriorly, the main body of the maxilla flares dorsoventrally owing to the presence of a well-developed, triangular lacrimal process that occupies its posterodorsal corner and a blunt, posteroventral extension of the maxillary body that articulated with the jugal and possibly the quadratojugal (Figures 4,6). The posterior margin of the maxilla is concave between these two projections. The dorsal surface of a pronounced palatal shelf meets the edge of the antorbital fenestra laterally and extends posteriorly as far as the lacrimal process, nearly reaching the posterior edge of the maxilla. The dorsal surface of the antorbital cavity is bordered anterolaterally by the ascending process, which has a large, smooth fossa on its internal surface. This large fossa of the ascending process is continuous with an anteroposteriorly elongate fossa on the dorsal aspect of the palatal shelf. Two adjacent sutural scars are present at the posteromedial extent of the palatal shelf: a nearly flat, subtriangular facet for the palatine and a larger, oval-shaped concavity immediately posterior to it, at the posterior end of the palatal shelf at a level subequal with the posterior extent of the maxillary tooth row, for the ectopterygoid; this region is damaged in IVPP V17768.3, but the facets are well-preserved in IVPP V17768.1 (Figures 4C, E). In theropods, basal ornithischians, and non-neosauropod sauropodomorphs, the ectopterygoid articulates laterally with the jugal (Wilson \& Sereno, 1998); by contrast, in neosauropods, the ectopterygoid articulates with the maxilla. Abrosaurus and Bellusaurus preserve morphologies that presumably reflect the anterior migration of the lateral articulation of the ectopterygoid through sauropod evolution: in Abrosaurus, only a small portion of the ectopterygoid articulates laterally with the posterior process of the maxilla, the rest of it articulating with medial face of the jugal (ZDM 5009), while in Bellusaurus, the ectopterygoid 
389 facet of the maxilla is large and pronounced, though continuity of the ectopterygoid and jugal

390 facets (see below) suggests that the ectopterygoid may have had a small articulation with the

391 jugal. As in Camarasaurus (e.g., CM11338, DMNH 32126, UMNH VP 5959), the palatine scar

392 in Bellusaurus is directed medially and is less distinct than the posteromedially-facing

393 ectopterygoid scar.

394 The lacrimal process is immediately dorsal to the facet for the ectopterygoid. An

395 anteroventrally directed posterior alveolar foramen for the passage of the maxillary artery and

396 superior alveolar nerve (White, 1958) pierces the palatal shelf fossa at the anterior base of the

397 lacrimal process; this foramen is weakly developed in IVPP V17786.1 but pronounced in IVPP

398 V17786.3 (Figure 6B). In the preserved maxillae, the posterior alveolar foramen is the only

399 pronounced foramen within the palatal shelf fossa, though IVPP V17768.3 exhibits at least two

400 small holes piercing the middle of the palatal shelf fossa, which may be incipient instances of

401 similarly positioned, well-developed foramina present on the dorsal surface of the shelf in some

402 specimens of Camarasaurus (e.g., UMNH 5959, 11393).

403

404

405

406

407

408

409

410

411

412

413

414

415

416

417

418

419

420

421

422

423

424

425

426

427

428

429

430

431

432

433

434

Abutting the posterior end of the ectopterygoid facet and continuous with the posteriormost extent of the dorsal palatal shelf is a narrow, elongate facet on the medial surface of the maxilla for articulation with the jugal (Figures 4C, E). Thus, in an articulated skull, a narrow fringe of the maxilla would overlap the jugal laterally; such a simple lap joint, consisting of a laterally overlapping maxilla and medially underlapping jugal, is present in Camarasaurus (Gilmore, 1925; UMNH 5959), cf. Brachiosaurus sp. (USNM 5370), and Europasaurus (Marpmann et al., 2014). Notably, in Mamenchisaurus youngi, the jugal overlaps the maxilla laterally (Ouyang \& Ye, 2002: p.93), though it is possible that this articulation was somewhat more complex than a simple lap joint (see below). Partial overlap of the jugal by the maxilla can also be inferred for Turiasaurus, based on the presence of a longitudinal facet on the lateral face of the anteroventral edge of the jugal (Royo Torres \& Upchurch, 2012; CPT-1211), though in this taxon, the lateral bulging of a marked, autapomorphic boss on the external surface of the jugal produces a shallow groove that would have weakly clasped the maxilla. The internal surface of the lacrimal process is excavated at its base just anterodorsal to the narrow jugal facet, and may have accommodated an anterior projection of the jugal (Figure 4C, E).

On the lateral surface of the posterior process of the maxilla, ventral to the level of the facet for the jugal, is a transversely narrow, elongate facet (19 millimeters in length) that extends posteroventrally to reach the posterior edge the of maxilla (Figure 4A, B, E; Figure 6A, C), indicating that an element of the zygomatic region overlapped the maxilla laterally, leaving a posteroventrally tapering external surface of the maxilla in lateral view, as in Mamenchisaurus youngi (Ouyang \& Ye, 2002: Fig. 3). Several possible identifications obtain for this facet, none of which can be asserted confidently for Bellusaurus: it could constitute an additional, lateral facet for the jugal, implying a tongue-and-groove articulation with a narrow (2 millimeters wide) and deep (3-8 millimeters) channel on the anteroventral aspect of the jugal; the narrow shelf and the lateral surface of the maxilla immediately above could be a broad articular facet for the quadratojugal; or both of these conditions may jointly apply, with the lateral facet being occupied dorsally by the jugal and ventrally by the quadratojugal. That the jugal overlaps the maxilla laterally in Mamenchisaurus youngi suggests that this taxon could having a clasping jugal, but it is not clear whether the jugal also extended onto the medial face of the maxilla in $M$. youngi.

Anteroventral to the antorbital fenestra, a shallow but distinct fossa is apparent. In IVPP V17768.1, this depression lacks large foramina, exhibiting only a small subcircular nutrient 
435 foramen in its anterodorsal corner; IVPP V17768.3 exhibits the same nutrient foramen, but also

436 bears a deep, oval-shaped neurovascular foramen that pierces the anteroventral corner of the

437 depression (Figures 4A; Figure 6A, C; Figure 7). That the foramen is larger than any other on the

438 lateral surface of the maxilla, is located anteroventral to the antorbital fenestra, and

439 communicates with a canal for maxillary neurovasculature (traceable in micro-CT scan data)

440 suggest that it is homologous to the preantorbital fenestra (Wilson \& Sereno, 1998; Martinez et

441 al., 2016), which has been recovered as synapomorphic for Neosauropoda (e.g. Wilson \&

442 Sereno, 1998; Upchurch, Barrett \& Dodson 2004; Whitlock, 2011a) or a slightly more inclusive

443 clade (e.g., Wilson, 2002). The structure referred to as the preantorbital fenestra by various

444 sauropod workers exhibits substantial morphological variation (Martinez et al., 2016), ranging

445 from a small, slit-like foramen without obvious communication with the antorbital cavity (most

446 Camarasaurus specimens, e.g., CM 11338, CM 113; Europasaurus: Marpmann et al., 2014) to a

447 comparatively large foramen with (Abydosaurus: DINO 17849; cf. Brachiosaurus: USNM 5370;

448 Giraffatitan: MB.R.2180.2) or without (e.g., Jobaria: MNBH TIG 5; Bellusaurus: IVPP

449 V17768.1, V17768.3; Dicraeosaurus: MB.R.2336.1-3) direct medial communication with the

450 antorbital cavity to a definitive preantorbital fenestra manifesting as a broad window that is

451 confluent medially with the antorbital cavity (e.g. cf. Diplodocus: USNM 2672; Galeamopus:

452 Tschopp \& Mateus 2017). While the functional significance of the preantorbital opening and the

453 full complement of morphogenetically pertinent soft-tissue structures associated with

454 evolutionary elaboration of the foramen have not been critically evaluated across sauropods,

455 recent work (Porter, 2015; Martinez et al,. 2016) indicates that the preantorbital opening is

456 vascular in origin (see Discussion).

457

458

459

In addition to the preantorbital foramen, the maxilla bears numerous other foramina surrounding the base of the ascending process and within the narial fossa (Figures 3-7). A row of neurovascular foramina extends along the length of the lateral surface of the maxilla just above

460

461

462

463

464

465

466

467

468

469

470 the alveolar margin, and transmitted nerve and blood vessels to the skin in life. Several foramina set within deep, elongate troughs surround the ascending process anteroventrally and extend onto its base, and generally exhibit topological consistency across the three referred maxillae. As with the other holotypic cranial material, the external surface of the holotypic maxilla is poorly preserved. However, at least three foramen-trough structures are discernible on the holotype and correspond to similarly positioned foramina on the referred maxillae: one positioned anteroventral to the ascending process and just ventral to the narial fossa, one on the anteroventral corner of the ascending process itself, and one set within the narial fossa at its lateral border, which we interpret as the anterior maxillary foramen.

Unlike the markedly sigmoid ventral margin of the maxilla in Shunosaurus (ZDM 5009), Omeisaurus maoianus (Tang et al., 2001: Fig. 8), some Camarasaurus specimens (Woodruff \&

471

472

473

474

475

476

477

478

479

480 Foster, 2017), brachiosaurids, and titanosaurians, Bellusaurus has a slightly convex alveolar margin in lateral view (Figure 4A, C). The ventral margin of the holotypic maxilla is badly abraded and does not preserve the lateral plate that bounds the tooth row laterally in sauropods (Upchurch, Barrett \& Dodson, 2004; Upchurch et al., 2007); however, this structure is nearly complete in IVPP V17768.1. Viewed ventrally, the lateral plate is essentially straight posterior to the fifth or sixth alveolus; anterior to this region, the maxilla curves gently medially. IVPP V17768.1 bears thirteen alveoli, which are separated from each other by low interdental ridges that arise from the medial surface of the lateral plate. Anteriorly, the interdental ridges reach the ventral margin at an angle of approximately 70 degrees, suggesting slight procumbency of the anterior dentition. The largest teeth occur at the anterior end of the maxilla, as indicated by the 
481

482

483

484

485

486

487

488

489

490

491

492

493

494

495

496

497

498

499

500

501

502

503

504

505

506

507

508

509

510

511

512

513

514

515

516

517

518

519

520

521

522

523

524

525

526

gradual decrease in size of the alveoli posteriorly.

Nasal (IVPP V17786.4; Figure 8) The nasal is a thin, plate-like bone. The dorsal surface of the nasal is flat, and the element is thinnest $(\sim 1.5 \mathrm{~mm})$ where it roofs the nasal cavity dorsally. The posterior margin of the nasal and its articulation with the frontal are missing; however, the frontal-nasal suture is preserved on the frontal (IVPP V17768.5, V17768.7) and indicates that the medial half of the nasal would have articulated with the frontal in a nearly transverse contact while the lateral half of the nasal was directed posteriorly as an acute, tab-like process that contacted the prefrontal laterally and overlapped the frontal dorsally. A triangular posterolateral process of the nasal with significant excursion posteriorly onto the frontal is likewise inferred to be present in Europasaurus (Marpmann et al., 2014: Fig. 6) and probably Jobaria (MNBH TIG 7), is less well-developed in Mamenchisaurus youngi (Ouyang \& Ye, 2002: Fig. 5A), Camarasaurus (Madsen et al., 1995), Giraffatitan (MB.R.2180.22) and possibly Omeisaurus tianfuensis (He et al., 1988: Fig. 8), and is absent in Spinophorosaurus (Knoll et al., 2012: Fig. 3C), diplodocoids (e.g., Tschopp, Mateus \& Benson, 2015: Fig. 7), and somphospondylans (Martinez et al., 2016: Fig. 34). (Note that the skull reconstruction of Europasaurus depicted in Marpmann et al., 2014: Fig.1 illustrates the prefrontal as having a large, two-pronged articulation with the frontal, rather than the medial of these two rami belonging to the nasal, as suggested by the condition in other sauropods and as depicted in Fig. 6A of Marpmann et al., 2014, though the labels for the nasal and prefrontal are switched).

The nasal thickens dorsoventrally as it curves gently downward towards its ventrolateral process, which is largely missing. In other sauropods, the ventrolateral process articulates with the maxilla, lacrimal, and prefrontal. Near the medial edge of this thickened region of the nasal is a low ridge that traverses the ventral surface almost parallel to the midline internasal suture, being canted slightly anterolaterally-posteromedially. This ridge is an anterior extension of the right crista cranii (see below). The crista apparently traverses the medial edge of the ventral surface of the prefrontal (not preserved) and extends onto the nasal, dividing its ventral surface into a large, medial fossa of the nasal cavity roof and a smaller lateral fossa representing the anteriormost portion of the orbital cavity.

Anteriorly, the nasal tapers to an attenuated premaxillary process, its lateral border curving gently medially to form the dorsal rim of the bony naris. The dorsomedial surface of the premaxillary process preserves a deep, narrow groove for reception of the nasal process of the premaxilla. The groove projects medially and is deepest at its anterior end, but it shallows and its orientation becomes increasingly dorsal as it courses posteriorly, until it dissipates on the dorsal surface of the nasal.

Frontal (IVPP V17768.5-7; Figures 9-11) Two left frontals and one right frontal are preserved. The frontal contacts its counterpart medially as well as the parietal posteriorly, the postorbital posterolaterally, the prefrontal and nasal anteriorly, and the orbitosphenoid ventrally. All three frontals are preserved in contact with their parietals; the bones are strongly sutured, but obliteration of the suture is incomplete, and it remains visible along most of its extent. The suture extends laterally from the frontoparietal fenestra, which is located on the midline of the frontalparietal suture. As it approaches the supratemporal fenestra, the frontal-parietal suture turns anteriorly, skirting the anteromedial margin of the fenestra, which is comprised of a narrow flange of the parietal. Laterally, this flange of the parietal is stepped: a ventral projection of the parietal extends laterally, and would interlock with a dorsal and medial extension of the 
527 postorbital. Beyond its posterior contact with the parietal, the lateral wing of the frontal provides 528 a broad, flat posterior face for reception of the postorbital (Figure 9A, D; Figure 10A, D; Figure 529 11A, D). The frontal-postorbital and postorbital-parietal articulations exclude the frontal from

530

531

532

533

534

535

536

537

538

539

540

541

542

543

544

545

546

547

548

549

550

551

552

553

554

555

556

557

558

559

560

561

562

563

564

565

566

567

568

569

570

571

572

the supratemporal fenestra, which lacks a supratemporal fossa.

The frontal is dorsally concave, especially in V17768.7. At the anterolateral margin of its dorsal surface, the frontal bears two V-shaped facets (Figure 9A; Figure 11A). The lateral facet received the posterior process of the prefrontal, and the less acute medial facet received the posterolateral corner of the nasal. The nasal facet extends further posteriorly onto the frontal than does that of the prefrontal, a condition that we interpret as autapomorphic for Bellusaurus.

The orbital rim is deeply concave in dorsal view (Figure 9A, B; Figure 11A, B), as in mamenchisaurids, some flagellicaudatans (Tschopp, Mateus \& Benson, 2015), Europasaurus (Marpmann et al., 2014: Fig. 6), and cf. Brachiosaurus (USNM 5730). Marpmann et al. (2014) considered the combination of a long and narrow frontal with a deep orbital rim and relatively narrow articular surface for the prefrontal and nasal to be autapomorphic for Europasaurus, and stated that the general condition in sauropods is for the anterior edge of the frontal to form an articular surface for the nasal and prefrontal that is nearly as wide as the widest section of the frontal. However, a relative reduction in transverse breadth of the anterior articular surface is known in other sauropodomorphs, and indeed, may be the plesiomorphic condition for Sauropodomorpha, with the breadth of the anterior articular surface for the nasal and prefrontal being $80 \%$ or less the width of the widest dimension of the frontal (i.e., where the posterolateral wing of the frontal extends towards the postorbital) in Lufengosaurus and Massospondylus, as well as in Jobaria, some diplodocoids, Daanosaurus, Europasaurus, and Bellusaurus (Table 2). Moreover, it is not universally true that the concavity of the orbital margin and the breadth of the anterior articular region of the frontal covary (Table 2).

A pronounced crista cranii divides the ventral surface of the frontal into two fossae anteriorly (Figure 9B; Figure 10B; Figure 11B). The smaller anteromedial fossa housed the olfactory region of the nasal cavity and forms the dorsal margin of the anterior fenestra that transmitted the olfactory tracts of cranial nerve I into the endocranial cavity, while the larger lateral concavity roofs the orbit. In most sauropodomorphs, the frontal portion of the external rim of the orbit bears rugose ornamentation, but this margin is smooth in Bellusaurus, Qijianglong (Xing et al,. 2015b: Fig. 2), Daanosaurus (ZDM 0193), Abrosaurus (ZDM 5033), Dicraeosaurus (Tschopp, Mateus \& Benson, 2015), Europasaurus (Marpmann et al,. 2014), Giraffatitan (MB.R.2180.22.4), and Sarmientosaurus (Martinez et al., 2016). In Bellusaurus, the orbital margin of the frontal is also noteworthy in having a defined edge at the juncture of the dorsal and ventral surfaces of the frontal, rather than a broadly rounded surface.

Posterior to the orbital cavity, the ventral surface of the frontal preserves sutural scars for the orbitosphenoid. The posterior margin of the orbital portion of the frontal forms a transversely and somewhat anteriorly oriented ridge that lies just anterior to the parietal-laterosphenoid suture and the contact between the ventromedial edge of the postorbital and the crista antotica of the laterosphenoid. A short, distinct, anterolaterally directed groove is apparent between the broad posteromedial end of the crista cranii and the medialmost contribution of the frontal to the posterior orbital surface (Figure 9B). This groove may correspond to the dorsal margin of the supraorbital foramen, which allows passage of the supraorbital branch of the ophthalmic artery. A supraorbital foramen has generally not been described in sauropods, but has been recognized in a digital endocast of cf. Apatosaurus BYU17096 by the presence of small, paired canals near the base of the olfactory tract that exit the skull in the dorsomedial wall of the orbit (Balanoff,

Peer] reviewing PDF | (2018:02:25749:1:1:NEW 7 May 2018) 
573

574

575

576

577

578

579

580

581

582

583

584

585

586

587

588

589

590

591

592

593

594

595

596

597

598

599

600

601

602

603

604

605

606

607

608

609

610

611

612

613

614

615

616

617

618

Bever \& Ikejiri, 2010).

A large midline foramen, historically homologized with the pineal (or parietal) foramen (e.g., Marsh, 1891; White, 1958) and present in Spinophorosaurus (Knoll et al., 2012), Europasaurus (Marpmann et al., 2014), some Camarasaurus specimens (Madsen et al., 1995; Woodruff \& Foster, 2017), and some flagellicaudatans (Harris, 2006; Tschopp, Mateus \& Benson, 2015), is situated on the frontal-parietal suture (Figure 9A, B, E; Figure 10A, B, E; Figure 11 A, B, E), and here referred to as the frontoparietal fenestra. The medial edges of the frontal and parietal thin dramatically where they bound the fenestra; these edges have chipped in IVPP V17768.6 and IVPP V17778.7, but are essentially complete in IVPP V17768.5, indicating that the foramen is a genuine osseous feature of the dermal skull roof - or at least that portion of it that had ossified at death - and not an artifact of preservation. Ventrally, the posteromedial corner of each frontal makes up slightly less than a quarter of a subcircular, endocranial fossa that likely housed the pineal body and the anterior portion of the overlying system of dural venous sinuses that intervened between the neural tissue and endocranial ceiling in life (Witmer et al., 2008; Witmer \& Ridgely, 2009; see below); this fossa is abruptly offset from the adjacent ventral surface of the frontal. Except where they bound the frontoparietal fenestra, the medial edges of the frontal and parietal are dorsoventrally thick, preserving pronounced sutural grooves for contact with their contralateral counterparts.

Parietal (IVPP V17768.5-7; Figures 9-11) Two left parietals and one right parietal are nearly completely preserved. The parietal contacted its counterpart medially and is sutured to the frontal anteriorly, and also likely articulated with the postorbital anterolaterally, squamosal posterolaterally, laterosphenoid ventrolaterally, prootic ventrally, and supraocciptial and perhaps otoccipital posteroventrally. The dorsal surface of the parietal along the interparietal suture is roughly half as long anteroposteriorly as that of the frontal and forms the posterior part of the skull roof between the transversely-oriented supratemporal fenestrae. The slender anterolateral wing of the parietal comprises the anteromedial half of the supratemporal fenestra and contacted the anterodorsal process of the postorbital in a stepped sutural contact that excludes the frontal from the supratemporal fenestra. The posterior margin of the supratemporal opening is composed of the long, wing-like occipital, or posterolateral, process of the parietal, which contacted the head of the squamosal ventrolaterally. The rounded anteromedial corner of the supratemporal fenestra is gently obtuse and the posteromedial corner is acute, especially in IVPP V17768.5 \& IVPP V17768.7. Although the lateral and anterolateral margins of the supratemporal fenestrae are missing, the preserved portions indicate that the length of the long axis of the fenestra was probably slightly greater than the distance separating the fenestrae. The parietal-squamosal contact is ventrally offset with respect to the parietal-postorbital suture, indicating that the temporal bar would have been shifted sufficiently ventrally to expose the supratemporal fenestra in lateral view, as in most sauropods.

At the posterior extent of the interparietal suture, the posterodorsal margin of the parietal curves laterally to meet the dorsomedial corner of the occipital face of the parietal (Figure 9A, C, E; Figure 11A, C, E). This smooth, curved posteromedial lip constitutes the anterolateral border of a postparietal foramen, which in life was bounded posteriorly by the supraoccipital. The postparietal foramen has previously been hypothesized to be a synapomorphy of Dicraeosauridae (e.g. Salgado and Calvo, 1992; Whitlock, 2011a) but was recently recognized as plesiomorphic for Flagellicaudata (and lost in Tornieria and Diplodocus; Tschopp, Mateus \& Benson, 2015), and has a broad distribution within Sauropodomorpha, being present in Massospondylus 
619 (BP/1/4779; Chapelle, 2016), the basal sauropods Spinophorosaurus (Knoll et al., 2012),

620 Nebulasaurus (Xing et al., 2015a), Qijianglong (Xing et al., 2015b), and possibly Abrosaurus

621 (Ouyang, 1989), and the probable brachiosaurid Europasaurus (Marpmann et al., 2014).

622

623

The ventral surface of the parietal is complex. Anterolaterally, a wide, crescentic sutural contact for the laterosphenoid hugs the edge the supratemporal fenestra and abuts the frontalorbitosphenoid contact anteromedially (Figure 9B; Figure 10B; Figure 11B). The remainder of the ventral surface is dominated by endocranial fossae that correspond to the large dural venous sinuses that are common in sauropods (Witmer et al., 2008; Janensch 1935-1936; Knoll \& Schwarz-Wings, 2009; Knoll et al., 2012; Paulina Carabajal, Carballido \& Currie, 2014; Martinez et al., 2016). The anteromedial corner of the parietal makes up slightly more than a quarter of the frontoparietal fenestra and fossa, and thus differs from Europasaurus, in which a similar midline skull roof aperture lacks a contribution from the frontal and is wholly bounded by the paired parietals (Marpmann et al., 2014). Two distinct pits, roughly three millimeters in diameter, dimple the dorsolateral wall of the endocranial fossa and are weakly separated by a narrow, transverse ridge (Figure 9B); these are especially pronounced in IVPP V17768.5, and may correspond to impressions of diploic veins (Witmer et al., 2008). Posteriorly, the fossa

635

636

637 associated with the frontoparietal fenestra is bounded by a transverse ridge that, in an articulated skull, would cross the interparietal suture between the thick medial walls of the supratemporal fenestra at the level of the posteromedial edge of the parietal-laterosphenoid suture (Figure 9B, E; Figure 10B, E; Figure 11B, E). This ridge forms the anterior boundary of the posterior endocranial fossa that communicates with the postparietal foramen and that in life was associated with the posterior portion of the network of dural venous sinuses that overlaid the cerebrum and

641

642 cerebellum in most sauropods (Witmer et al., 2008; Martinez et al., 2016). This transverse ridge is present on the endocranial ceiling of the parietal of a relatively adult Massospondylus individual (Chapelle \& Choiniere, 2018: Fig. 36) but is incipiently developed or absent in more juvenile specimens (Sereno et al., 2007; Chapelle, 2016: Fig. 2.20A,B); it also appears to be present in Europasaurus (Marpmann et al., 2014: Fig. 7B). Moreover, the presence of this ridge is manifest in the endocasts of non-titanosaurian macronarians as the distinct division dorsally of the longitudinal dural expansion into anterior and posterior components (Janensch 1935-1936; Knoll \& Schwarz-Wings, 2009; Witmer et al., 2008; Martinez et al., 2016; confirmed through inspection of CT scans of Camarasaurus CM 11338). By contrast, this transverse ridge is absent from the endocranial ceiling (Xing et al., 2015b) and endocasts (Janensch, 1935-1936; Chatterjee \& Zheng, 2002; Sereno et al., 2007; Witmer et al., 2008; Balanoff, Bever \& Ikejiri, 2010; Paulina Carabajal, Carballido \& Currie, 2014) of non-macronarian sauropodomorphs other than adult Massospondylus. We hypothesize that development of the transverse ridge varies both ontogenetically and phylogenetically (see Discussion).

The endocranial fossa associated with the postpartietal foramen is bordered laterally by a

655

656

657

658

659 thick ridge of bone that would contact the prootic and the supraoccipital (Figure 9B; Figure 10B; Figure 11B). This ridge also constitutes the medial boundary of an additional endocranial depression that is likely associated with the transverse (= middle cerebral) venous system, which drains into the dural sinuses (Witmer et al., 2008; Martinez et al., 2016); a bulbous expansion of the endocast ventrolateral to the posterior portion of the longitudinal dural venous sinus and corresponding to the transverse sinus system is present in Camarasaurus (Witmer et al., 2008) and is especially well-developed in Sarmientosaurus (Martinez et al., 2016), but is essentially 
665

666

667

668

669

670

671

672

673

674

675

676

677

678

679

680

681

682

683

684

685

686

687

688

689

690

691

692

693

694

695

696

697

698

699

700

701

702

703

704

705

706

707

708

709

710

2002; Knoll et al., 2012). The medial wall of this fossa is pitted with small foramina (2-4 millimeters in diameter; Figure 9B), which may correspond to diploic veins (Witmer et al., 2008); in IVPP V17768.5, these manifest as a discrete posterior pit and two conjoined anterior pits, while IVPP V17768.6 bears a single foramen. The subtriangular facet for the head of the squamosal occupies the lateral portion of the ventral surface of the parietal and is adjacent to the posterior wall of the supratemporal fenestra, from which is it gently offset by a low ridge.

The wing-like occipital process of the parietal arches strongly ventrolaterally. The dorsomedial portion of the occipital surface of the process is marked by a fossa for the $m$. transversospinalis capitus ( $=$ m. complexus) (Tsuihiji, 2005; Button, Rayfield \& Barrett, 2014). The curved dorsomedial margin of the fossa is strongly lipped, and in IVPP V17768.5 the posteriormost portion of this lip thickens to a nodular projection that is subtriangular in posterior view. Ventrolateral to the fossa for the $m$. transversospinalis capitus, the occipital surface of the parietal becomes gently convex as the occipital process curves to meet the squamosal anteroventrally. Medially, the occipital process bears a near-vertical suture for contact with the lateral aspect of the supraoccipital. All three parietals exhibit a stepped ventral margin to the occipital process, though this morphology is at least partly a preservational artifact, as the thin bony margin has partially chipped away in all three specimens. At its curved instep, the thin ventral margin makes up the posterodorsal roof of the endocranial fossa associated with the transverse venous system; in the absence of the supraoccipital, it is not possible to observe the presence or precise position of the external occipital foramen (= caudal middle cerebral vein foramen), which communicates with the transverse venous system and traverses the supraoccipital or the supraoccipital-parietal suture (Tschopp, Mateus \& Benson, 2015) to exit onto the occipital plate (Balanoff, Bever \& Ikejiri, 2010).

Squamosal (IVPP V17768.8; Figure 12) The squamosal is tetraradiate, with an anterior process, a broad dorsomedial process, an elongate ventral process, and a shelf-like, transversely broad posterior process. This latter process does not seem to be homologous to the long, flange-like posterior process of non-sauropod sauropodomorphs, which is absent in early branching eusauropods such as Shunosaurus (ZDM 5009) and Mamenchisaurus youngi (ZDM 0083), and instead manifests in Bellusaurus as a result of the autapomorphic development of a pair of medial and lateral notches in the posterior margin of the ventral process near its base (see below). The squamosal is nearly complete, lacking only the tip of its ventral process and small portions of the margins of its dorsomedial and anterior processes, and articulated with the postorbital anteriorly, the parietal dorsomedially, the paroccipital process of the otoccipital posteriorly, and the quadrate and possibly the quadratojugal ventrally.

The anterior process of the squamosal accommodated the posterior process of the postorbital in an elongate groove that tapers in dorsoventral height posteriorly, indicating a subtriangular posterior process of the postorbital. The dorsomedial roof of the postorbital facet is largely missing, but the trajectory of the preserved portion indicates that the squamosal probably made a small contribution to the posterolateral corner of the supratemporal fenestra, as in most sauropods. The ventral margin of the anterior process is strongly arched and forms the acutely curved posterodorsal corner of the lateral temporal fenestra, the posterior border of which is provided by the sigmoid anterior margin of the ventral process of the squamosal. The lateral edge of the anterior process forms a lip-like ridge that arcs through a curve of approximately 90 degrees as it proceeds posteroventrally across the lateral surface of the ventral process, bounding a shallow lateral temporal fossa posterodorsally. This ridge gradually dissipates before reaching 
711 the posterior margin of the ventral process (Figure 12B).

712 The dorsomedial process of the squamosal is a plate-like structure that projects

713 dorsomedially to receive the occipital process of the parietal. The articular portion of the

714 dorsomedial process is very slightly offset from the rest of the squamosal head, and there is a

715 subtle but abrupt change in bone texture and color across the dorsal surface of the squamosal,

716 with the medial, articular half of the squamosal head being darker and more smoothly textured

717 than the lateral surface, which exhibits fine striae that radiate from the posterolateral corner of

718 the head of the squamosal. A similar textural difference is apparent in Camarasaurus (UMNH

719 VP5594; UMNH VP5598; UMNH VP5665), with the lateral portion of the squamosal head,

720 which is exposed dorsolaterally in articulated skulls, being markedly rugose.

721 The ventral, or quadrate, process of the squamosal is the longest of the processes. As in other

722 sauropods, the lateral wall of the ventral process extends much farther posteriorly than does the

723 medial wall; in Bellusaurus, the medial wall is a low lip that is most strongly developed on the

724 proximal half. Viewed posteriorly, the lateral and medial sides of the ventral process are very

725 slightly convex and are nearly subparallel throughout their preserved length. In lateral view, the

726 posterior margin of the ventral process is essentially straight but for the presence of a large,

727 posteriorly open U-shaped notch at the base of the ventral process. A shallower notch is similarly

728 positioned on the medial aspect of the ventral process, and together these notches undercut the

729 posterior shelf that buttresses the paroccipital process of the otoccipital to produce a posterior

730 process (Figure 12B, C, E). This process is reminiscent of the prong- or spur-like projection that

731 is widespread among flagellicaudatans (Janensch, 1935-36; Salgado \& Bonaparte 1991; Salgado

732 \& Calvo 1992; Berman \& McIntosh, 1978; Tschopp \& Mateus, 2013; Tschopp, Mateus \&

733 Benson, 2015; Tschopp \& Mateus 2017) and is also present in Nemegtosaurus (Wilson, 2005);

734 however, Bellusaurus is distinct from these taxa in that the excavation beneath the posterior

735 projection is abruptly discontinuous with the posterior margin of the squamosal, forming a U-

736 shaped notch that has the appearance of having been 'hole-punched' out of posterior margin of

737 the ventral process and interrupting an otherwise smooth, straight edge. The presence of the U-

738 shaped notches at the posterodorsal margins of the ventral process exposes the sulcus for the

739 quadrate anteromedially and posterolaterally. The sulcus for the head of the quadrate is unlike

740 the deep, cup-like cotyle that receives the quadrate head in Eoraptor (Sereno, Martinez \&

741 Alcober, 2013), Camarasaurus (UMNH VP5594; UMNH VP5598; UMNH VP5665) and cf.

742 Brachiosaurus sp. (USNM 5370) and instead manifests as a broad, shallowly concave,

743 anteromedially canted surface that meets the posterior face of the ventral process at roughly a

744 right angle.

745 Above the quadrate sulcus, the posterior process forms a steep, gently concave shelf that is

746 distinctly offset from the dorsal surface of the quadrate head and that buttressed the paroccipital

747 process anteroventrally. A small portion of the medial edge of the squamosal head contributes

748 neither to the articular surface for the paroccipital process nor to the dorsomedial facet for the

749 parietal, and is sandwiched between these two facets. This smoothly rounded edge presumably

750 supplied the lateral boundary of the posttemporal foramen.

751

752 Quadrate (IVPP V17768.9; Figure 13) The quadrate lacks much of its anterior, pterygoid

753 process but is otherwise complete. Posteriorly, the quadrate bears a deep pneumatic fossa. The

754 quadrate fossa is dorsoventrally tall, occupying $70 \%$ of the total height of the quadrate. In lateral

755 view, the posterior margin of the quadrate is concave. The medial wall of the fossa extends

756 farther posteriorly than does the lateral wall. Much of the lateral wall of the quadrate fossa is 
757 complete along its posterior edge, though taphonomic distortion has pushed a segment of the 758 wall medially. Just above the ventral process for the articular and beginning just lateral to the 759 ventrolateral corner of the quadrate fossa is a flat, dorsoventrally elongate articular surface for 760 the quadratojugal (Figure 13A). There is no distinct and well-preserved scar for the squamosal on the lateral surface of the quadrate, though the head of the quadrate and portions of the adjacent surfaces are generally rugose. It cannot be determined from the morphology of the quadrate or the squamosal whether the squamosal overlapped the quadratojugal ventrally, as it does in sauropodomorphs other than Flagellicaudata (Tschopp, Mateus \& Benson, 2015) and perhaps Giraffatitan (Janensch, 1935-36). On the lateral surface of the preserved portion of the pterygoid process, the quadrate takes on a smooth, polished texture that extends across most of its anterolateral surface.

Only the base of the pterygoid wing of the quadrate is preserved. On its medial face, the quadrate preserves the posterior portion of a broad, shallow fossa for the lateral side of the fanshaped quadrate process of the pterygoid. This fossa exhibits the same polished texture as the anterolateral face of the quadrate. Unlike Camarasaurus (UMNH VP5517; UMNH VP5910; UMNH VP5530; UMNH VP6185), the medial side of the quadrate above the ventral articular process in Bellusaurus is not widely rugose and lacks an anteroposteriorly oriented ridge dividing the medial fossa into a large dorsal concavity and smaller ventral fossa (the latter feature being especially pronounced in UMNH VP6815).

The head of the quadrate articulates with the squamosal dorsally, and is rugose and subtriangular, narrowing posteriorly to meet the medial wall of the quadrate fossa. The distal surface for the articular is finely rugose and roughly crescentic in outline, with a concave anterior edge and convex posterior edge. The articular surface is very weakly divided into two condyles; the lateral condyle does not extend as far ventrally as the medial condyle. A shallow, anteromedially-facing concavity extends dorsally from the medial condyle to the anteroventral edge of the pterygoid wing, and is separated from the remainder of the anterior surface by a low vertical ridge (Figure 13B, D). The significance of this concavity is not clear, but may represent an accessory articulation for the pterygoid. We interpret the anteromedial concavity on the ventral articular process of the quadrate to be an autapomorphy of Bellusaurus.

Pterygoid (IVPP V17768.10; Figure 14) The pterygoid is largely complete and triradiate, consisting of vomerine, transverse, and quadrate processes. Given the fragility of the vomerine process, a large piece of supporting matrix has been left intact, obscuring its medial face. The pterygoid would have articulated with its counterpart along the midline, as well as with the vomer, palatine, ectopterygoid, quadrate, and basisphenoid; these articulations are described below. As in most sauropods (Wilson, 2005), the pterygoid processes in Bellusaurus are not coplanar, and the transverse and quadrate processes project somewhat laterally relative to the plane of the vomerine process. Additionally, the base of the vomerine process is separated medially from the rest of the pterygoid by a wide, shallow trough; in dorsal view, this trough can be seen extending from the posteromedial corner of the pterygoid, just posterior to the vomerine process, to the base of the transverse process, where the trough merges with the lateral surface of the transverse process (Figure 14C). This trough is very weakly developed in Camarasaurus (UMNH VP5909, UMNH VP5587) and Europasaurus (cast of DFMMh/FV 100.2 at Univ. of Chicago), but is absent in Giraffatitan (MB.R.2180.12); we provisionally consider this trough to be autapomorphic in its development in Bellusaurus. At its posterolateral extent, the trough is bounded by a narrow ridge that courses onto the dorsal margin of the quadrate process and 
803 provides the lateral wall of a narrow $(4.3 \mathrm{~mm})$ shelf that extends along the dorsal surface of the

804 quadrate process. This dorsal shelf of the quadrate process is widest distally, and here it

805 overhangs the medial fossa of the quadrate process (see below); anteriorly, the shelf turns 90

806

807

808

809

810

811

812

813

814

815

816

817

818

819 degrees to face medially, and fades into the medial surface of the quadrate process.

The vomerine process is a winglike plate of bone that tapers to a point anteriorly; in life, the paired vomerine processes would have been clasped anterolaterally by the vomers. The ventral half of the vomerine process is missing, but its approximate shape is indicated by the block of supporting matrix, which preserves a partial impression of its medial face. In lateral view, the anterior process has a gently stepped dorsal margin; plesiomorphically, the dorsal margin of the vomerine process is essentially straight or gently curved (e.g., Plateosaurus: Prieto-Marquez \& Norell, 2011: Fig.19; Spinophorosaurus: Remes et al., 2009: Fig.2; Mamenchisaurus youngi: Ouyang \& Ye, 2002: Fig.3; Mamenchisaurus sinocanadorum: Russell \& Zhang, 1993: Fig.1), but by Neosauropoda it becomes gently (Abydosaurus: DINO 17849) to strongly (Camarasaurus: UMNH VP5586, UMNH VP5909; Europasaurus: cast of DFMMh/FV 100.2 at Univ. of Chicago; Giraffatitan: MB.R.2180.12; Diplodocus: Whitlock, Wilson \& Lamanna, 2010: Fig.5; Galeamopus pabsti: Tschopp \& Mateus, 2017: Fig.13; Rapetosaurus: Curry Rogers \& Forster, 2004: Fig.26) stepped. The lateral surface of the vomerine process preserves the dorsal portion of two shallow fossae, separated anteroposteriorly by a low, broad, vertical ridge

822

823

824 that extends ventrally from the dorsal margin of the process. Posterodorsally, above these fossae, the lateral face of the vomerine process forms a flat, subtly rugose, anterodorsally elongate surface that was described by Madsen et al. (1995) as marking the line of contact with the posterior edge of the palatine. At its anterodorsal extent, this surface becomes continuous with a short, longitudinal groove of unclear significance on the dorsal margin of the vomerine process (Figure 14A, C, F); this region of the palate is poorly known in sauropods, and such a groove has not been described in other taxa preserving the pterygoid.

The transverse process is long and rod-like, as in Mamenchisaurus sinocanadorum (Russell

829

830

831

832

833

834

835

836

837

838

839

840

841

842

843 and Zheng, 1993: Fig. 1) but unlike most sauropodomorphs, in which it is curvilinear with a gently hooked distal end (e.g., Plateosaurus: Prieto-Marquez \& Norell, 2011; Spinophorosaurus: Remes et al., 2009; Abydosaurus: DINO 17849; Camarasaurus: UMNH VP5586; Giraffatitan: MB.R.2180.12). The process is transversely crushed distally and lacks a portion of its dorsal surface, including the sheet of bone connecting it to the vomerine process; however, this sheet seems not to have extended far anterior to the block of supporting matrix. A shallow, trough-like articular facet for the ectopterygoid extends longitudinally along the anteromedial aspect of the transverse process (Figure 14A, B, C, E); the ectopterygoid articular facet is similarly positioned in Camarasaurus (UMNH VP5586) and Giraffatitan (MB.R.2180.12), but in these taxa manifests as a deep, rugose channel.

The quadrate process lacks its posterior margin and part of the medial wall of the facet that receives the basipterygoid process of the basisphenoid. Most of the process is comprised of a dorsoventrally tall, fan-shaped plate of bone, with the ventral margin deflected strongly downward, roughly collinear with the ventral margin of the vomerine process (Figure 14A, B).

844

845

846

847

848 Such marked dorsoventral expansion of the quadrate process compares most favorably with the quadrate processes of Spinophorosaurus (Remes et al., 2009: Fig. 2D) and a juvenile diplodocid (Whitlock, Wilson \& Lamanna, 2010: Fig.5) and contrasts with the condition in most macronarians, wherein the dorsal margin of the quadrate process expands only slightly (Giraffatitan: MB.R.2180.12; Europasaurus: cast of DFMMh/FV 100.2 at Univ. of Chicago) or slopes posteroventrally (Abydosaurus: DINO 17849; Camarasaurus: UMNH VP5586, UMNH 
849 VP5909; Galeamopus: Tschopp \& Mateus, 2017; Rapetosaurus: Curry Rogers \& Forster, 2004: 850 Fig.26).

851 A shallow depression occupies the center of the lateral surface of the quadrate process. This 852 depression and the region immediately ventral and posterior to it develop distinct, longitudinal striations, demarcating the articular region for the medial face of the pterygoid wing of the quadrate. The medial face of the quadrate process bears a low, distinct fossa posteriorly, below the narrow shelf that comprises the dorsal margin of the process. Anterior to this medial fossa, the ventral edge of the quadrate process expands anteromedially to floor the socket for the basipterygoid process, then continues dorsomedially and anteriorly to form its medial wall. The basipterygoid socket is completely intact save for a small portion of the dorsal margin of its medial wall, and the preserved portion indicates that Bellusaurus almost certainly lacked the dorsolaterally oriented hook that clasps the basipterygoid process posteriorly and is homoplastically distributed across Sauropodomorpha (Melanorosaurus: Yates, 2007, Mamenchisaurus youngi: ZDM 0083, Turiasaurus: CPT-1211, Dicraeosaurus: Janensch, 19351936, Camarasaurus: CM 11338, UMNH VP 5586, 5909, 5587). The basipterygoid socket is longer anteroposteriorly than wide transversely, and extends for less than half of the preserved length of the quadrate process. Its internal surface is irregularly textured, and at its center, a single, distinct, subcircular pit, approximately four millimeters in diameter, pockmarks the socket.

Supraoccipital Dong (1990) included a supraoccipital in the holotype of Bellusaurus, but this element was not figured in the original description and could not be located for study. Dong (1990) describes the supraoccipital as similar in size and morphology to Shunosaurus, noting that it is butterfly-shaped, with a "swollen" nuchal crest on the midline and a smooth, rounded ventral notch roofing the foramen magnum.

\section{Otoccipital (= exoccipital-opisthotic) (IVPP 8299.1; Figure 15) In his description of the} holotype of Bellusaurus, Dong (1990) described a right exoccipital, which we recognize here as the right exoccipital-opisthotic complex, or otoccipital (Sampson \& Witmer, 2007; Martinez et al., 2016). This element is largely complete, but has suffered some wear and chipping on the dorsomedial, distal, and ventromedial margins of the paroccipital process and probably along its articular surfaces, which generally lack fine detail. As in most post-hatching archosaurs, no suture between the exoccipital and opisthotic can be discerned (Sampson \& Witmer, 2007). The otoccipital makes up the ventrolateral portion of the occiput, and, as in most sauropods, presumably contacted the supraoccipital and prootic dorsally, the basioccipital posteroventrally, the basisphenoid anteroventrally, and the squamosal anterolaterally.

An anteroposteriorly elongate, foot-like ventral process comprised mostly of exoccipital (Madsen et al., 1995) extends ventrally from the body of the otoccipital and bounds the foramen magnum laterally (Figure 15), and would have articulated with the parabasisphenoid and basioccipital ventrally. Viewed medially, the outline of the foot is nearly symmetrical about the base of the ventral process. The posteriorly pointing excursion of the foot projects beyond the posterior face of the otoccipital - and thus beyond the occipital surface of the skull - where it would have contacted the basioccipital and contributed to the dorsolateral margin of the occipital condyle.

The crista interfenestralis, a tongue-like tab of bone derived from the opisthotic (Sampson \& Witmer, 2007), extends ventrally from the anterior surface of the otoccipital, forming a tall, 
895 narrow channel - the cavum metoticum - that opens laterally as the metotic (or jugular)

896 foramen and would have transmitted the jugular vein, cranial nerves IX-XI, and the distal end of 897 the perilymphatic duct (Figure 15E, F; Sampson \& Witmer, 2007; Balanoff, Bever \& Ikejiri, 898 2010). The dorsal margin of the cavum metoticum is pinched, producing a narrow groove that 899 extends across the mediolateral width of the channel and that lies near the exoccipital-opisthotic 900 boundary (Sampson \& Witmer, 2007). Ventrally, the crista interfenestralis approaches but does 901 not contact the anterodorsal surface of the otoccipital foot; because of this gap, the cavum 902 metoticum would have had a small connection anteroventrally to the fenestra vestibuli (foramen 903 ovalis). In most sauropodomorphs, the crista interfenestralis entirely separates the fenestra 904 vestibuli from the metotic foramen, and Bellusaurus approaches this condition. However, there is 905 broad confluence between the metotic and vestibular fenestrae in Apatosaurus (Balanoff, Bever $906 \&$ Ikejiri, 2010) and Nebulasaurus (Xing et al., 2015a), the latter taxon showing separate dorsal 907 and ventral struts that incompletely divide these spaces. (Qijianglong was also described as 908 having an incomplete crista interfenestralis [Xing et al., 2015b], but this portion of the opisthotic 909 appears to be unpreserved [Xing et al., 2015b: Fig.4D], prohibiting assessments of the process).

910 It is possible that the continuity between the metotic and vestibular fenestrae in Apatosaurus,

911 Nebulasaurus, and, to a lesser degree, Bellusaurus, results from late postnatal ossification of the

912

913

914

915

916

917

918

919

920

921

922

923

924

925

926

927

928

929

930

931

932

933

934

935

936

937

938

939

940 crista interfenestralis (Balanoff, Bever \& Ikejiri, 2010).

The ventral process of the otoccipital is pierced by a pair of foramina that likely carried posterior and anterior branches of the hypoglossal nerve (XII), as is typical for sauropodomorphs other than Amargasaurus and most titanosaurians (Wilson, Malkani \& Gingerich, 2005; Paulina Carabajal, 2012; Paulina Carabajal, Carballido \& Currie, 2014), which bear a single hypoglossal nerve foramen, and Camarasaurus, specimens of which may have one or two foramina for the hypoglossal nerve (Witmer et al., 2008; Paulina Carabajal, 2012; E. Tschopp, pers. comm., 2018). Posteroventral to the metotic foramen, the lateral face of the ventral process bears a conspicuous, dorsoventrally tall, oval-shaped hypoglossal foramen and a small, elongate hypoglossal foramen, formerly infilled by matrix and seemingly unrecognized by Dong (1990). The medial face likewise bears two oblong foramina - a smaller posteroventral opening and a larger foramen at the base of the ventral process - though these are more vertically arrayed than the lateral foramina, which are positioned in an essentially horizontal plane. We note that our interpretation of the foramina of the otoccipital differs from that of Dong (1990), who seems to have recognized only two foramina: an anterior foramen, which we interpret as the metotic foramen and that he hypothesized to accommodate cranial nerve $\mathrm{X}$, and a posterior foramen, which we interpret as the posteriormost hypoglossal foramen and that he ascribed to cranial nerves XI and XII.

The paroccipital process extends laterally and slightly posteriorly from the body of the otoccipital. As in most sauropods, the paroccipital process is anteroposteriorly compressed, forming an elongate oval in cross-section. The ventral margin of the paroccipital process is straight, and forms an angle of approximately 114 degrees with the lateral margin of the ventral process. Although the paroccipital process is incomplete distally, the pronounced flaring of its dorsal margin near the distal extent of the preserved portion indicates that the process likely did not extend much farther laterally, as this dorsal flaring occurs near the terminus of the paroccipital process in other sauropods.

The medial half of the anterior face of the otoccipital bears a suture for contact with the prootic. Though poorly preserved generally, this suture clearly encompasses the anterior face of the crista interfenestralis and extends dorsolaterally onto the anterior surface of the paroccipital 
941 process, ending abruptly just beyond the midpoint of the process. The anteroventral surface of 942 the paroccipital process is gently concave and preserves fine striae that we interpret as marking 943 the contact with the posterior process of the squamosal, which buttresses the paroccipital process 944 anteroventrally. If correct, this buttressing configuration would have prevented contact between 945 the quadrate and paroccipital process, contra Dong (1990). Shifting the position of the paroccipital process ventrally, such that it covers the dorsal portion of the quadrate articular fossa of the squamosal, would leave the articular facet of the posterior process of the squamosal

948

949 unoccupied, and manually articulating these isolated elements indicates that such a configuration would produce a large, unrealistic gap between the parietal dorsally and the paroccipital process

950

951

952

953

954

955

956

957

958

959 ventrally. The smooth medial margin of the squamosal suggests that Bellusaurus would have had a well-defined posttemporal fenestra. However, the lack of the supraoccipital and slight wear on the dorsomedial margin of the paroccipital process make it unclear whether the parietal would participate in the margin of the posttemporal fenestra, as in most sauropods, or be excluded from participation in the fenestra by a spur of the supraoccipital, as in Mamenchisaurus youngi (ZDM 0083, Ouyang \& Ye 2002) or by an extension of the exoccipital (the 'posttemporal process' of Harris, 2006), as in flagellicaudatan diplodocoids (Tschopp, Mateus \& Benson, 2015).

A shallow fossa embays the posterior face of the otoccipital ventromedially, at the base of the paroccipital process (Figure 15A). Among sauropods, this fossa is especially pronounced in Apatosaurus (BYU 17096) and Amargasaurus (Paulina Carabajal, Carballido \& Currie, 2014),

960

961

962

963

964

965

966

967 and has been reconstructed as accommodating $m$. iliocostalis capitis in some sauropods (Button, Rayfield \& Barrett, 2014; Paulina Carabajal, Carballido \& Currie, 2014) and theropods (Snively \& Russell, 2007); however, insertion of $m$. iliocostalis capitis on the paroccipital process appears to be autapomorphic for Crocodylia (Tsuihiji, 2005, 2010), and the fossa at the ventromedial base of the paroccipital process may be more parsimoniously interpreted as being encompassed by the atlanto-occipital capsule, as in extant crocodylians and avians (Tsuihiji, 2010).

In Bellusaurus, a distinct prominence, which we interpret as a proatlantal facet, lies dorsomedial to the atlanto-occipital capsule fossa, bordering the foramen magnum laterally and

968

969

970

971

972

973

974

975

976

977

978

979

980

981

982

983

984

985

986 interrupted dorsomedially at the supraoccipital-otoccipital suture (Figure $15 \mathrm{~A}, \mathrm{C}, \mathrm{F}$ ). The ventral margin of the proatlantal facet is more sharply offset from the occipital surface than is its dorsolateral edge, which grades smoothly onto the paroccipital process. Proatlantal facets are present in some non-sauropod sauropodomorphs (e.g., Lufengosaurus: Barrett, Upchurch \& Wang 2005; Massospondylus: BP/1/4934). Wilson et al. (2005) described an isolated braincase from the Pab Formation as having pronounced proatlantal facets, and noted that proatlantal facets are uncommon in sauropods; however, whereas well-developed proatlantal facets are generally absent in mamenchisaurids (Mamenchisaurus youngi: ZDM 0083) and non-titanosaurian macronarians (Camarasaurus: CM 11338, USNM 13786, UMNH 5668, UMNH 5669; Giraffatitan: MB.R.2180.22; Europasaurus: cast of DFMMh/FV 581.1 at Univ. of Chicago; Sarmientosaurus: Martinez et al., 2016), these structures are otherwise broadly distributed in Sauropoda, being present in the early-branching sauropods Spinophorosaurus (Knoll et al., 2012) and Shunosaurus (ZDM 5009), the indeterminate sauropod Daanosaurus (ZDM 0193), the turiasaurians Losillasaurus (Lo-26 a\&b), Turiasaurus (CPT-1211, contra Royo-Torres \& Upchurch 2012), Mierasaurus (Royo-Torres et al., 2017), and Moabosaurus (Britt et al., 2017), flagellicaudatans (e.g., Apatosaurus: Balanoff, Bever \& Ikejiri, 2010; Amargasaurus: Paulina Carabajal, Carballido \& Currie, 2014: Fig. 1C; Kaatedocus: Tschopp \& Mateus, 2013; Galeamopus: Tschopp \& Mateus, 2017), and some titanosaurians (e.g., Quaesitosaurus: Wilson, 2005; Isisaurus: cast of GSP-UM7000 at Univ. of Chicago). 
988 Parabasisphenoid (IVPP V8299.2; Figure 16) The holotypic basisphenoid described by Dong (1990) is relatively complete. The basisphenoid floors the endocranium, and would have contacted the basioccipital posteriorly, the prootic and laterosphenoid dorsally, the parasphenoid anteriorly, and the otoccipital posterodorsally (Madsen et al., 1995; Balanoff, Bever \& Ikejiri, 2010; Marpmann et al., 2014). The parasphenoid rostrum is broken anteriorly, and none of the process is preserved; this breakage did not occur along a suture and no basisphenoidparasphenoid sutural scar is apparent in the preserved bone, supporting previous inferences (Madsen et al., 1995) that the parasphenoid fuses to the basisphenoid and their suture is obliterated early in sauropod ontogeny. We thus follow other authors (e.g. Balanoff, Bever \& Ikejiri, 2010; Marpmann et al., 2014) and refer to the whole element as the parabasisphenoid.

The parabasisphenoid preserves several sutural surfaces, but their precise boundaries are generally difficult to make out. A vertically oriented and transversely concave posterior suture marks an extensive zone of contact for the basioccipital. A narrow, sagittal sulcus separates the ventral half of the parabasisphenoid portion of the basal tubera, but the tubera - or at least their parabasisphenoid component — are nonetheless closely appressed throughout their length, differing from the widely divergent basal tubera of the mamenchisaurid Qijianglong (Xing et al., 2015b), the turiasaurians Turiasaurus (CPT-1211), Losillasaurus (Lo-26 a\&b), and Moabosaurus (Britt et al., 2017), and the early-branching macronarians Camarasaurus (USNM 13786, UMNH5668, UMNH5668), Europasaurus (cast of DFMMh/FV 581.1 at Univ. of Chicago) and Giraffatitan (MB.R.2180.22.2). Micro-CT scanning confirms that this sulcus lacks connection with the sella turcica, which housed the pituitary body in life, and thus that the craniopharyngeal canal - a remnant of the embryonic Rathke's pouch (Baumel \& Witmer, 1993) - was sealed off from the sella turcica early in ontogeny, unlike in Apatosaurus (Balanoff, Bever \& Ikejiri, 2010), Giraffatitan (Knoll \& Schwarz-Wings, 2009), and the Uzbekistan titanosaurian (Sues et al., 2015), in which the craniopharyngeal canal remains patent in more adult specimens.

Articular surfaces for the prootic and the laterosphenoid occupy most of the dorsal surface of the parabasisphenoid, extending from the edge of the basioccipital suture anteriorly onto the dorsum sellae, which bounds the sella turcica posterodorsally (Figure 16A-E). The dorsum sellae is incompletely preserved, and is missing much of its right half. A narrow, shallow sagittal trench, corresponding to the anterior extension of the midline trough that sometimes embays the dorsal aspect of the basioccipital in sauropods, separates the left and right prootic sutural scars and tapers anteriorly as it approaches the dorsum sellae.

The interior of the sella turcica is exposed anteriorly due to the incompleteness of the element. Several neurovascular structures may be associated with the sella turcica, and in Bellusaurus, the most clearly preserved of these are the internal carotid foramina. The carotid foramina pierce the lateral walls of the parabasisphenoid at a height subequal to the apex of the notch between the basal tubera and enter the sella turcica posteroventrally (Figure 16C, D). Externally, each carotid foramen is set within a shallow, subvertically oriented groove on the lateral surface of the parabasisphenoid that is bordered posteriorly by the basal tuber and anteriorly by a low, dorsoventrally oriented ridge corresponding to the ventralmost extent of the crista prootica (=crista otosphenoidalis). The internal carotid groove arises posteroventrally, below the basal tubera, then turns slightly dorsally toward the internal carotid foramen. At this turn, the groove is bounded medially by a fine, rugose ridge extending from the anterolateral edge of each basal tuber onto the base of the basipterygoid process (Figure 16C, D); this ridge 
1033 may correspond to the crista ventrolateralis, which is rarely described in sauropods (but see 1034 Balanoff, Bever \& Ikejiri, 2010) but is more commonly described in theropods (e.g., Sampson \& 1035 Witmer, 2007).

1036

1037

1038

1039

1040

1041

1042

1043

1044

Though the dorsum sellae is incompletely preserved, part of its median, ventral portion appears to be comprised of smooth, finished bone. If correct, this indicates the presence of a sagittal foramen piercing the dorsum sellae (Figure 16B, E). A similarly positioned median canal is present in other sauropodomorphs, including Plateosaurus (Galton, 1985: Fig. 4E), Chebsaurus (Läng \& Mahammed, 2010), Spinophorosaurus (Knoll et al., 2012), Mamenchisaurus youngi (ZDM 0083), Apatosaurus (Balanoff, Bever \& Ikejiri, 2010), Europasaurus (cast of DFMMh/FV 581.1 at Univ. of Chicago; Marpmann et al., 2014), Giraffatitan (Knoll \& Schwarz-Wings, 2009), Bonatitan (Paulina Carabajal, 2012), and the Uzbekistan titanosaurian (Sues et al., 2015), and has been interpreted as accommodating either the basilar artery (Galton, 1985; Knoll et al., 2012; Marpmann et al., 2014) - the anastomosis of paired, posterior branches of the internal carotid arteries that runs posteriorly beneath the brain (Knoll et al., 2012) - or a part of the ventral longitudinal sinus (Sues et al., 2015; Martinez et al., 2016). In Bellusaurus, the passage of the paired abducens nerves (VI) is not apparent under gross inspection or micro-CT imaging; we suspect this is due to the generally poor preservation of the dorsum sellae and anterolateral aspects of the parabasisphenoid and expect that, as in nontitanosaurian sauropods, the abducens nerve traversed the sella turcica rather than passing lateral to it (Paulina Carabajal, 2012).

Anterior to the basal tubera, the basipterygoid processes project ventrolaterally and perhaps

1054

1055

1056

1057

1058

1059

1060

1061

1062

1063

1064

1065

1066

1067

1068

1069

1070

1071

1072

1073

1074

1075

1076

1077

1078 somewhat posteriorly, though without the rest of the braincase the extent of any posterior deflection is unclear. The basipterygoid processes diverge from each other at an angle of approximately 56 degrees and are relatively short, being less than twice as long as the longest diameter of the process at its base. In cross-section, the shafts of the basipterygoid processes are oval to weakly triangular in shape. The terminus of each basipterygoid process is subtriangular and rugose, for articulation with the basipterygoid socket of the pterygoid. The ventral surface of the basisphenoid preserves a broad fossa that extends between the basipterygoid processes to the anterior edge of the basal tubera. As in Apatosaurus (BYU 17096) and Galeamopus sp. (USNM 2673) but unlike Mamenchisaurus youngi (ZDM 0083), Losillasaurus (Lo-26 a\&b), Camarasaurus (UMNH 5669), Europasaurus (cast of DFMMh/FV 581.1 at Univ. of Chicago), and Giraffatitan (MB.R.2180.22.4), no transverse ridge connects the posterior edges of the two basipterygoid processes, and thus the ventral fossa is continuous and uninterrupted anteroposteriorly.

\section{Dentary (IVPP V17786.11; Figure 17) A segment of the posterior half of the left dentary is} preserved. Transverse crushing of the anterior part of the element has compressed the dentigerous shelf and preserved teeth mediolaterally. The ventral margin of the dentary is straight for much its length, arcing ventrally and curving slightly medially in the anterior third of the element. At least eleven nutrient foramina pierce the lateral surface of the dentary on its anterior half, roughly corresponding to the dentigerous portion. Some of these foramina are relatively large (the largest measures $6 \mathrm{~mm} \times 3 \mathrm{~mm}$ ) and several are accompanied by a posteriorly shallowing trough. Like the maxilla, the dentary bears a lateral plate that borders the teeth labially and is marked by low interdental ridges on its medial face; the interdental ridges are generally less pronounced than those on the maxilla, and become difficult to discern posteriorly. The preserved portion of the dentary preserves at least seven alveoli, and possibly an eighth, 
1079 though transverse crushing of the element makes this assessment difficult. In Camarasaurus, the 1080 curvature of the dentary toward the symphysis begins at the level of its minimum vertical depth 1081 and the seventh alveolus (Madsen et al. 1995); in Tazoudasaurus, this curvature begins at the 1082 level of the fifth alveolus (Allain and Aquesbi 2008), at approximately the eight alveolus in 1083 Jobaria (MNBH TIG 5), and at the sixth alveolus in Astrodon (USMN 5669). In Bellusaurus, 1084 this curvature begins at the level of the third preserved alveolus; interpolating from patterns 1085 exhibited in other sauropods, each dentary would likely have housed 9-13 alveoli, far fewer than 1086 1087 the 18 or more dentary teeth typical of most non-neosauropods, including Massospondylus (BP/1/4934), Tazoudasaurus (Allain \& Aquesbi, 2008), Mamenchisaurus (Russell \& Zheng, 1993; Zhang et al. 1998; Ouyang \& Ye, 2002), Omeisaurus maoianus (Tang et al., 2001), and perhaps Jobaria (MNBH TIG 5).

The medial surface of the dentary is marked by a pronounced, anteriorly tapering embayment that is bounded by two rami: a dorsal ramus comprised of the dentigerous shelf (which, along with its non-dentigerous posterior portion, constitutes the "medial process" of Madsen et al., 1995) and a ventral ramus comprised of a medially offset strip of the dentary (the "lateral process" of Madsen et al., 1995). The Meckelian groove becomes a distinct, ventromedially oriented channel at the anterior union of the two rami and continues anteriorly to the broken distal edge of the dentary (Figure 17B).

An anteriorly expanded dentary ramus exceeding the minimum depth of the ramus by approximately 150 percent has previously been recovered as a synapomorphy of Eusauropoda (e.g., Upchurch, 1998; Wilson \& Sereno, 1998; Wilson, 2002;). This character cannot be confidently assessed in the incompletely preserved Bellusaurus dentary, but measurements of the dorsoventral heights of the element posteriorly $(31 \mathrm{~mm})$ and anteriorly $(28 \mathrm{~mm})$ indicate that the dentary decreases slightly in depth towards the mandibular symphysis, at least briefly. A decrease in the dorsoventral height of the dentary anterior to the coronoid and a subsequent increase in height toward the mandibular symphysis is typical for eusauropods, and occurs in taxa such as Abrosaurus (ZDM 5033), Jobaria (MNBH TIG 5), Camarasaurus (UMNH VP 11394), and Abydosaurus (DINO 17848).

Angular (IVPP V17768.12; Figure 18) The angular is a simple, elongate, platelike bone, composed of a mediolaterally expanded ventral body and a dorsolateral laminar flange. The anterior half of the lateral surface of the angular has been abraded and mediolaterally crushed, but the remainder of the angular, including the exceedingly thin dorsal margin of its dorsolateral lamina, is mostly intact. Anteriorly, the angular would have been sandwiched laterally by the dentary and medially by the splenial (Madsen et al., 1995); a facet for the splenial is apparent on the anterior half of the ventral body of the angular, indicating contact with the splenial ventrally and medially. Immediately posterior to the articulation of the splenial, the angular bears a facet for the prearticular, which extends principally along the ventral aspect of posterior half of the angular (Figure 18B).

The transverse width of the ventral body is greatest posteriorly, forming a pronounced horizontal shelf that would floor the adductor fossa. The shelf narrows and rotates medially as the breadth of the ventral body tapers from a posterior maximum of $7 \mathrm{~mm}$ to $3 \mathrm{~mm}$ at its distal tip. The angular is laterally convex along its length, and its ventral margin is gently sigmoid in lateral view, unlike the more markedly sinuous ventral margin of Camarasaurus (UMNH VP 6814). The dorsoventral height of the angular increases for the posterior third of its length, then decreases gently to the blunt, distal tip of the bone. Where the dorsal lamina is tallest, it would 
1125 overlap the lateral surface of the surangular (Madsen et al., 1995).

1126

1127

1128

1129

1130

1131

1132

1133

1134

1135

1136

1137

1138

1139

1140

1141

1142

1143

1144

1145

1146

1147

1148

1149

1150

1151

1152

1153

1154

1155

1156

1157

1158

1159

1160

1161

1162

1163

1164

1165

1166

1167

1168

1169

1170

Dentition (IVPP V8299.3, V8299.4, V8299.6; IVPP V17768.12-21; Figure 4, 7, 17, 19-21; Table 3) Numerous teeth are preserved in situ across the four maxillae and at least three are preserved within the dentary (IVPP V17786.11). Dong (1990) also included six isolated teeth in the Bellusaurus holotype (IVPP 8299), of which four have been located, and the referred material (IVPP 17768) includes an additional ten isolated teeth. As described below, in situ maxillary and dentary teeth exhibit distinct morphologies, and in all cases, the morphology of the isolated teeth is consistent only with that of the in situ maxillary teeth.

None of the teeth preserved in situ show evidence of wear, and only the first and fourth alveoli of IVPP V17768.1 preserve teeth that have erupted beyond the margin of the medial plate (Figure 4C; Figure 21). Additional replacement teeth are visible through the row of replacement foramina that line the alveolar margin in IVPP V17768.1. Micro-CT scans reveal that, including an erupting tooth, each alveolus houses up to two replacement teeth (Figures 7, 21). The second generation of replacement teeth is only preserved in situ in alveoli 1-5 and 7; more posterior alveoli only house a single tooth, and alveolus 10 does not preserve any teeth. Replacement teeth are imbricated, with more anterior teeth generally overlapping the next most posterior tooth mesiolabially. The second generation replacement tooth in a given alveolus is positioned somewhat mesiolingual to the first generation tooth in that alveolus. It is possible that the lack of a second generation of replacement teeth in more posterior alveoli reflects differential rates of tooth replacement along the tooth row, as has been noted for some other sauropods (Sereno \& Wilson, 2005; Wiersma \& Sander, 2016). Ontogenetic influences on tooth replacement rates and number are not known for sauropods.

The crowns of the maxillary and isolated teeth have mesiodistally convex labial surfaces and concave or nearly flat lingual surfaces, and the base of the crown has a D-shaped cross-section (Figure 4C, D; Figures 19-21). The crowns curve lingually and are gently recurved distally, especially in isolated teeth with smaller crowns, presumably originating from more posterior positions in the tooth row. At approximately midheight, the crowns of the maxillary and isolated teeth expand slightly mesiodistally, then taper to an apical point. The increase in crown breadth is much less dramatic than in the distinctly spatulate teeth of taxa such as Chebsaurus (Läng \& Mahammed, 2010: Fig. 6), Tazoudasaurus (Allain \& Aquesbi, 2008: Fig. 7), and turiasaurians (Royo-Torres \& Upchurch, 2012: Fig. 7; Mateus, Mannion \& Upchurch, 2014: Fig. 3), and some teeth (e.g., IVPP V17768.13, IVPP V17768.17, IVPP V17768.20) resemble the more parallelsided condition of Mamenchisaurus sinocanadorum (IVPP V10603), Mamenchisaurus youngi (Ouyang \& Ye, 2002: Fig. 8-11), Euhelopus (PMU 24705/1a-b), and brachiosaurids (e.g., Giraffatitan MB.R. 2180.20.12; Mannion et al., 2017: Fig. 9). A low ridge extends apicobasally along the midline of the lingual surface of the crown, from the mid-crown mesiodistal expansion to the apex of the tooth, producing shallow troughs on either side. The teeth of non-diplodocoid and non-titanosaurian sauropods also exhibit apicobasal labial grooves near their mesial and distal margins (Upchurch, 1995; Upchurch, 1998; Wilson \& Sereno, 1998; Mannion et al., 2013; Mannion, Allain \& Moine, 2017) - a feature identified as a synapomorphy of eusauropods and their closest outgroups (Wilson \& Sereno, 1998; Carballido \& Pol, 2010; Carballido et al., 2017) — but these are very weakly developed in Bellusaurus, manifesting as flat or shallowly concave surfaces. Tooth size decreases distally along the tooth row, and smaller teeth bear a shorter crown and are more distinctly recurved.

The maxillary teeth were closely spaced in the tooth row; this is clear not only from 
1171 inspection of the preserved maxillae and their in situ teeth (IVPP V 8299; IVPP V17768.1), but

1172 is also suggested by the nearly-flat facet on the distolingual aspect of the isolated teeth that

1173 extends between the base of the crown and the mid-crown mesiodistal expansion (Figures 19-

117420 ), suggesting that the distal edge of the tooth slightly overlapped the mesiolabial aspect of the

1175 succeeding tooth. This relationship cannot be confirmed in the preserved maxillae, which lack

1176 well-exposed, sequentially preserved teeth, but the presence of such a facet suggests that

1177 Bellusaurus had imbricated teeth.

1178 Denticles are absent on both the mesial and distal margins of the maxillary and isolated

1179 teeth (contra Dong 1990). As in other sauropods, the enamel on the maxillary teeth is wrinkled

1180 throughout the crown, most closely resembling morphotype I of Holwerda, Pol \& Rauhut (2015):

1181 the enamel is arranged into coarse, longitudinal ridges at the base of the crown, below the

1182 mesiodistal expansion, with crests and grooves becoming shorter and mesially and distally

1183

1184

1185

1186

1187

1188

1189

1190

1191

1192

1193

1194

1195

1196

1197

1198

1199

1200

1201

1202

1203

1204

1205

1206

1207

1208

1209

1210

1211

1212

1213

1214

1215

1216 deflected closer to the apex of the crown. In some isolated maxillary teeth but in none of the in situ teeth, the finely wrinkled texture of the enamel has been partially worn away from the mesial and distal margins of the upper crown (IVPP V8299.3; IVPP V17768.16-21), producing a polished finish apically and several forms of wear pattern: paired mesial and distal V-shaped facets (IVPP V8299.3, IVPP V17768.17, IVPP V17768.20), a single, mesial V-shaped facet (IVPP V17768.18, IVPP V17768.19), and a single apical wear facet (IVPP V17768.21), though this may reflect the early stages of a low-angled, V-shaped wear facet (Chatterjee \& Zheng, 2002). Among the teeth bearing paired, V-shaped wear facets, IVPP V17768.20 and IVPP V8299.3 exhibit markedly asymmetrical facets, the distal edge being more deeply worn and developing a pronounced shoulder (Figure 19A-B; Figure 20GG-HH). That most tooth wear consists of low-angled, V-shaped wear facets suggests an interlocking upper and lower jaw occlusion typical of eusauropods (Chatterjee \& Zheng, 2002; Carballido et al., 2017). In IVPP V17768.20, the enamel has been worn away basally, and the paired wear facets meet on the lingual aspect of the tooth. In no tooth do the wear facets extend appreciably onto the labial surface.

The left dentary preserves three teeth, though the middle tooth is poorly preserved and morphologically uninformative (Figure 17E). Only the upper part of the crowns of the dentary teeth are exposed lingually, and no wear facets are apparent on these. Like the maxillary and isolated teeth, the dentary teeth exhibit fine wrinkling of the enamel, bear a low apicobasal ridge that extends to the tip of the tooth and divides the lingual surface in two, and are gently recurved distally. However, the preserved dentary teeth differ from the maxillary and isolated teeth in at least two regards. First, though somewhat transversely crushed, the dentary teeth appear to lack the lingual excavation of the crown that gives the maxillary teeth their spoon-shaped morphology as well as the paired troughs on either side of the midline apicobasal ridge, and the apical portions of their crowns are overall slightly convex lingually. Second, the dentary teeth exhibit marginal denticles, which are entirely absent in all preserved maxillary and isolated teeth. Both well-preserved dentary teeth preserve five enamel tuberosities along their mesial edges, and two to three small tuberosities (including the apical denticle) along their distal edges, as in Omeisaurus tianfuensis (He et al., 1988: Fig. 16-17) and Abrosaurus (Ouyang, 1989; ZDM 5033).

Denticles are plesiomorphic for Sauropodomorpha and are generally reduced towards Neosauropoda (Upchurch, Barrett \& Dodson, 2004), though they are homoplastically present in some brachiosaurids (Janensch 1935-1936; Marpmann et al., 2014; Mannion et al., 2017) and may develop plastically within species or individuals, as in Giraffatitan (Janensch 1935-1936) 
1217 and Abrosaurus (Ouyang, 1989). That all erupting or replacement maxillary teeth in Bellusaurus

1218 lack denticles suggests that denticles may be unique to replacement teeth in the middle of the

1219 dentary tooth row, or perhaps more generally to teeth of the lower jaw. Such distinct upper and

1220 lower jaw tooth morphologies are not uncommon in sauropods. Denticles are most strongly, but

1221 not exclusively, developed in the dentary teeth in Abrosaurus (Ouyang, 1989), and some

1222 sauropods have notably larger upper jaw than lower jaw crown diameters (e.g., Ouyang \& Ye,

1223 2002; Wilson, 2005; Whitlock, Wilson \& Lamanna, 2010; Mannion et al., 2013) or show

1224 differences in crown cross-sectional shape and curvature (Wilson, 2005) or wear facet pattern

1225 and orientation between upper and lower dentitions (Martinez et al., 2016).

1226

1227

1228

1229

1230

1231

1232

1233

1234

1235

1236

1237

1238

1239

1240

1241

1242

1243

1244

1245

1246

1247

1248

1249

1250

1251

1252

1253

1254

1255

1256

1257

1258

1259

1260

1261

1262

\section{DISCUSSION}

The abundance of cranial and postcranial material now assignable to Bellusaurus makes the taxon among the more completely known sauropods. However, interpretation of this material for phylogenetic and morphofunctional analyses is potentially complicated by the dissociation of almost all elements and by the juvenile status of the material. As pointed out above, all duplicate elements within the bone bed are of subequal size (Table 1), and among long bones, the smallest exemplars of an element are at least $77 \%$ the length of the largest element, and typically more than $85 \%$ of this length (AJM, unpublished data). In concert with histological information indicating that individuals in the bone bed were within two years of hatching at time of death (Mo, 2013), these data suggest that inter-element ratios (e.g., limb proportions; skull proportions) of average linear measurements are likely to be reasonably accurate reflections of the body proportions of young juvenile Bellusaurus. In the absence of adult specimens, what is less clear is how to parse features of the known Bellusaurus material that are likely to reflect adult morphologies from those that might be expected to show substantial ontogenetic variation based on patterns in other sauropod taxa (Table 4).

Until recently, much of what was known about sauropod skull anatomy relied on a handful of exceptional specimens (e.g., Marsh, 1884; Holland, 1924; Gilmore, 1925; Janensch 19351936; Nowinski, 1971; Berman \& McIntosh, 1978; Chatterjee \& Zheng, 2002). A spate of recent discoveries and redescriptions has dramatically expanded our understanding of sauropod cranial diversity and morphology (e.g., Chure et al., 2010; Whitlock et al., 2010; Knoll et al., 2012; Royo-Torres \& Upchurch, 2012; Poropat \& Kear, 2013; Tschopp \& Mateus, 2013; Xing et al., 2015a; Marpmann et al., 2014; Sues et al., 2015; Martinez et al., 2016; Wilson, Pol \& Zaher, 2016; Britt et al., 2017; Tschopp \& Mateus, 2017), but ontogenetic variants of sauropod skulls remain exceedingly rare, and relatively little is known about how the sauropod skull changed as it developed.

Below, we review the state of knowledge of ontogenetic trends in sauropod skulls, summarizing major hypothesized transformations in Table 5, and discuss the implications of the juvenile status of the available Bellusaurus material for interpretation of several cranial characters that likely inform its phylogenetic position.

\section{Sauropod cranial ontogeny}

\section{Homology and ontogeny of the preantorbital opening}

Understanding patterns of ontogenetic variation and evolutionary elaboration of the preantorbital opening requires insight on the morphogenetic antecedents of this structure. Before discussing evidence for ontogenetic variability in the preantorbital opening, we first review new information on the primary homology (sensu de Pinna, 1991) of the foramen and summarize 
1263

1264

1265

1266

1267

1268

1269

1270

1271

1272

1273

1274

1275

1276

1277

1278

1279

1280

1281

1282

1283

1284

1285

1286

1287

1288

1289

1290

1291

1292

1293

1294

1295

1296

1297

1298

1299

1300

1301

1302

1303

1304

1305

1306

1307

1308

criteria for its identification.

Recent studies have argued that the definitive preantorbital fenestra of diplodocids is vascular in origin. This work posits that the broad window into the antorbital cavity that is present in various advanced neosauropods arose from a neurovascular opening on the lateral surface of the maxilla, and provides topological criteria for establishing the primary homology of these openings, which, as discussed above, can be quite disparate in form (Porter, 2015; Martinez et al., 2016). These homology criteria are: (1) the foramen/fenestra is located dorsal to the maxillary palatal shelf, where it communicates with the canal for the maxillary neurovascular bundle; (2) the foramen/fenestra is in the vicinity of the suborbital fenestra, (i.e., where the palatine and ectopterygoid unite with the maxillary palatal shelf); and (3) the foramen/fenestra is generally just posterior to the alveolar tooth chamber (which houses the replacement teeth and may extend somewhat posterior to the most distal [= posterior] erupted tooth position) (Martinez et al., 2016).

Previous study of Bellusaurus overlooked the presence of a large neurovascular foramen anteroventral to the antorbital fenestra (Mo, 2013), which we recognize as the preantorbital foramen. We note that the preantorbital foramen in Bellusaurus does not meet all of the homology criteria proposed by Martinez et al. (2016): while the foramen communicates with the canal for the maxillary neurovascular bundle (and hence with both the anterior maxillary foramen and posterior alveolar foramen), it is at the level of, rather than fully dorsal to, the maxillary palatal shelf, and is well anterior of both the suborbital fenestra and the posterior margin of the alveolar tooth chamber. However, some of the taxa that Martinez et al. (2016) highlight as having a preantorbital foramen also appear to violate these criteria. In Giraffatitan (MB.R.2180.2) and Abydosaurus (DINO 17849), the preantorbital fenestra is ventral or level with the maxillary palatal shelf, while in Euhelopus, the possible perforation of the maxilla posteroventral to the lacrimal process that has been interpreted as the preantorbital opening (Wilson \& Upchurch, 2009; Martinez et al., 2016) lacks an apparent connection to the neurovascular bundle of the maxilla (based on study of CT scans of PMU 24705/1a-b). In addition, the preantorbital foramen is anterior to the posterior extent of the tooth row, and presumably the alveolar tooth chamber, in Giraffatitan (MB.R.2180.2), embryos of the Auca Mahuevo titanosaurian (García et al., 2010), and Abydosaurus (DINO 17849), and is level with, rather than posterior to, the posterior margin of the tooth row in Rapetosaurus (Curry Rogers \& Forster, 2004) and perhaps Sarmientosaurus (Martinez et al., 2016: Fig. 6-7). With the exception of Euhelopus, we do not question the presence of a preantorbital foramen in these taxa, but rather suggest that the criteria proposed by Martinez et al., (2016) may be overly stringent, and principally reflect the topological relationships of the preantorbital opening in adult specimens of diplodocids (e.g., Galeamopus) and titanosaurians (e.g., Tapuiasaurus) for which the identity of this structure is unambiguous. Our current state of knowledge is insufficient to assess whether specific topological information for the preantorbital opening is static through development, though conjectural hypotheses for ontogenetic transformations of the maxilla of titanosaurians (García \& Cerda, 2010: Fig. 7) suggest substantial ontogenetic variability is plausible. In asserting the primary homology of the large neurovascular foramen on the lateral surface of the maxilla of Bellusaurus with the preantorbital opening that has been recovered as a synapomorphy of Neosauropoda + Jobaria (Wilson, 2002), we adopt part of the first criterion of Martinez et al. (2016) - that is, connectivity with the maxillary neurovascular bundle - and also draw on criteria that have been used by previous authors (e.g., Wilson \& Sereno, 1998; Curry Rogers \& Forster, 2004) and that obtain for all taxa listed by Martinez et al., (2016), with 
1309 the exception of Euhelopus - specifically, the relatively large size of the opening vis-à-vis other

1310

1311

1312

1313

1314

1315

1316

1317

1318

1319

1320

1321

1322

1323

1324

1325

1326

1327

1328

1329

1330

1331

1332

1333

1334

1335

1336

1337

1338

1339

1340

1341

1342

1343

1344

1345

1346

1347

1348

1349

1350

1351

1352

1353

1354

maxillary neurovascular foramina, the general positioning of the opening anteroventral to the antorbital fenestra, and the anteroventral orientation of the associated channel.

Little is known about the ontogeny of the preantorbital opening. Wilson \& Sereno (1998) noted that the slit-like preantorbital opening of Camarasaurus is sometimes reduced in size or essentially absent in adult specimens, but an exhaustive sampling of this feature across Camarasaurus specimens has not yet been conducted, and the generally weak development of this neurovascular foramen even in those specimens that clearly have it (e.g., CM 11338; CM 113; DMNH 32162, a cast of GMNH [Gunma Museum of Natural History] PV 101) make putative ontogenetic transformations difficult to assess. The presence of a distinct preantorbital opening in one maxilla of Bellusaurus (IVPP V17768.3) but not another (IVPP V17768.1) could suggest slight individual variation in the timing of the development of the foramen.

Alternatively, this difference could reflect population-level variation in the presence of the opening, or, depending on the phylogenetic affinities of Bellusaurus, the presence of a protracted "zone of variability" (Bever et al., 2011) near the base of Neosauropoda resulting in sustained polymorphism across several nodes; the latter explanation could also account for the inconsistent development of the opening in Camarasaurus specimens. The development of the preantorbital fenestra in embryonic titanosaurians (García, 2007) and its apparent persistence as a welldeveloped aperture in more adult titanosaurians suggests that this feature arose early in titanosaurian ontogeny and persisted through development, though this remains conjectural until adult individuals of the Auca Mahuevo titanosaurian are discovered.

\section{Ontogeny of the tooth row and snout}

Previous studies of diplodicines and titanosaurians indicate that the posterior extent of the maxillary tooth row becomes displaced anteriorly over the course of ontogeny in these longsnouted lineages (Salgado, Coria \& Chiappe, 2005; García \& Cerda, 2010; García et al., 2010; Whitlock, Wilson \& Lamanna, 2010; Tschopp \& Mateus, 2013; Table 5). The disparity in the extent of the tooth row and the form of the maxilla that has been hypothesized to exist between embryonic and adult titanosaurians is extreme (García \& Cerda, 2010: Fig. 7), and seems likely to predict ecological separation of young juveniles and adults. The muzzle was noted to increase in relative width through ontogeny in Europasaurus (Marpmann et al., 2014), and in cf.

Diplodocus, differences in muzzle shape between juvenile and more adult specimens have been suggested to reflect ontogenetic resource partitioning (Whitlock, Wilson \& Lamanna, 2010), a pattern that has also been proposed as a possible explanation for divergent patterns of enamel microwear between juvenile and adult Camarasaurus teeth (Fiorillo, 1998).

Relevance to interpretations of Bellusaurus. It is possible that the posterior extent of the maxillary tooth row migrates somewhat farther anteriorly in more adult specimens of Bellusaurus, especially if adults developed a more elongate rostrum than the shape inferred for juvenile Bellusaurus (Figure 1). The morphologically similar taxon Camarasaurus shows little or no tooth row migration through ontogeny, though the youngest relevant Camarasaurus material (CM 11338) may not reflect the condition present at the beginning of post-hatching ontogeny, a caveat that likely hinders other inferences of cranial ontogeny in this taxon. Nevertheless, we predict that the posterior margin of the maxillary tooth row remains posterior to the anterior edge of the antorbital fenestra in adult specimens of Bellusaurus, as in eusauropods other than diplodocoids, some brachiosaurids, and some titanosaurians. 
1355

1356

1357

1358

1359

1360

1361

1362

1363

1364

1365

1366

1367

1368

1369

1370

1371

1372

1373

1374

1375

1376

1377

1378

1379

1380

1381

1382

1383

1384

1385

1386

1387

1388

1389

1390

1391

1392

1393

1394

1395

1396

1397

1398

1399

1400

Ontogeny of the frontal

The presence of an elongate frontal in basal sauropodomorphs (e.g., Wilson, 2002: character 20) and juvenile and paedomorphic sauropods (Table 5) but not in more adult sauropod specimens suggests that the frontal becomes relatively broader transversely through ontogeny. Marpmann et al. (2014) include in the diagnosis of Europasaurus an anteroposteriorly long frontal with a very deep orbital rim causing an extreme reduction of the frontal-prefrontal and frontal-nasal articulations; as noted above, however, this feature is not unique to Europasaurus, and occurs in a variety of other sauropodomorphs (Table 2). Several observations suggest that the form of the lateral margin of the frontal may change through ontogeny in some sauropods. The juvenile Camarasaurus CM 11338 and several other Camarasaurus specimens (Madsen et al., 1995: Figs. 14A-B; McIntosh et al., 1996: Fig. 10; Woodruff \& Foster, 2017: Fig. 4) have a concave lateral margin of the frontal, while this margin is weakly concave or entirely straight in some large braincases referred to Camarasaurus (UMNH VP 5668; Madsen et al., 1995: Figs. $25 \mathrm{~A}-\mathrm{C})$. Moreover, the observation that the frontal is more deeply embayed in basal sauropodomorphs, the paedomorphic Europasaurus, and the juvenile Bellusaurus and Daanosaurus than in most sauropods (Table 2), as well as the presence of an embayed orbital margin in embryonic but not adult titanosaurians (Chiappe et al., 1998; Wilson 2005; García et al., 2010) and a relatively less well-developed lateral margin of the frontal in a juvenile cf. Diplodocus (Whitlock, Wilson \& Lamanna, 2010), suggests that curvature of the orbital margin may be ontogenetically variable. We note, however, that the expression of a concave lateral margin in at least some relatively adult mamenchisaurid and diplodocoid skulls (Table 2) indicates that this feature may vary both ontogenetically and phylogenetically (see below).

Relevance to interpretations of Bellusaurus. We hypothesize that the frontal becomes relatively less elongate and broader transversely in more adult specimens of Bellusaurus. It is not currently possible to predict whether the orbital rim of the frontal would become less concave in adult Bellusaurus.

\section{Ontogeny of the supratemporal fenestra}

In Camarasaurus, the breadth of the skull roof separating the supratemporal fenestrae appears to diminish through ontogeny as the fenestrae expand in relative transverse width, a trend also noted for Europasaurus (Marpmann et al., 2014). In the juvenile Camarasaurus (CM 11338), the supratemporal fenestrae are separated by over twice their longest diameter, while in at least some more adult skulls (e.g., USNM 13786; UMNH VP 5669; Woodruff \& Foster, 2017), these widths are more nearly equal.

Relevance to interpretations of Bellusaurus. If, as in Camarasaurus and Europasaurus, the ratio of the distance separating the supratemporal fenestrae to the transverse width of the supratemporal fenestra decreases through ontogeny in Bellusaurus, then the juvenile Bellusaurus individuals described here may have already undergone much of this change, as the ratio in these specimens $(\sim 1.2)$ is far removed from the value observed in the most juvenile Camarasaurus ( 2.0; CM 11338) and Europasaurus ( 2.5; Marpmann et al., 2014: Fig.7E) specimens, and is instead more typical of the ratio observed in many non-diplodocoid eusauropods.

\section{Ontogeny and homology of the frontoparietal fenestra}

Previous authors have suggested that the presence of a frontoparietal fenestra at the juncture of the frontals and parietals of Apatosaurus (Balanoff, Bever \& Ikejiri, 2010) and dicraeosaurids (Salgado \& Calvo, 1992) may reflect the paedomorphic retention of the embryonic frontoparietal 
1401 fontanelle, possibly as a result of anterodorsal expansion of the superior sagittal sinus into the 1402 space between the developing dermal roof elements (Balanoff, Bever \& Ikejiri, 2010). This 1403 hypothesis of homology implies closure of the frontoparietal fenestra over the course of 1404 ontogeny for those sauropods lacking such an aperture, and may garner support from the 1405 observation that a midline aperture between the paired frontals and parietals is also present in titanosaurian embryos (Salgado, Coria \& Chiappe, 2005) but absent in the skulls of more mature titanosaurian specimens of Nemegtosaurus (Wilson, 2005) and possibly Tapuiasaurus (Wilson et al., 2016). Among theropods, a frontoparietal fenestra has been identified in the juvenile compsognathid Scipionyx (Dal Sasso \& Maganuco, 2011), embryonic paleognath Aepyornis (Balanoff \& Rowe, 2007), and extant juvenile birds, and may be present in the perinate troodontid Byronosaurus (Bever \& Norell, 2009), but is otherwise absent in more adult members of these lineages, suggesting an ontogenetic explanation for the aperture. The postparietal foramen - a median aperture between the parietals and supraoccipital that is unique to some sauropods, and distinct from the frontoparietal fenestra - has also been suggested to result from paedomorphic retention of an embryonic fontanelle (Salgado, 1999), but the influence of ontogeny on the development of the postparietal foramen is unclear (Tschopp \& Mateus, 2013).

The hypothesis of a fontanelle origin for the frontoparietal fenestra is challenged, however, by morphologies observed in some other sauropods. In Camarasaurus, the "frontoparietal" fenestra may be bounded entirely by the frontals (and is thus termed the "frontal aperture" by Woodruff \& Foster 2017), while a similar median opening in Europasaurus is wholly surrounded by the paired parietals and is termed the "parietal fenestra" (Marpmann et al., 2014), presumably implying primary homology with the parietal foramen associated with the photoreceptive parietal (pineal) organ in various extinct and extant vertebrates (Janensch, 19351936; Edinger, 1955). Notably, the definitive parietal foramen of some squamates may be present between the paired frontals, between the paired parietals, or at the frontoparietal juncture, and these placements can be intraspecifically variable (Edinger, 1955). The absence of a midline aperture in the dermal skull roof of the most juvenile Camarasaurus skull known (CM 11338) and the sporadic presence of such an opening in various skulls referred to Camarasaurus (White, 1958; Madsen et al., 1995; Woodruff \& Foster, 2017) allows for the possibility that the fenestra opens, rather than closes, over the course of ontogeny (Woodruff \& Foster, 2017), at least in some sauropods. A frontoparietal fenestra is also absent in Daanosaurus (ZDM 0193), a Chinese sauropod of unclear affinities that is known only from a partial juvenile skeleton subequal in size to Bellusaurus. Thus, at present, it is not possible to make definitive statements about the ontogeny — or even the homology — of the frontal/frontoparietal/parietal fenestrae of sauropods, though exhaustive study of skulls referred to Camarasaurus, discovery of additional juvenile sauropod skulls, and greater focus on unambiguous osteological correlates of the skull roof aperture for the photoreceptive pineal body may help clarify these issues (Woodruff \& Foster, 2017). We note that, as pointed out by Harris (2006), while a parietal fenestra allows for light to reach the pineal body, the imposition of a large dural venous system between the brain

1440 tissue and dorsal skull roof would presumably hinder photoreception, unless the pineal body was 1441

1442 distinct anteriorly from more posterior expansions of the superior sagittal sinus (Balanoff, Bever \& Ikejiri, 2010).

Relevance to interpretations of Bellusaurus. Given the ambiguity surrounding the ontogeny and homology of the preantorbital and postparietal fenestrae in sauropods, we refrain from making predictions about the fate of these apertures in more adult specimens of Bellusaurus. 
1447

1448

1449

1450

1451

1452

1453

1454

1455

1456

1457

1458

1459

1460

1461

1462

1463

1464

1465

1466

1467

1468

1469

1470

1471

1472

1473

1474

1475

1476

1477

1478

1479

1480

1481

1482

1483

1484

1485

1486

1487

1488

1489

1490

1491

1492

\section{Ontogeny of frontal-parietal fusion}

The frontal and parietal appear to be among the first bones to become tightly sutured within the sauropod skull. This has previously been suggested for Camarasaurus (Madsen et al., 1995) and is evidenced by the strong suturing in the three frontal-parietal pairs of Bellusaurus described above and the two frontal-parietal pairs known for the juvenile Chinese sauropod Daanosaurus (ZDM 0193). That the four frontals and five parietals known for Europasaurus were found in isolation is thus especially striking, and the general lack of inter-element fusion in Europasaurus, even between apparently adult elements, is likely an effect of cranial paedomorphosis (Marpmann et al., 2014).

Relevance to interpretations of Bellusaurus. Assuming a subequal age for the cranial material of Bellusaurus, we hypothesize that strong suturing of the frontal and parietal preceded strong suturing and fusion of the parabasisphenoid to adjacent elements.

\section{Ontogeny of the quadrate fossa}

Among the element-specific ontogenetic transformations detailed by Marpmann et al. (2014) for Europasaurus is increasing depth of the quadrate fossa in more mature specimens (Table 5). There is little difference in the depth of the quadrate fossa between juvenile and adult Camarasaurus, though this may reflect the completion of an ontogenetically progressing embayment of the quadrate in juvenile Camarasaurus CM11338 rather than the lack of an ontogenetic transformation in the taxon.

Relevance to interpretations of Bellusaurus. The quadrate fossa is deeply excavated in Bellusaurus and likely did not change much from the condition in the specimen described here, suggesting that ontogenetic embayment of the quadrate was accomplished by the first year or so of life.

\section{Ontogeny of the crista interfenestralis}

As noted above, the broad confluence between the metotic and vestibular fenestrae in Apatosaurus (Balanoff, Bever \& Ikejiri, 2010) and Nebulasaurus (Xing et al., 2015a) may result from late postnatal ossification of the crista interfenestralis (Balanoff, Bever \& Ikejiri, 2010).

Relevance to interpretations of Bellusaurus. In Bellusaurus, separation of the metotic foramen and foramen vestibuli is nearly complete, with only a small ventral gap uniting these apertures. If incomplete separation of the metotic foramen and foramen vestibuli indeed results from late postnatal ossification of the crista interfenestralis, we would predict the closure of this gap to occur in more adult specimens of Bellusaurus.

\section{Ontogeny of tooth count}

Ikejiri, Tidwell \& Trexler (2005) demonstrate that putative Camarasaurus lentus specimens show some variation in number of alveoli of the maxilla and dentary, and conclude that these differences are "due to individual variation because the juvenile (CM 11338) has more aveolae [sic] than the large WDC [Wyoming Dinosaur Center] specimens." McIntosh et al. (1996) also attributed tooth count variation in Camarasaurus to individual rather than ontogenetic variation. Maxillary tooth count (8-9) is consistent between the juvenile CM 11338 and the adult WDC Camarasaurus described by Ikejiri, Tidwell \& Trexler (2005), but CM 11338 has more dentary teeth (13) than does the WDC Camarasaurus (11 on the left, 10 on the right). A possibly subadult specimen of Kaatedocus has more maxillary $(\geqq 12)$ and dentary teeth (12-13) than is typical 
1493 for more adult diplodocid specimens (Tschopp \& Mateus, 2013), which have 10-11 teeth each in 1494 the maxilla and dentary (Whitlock, Wilson \& Lamanna, 2010). Citing apparent constancy in 1495 tooth count between a juvenile and more adult cf. Diplodocus skulls (Whitlock, Wilson \& 1496 Lamanna, 2010), Tschopp \& Mateus (2013) considered the larger tooth counts in Kaatedocus to 1497 be due to taxonomic rather than ontogenetic variation; however, preservation of the tooth rows in 1498 the juvenile diplodocid described by Whitlock, Wilson \& Lamanna (2010) is imperfect and tooth 1499 counts for this individual were estimated based on comparison to more adult skulls, suggesting

1500 the possibility of unrecognized ontogenetic variation in tooth count.

While more data are needed to robustly test the hypothesis that Camarasaurus, diplodocids, or other sauropods lost teeth through development, such a scenario could be consistent with the phenomenon of ontogenetic tooth loss present in many disparate lineages of vertebrates (Wang et al., 2017b). Notably, the pattern identified by Wang et al. (2017b) implies that lineages that show 1505 phylogenetic tooth reduction and include taxa with ontogenetic niche partitioning are expected to exhibit tooth reduction through ontogeny at some point in their evolutionary history. Previous research has demonstrated phylogenetic tooth reduction in Sauropodomorpha (e.g., Wilson \& Sereno, 1998), and, as discussed above, has suggested ontogenetic resource partitioning for Diplodocus and Camarasaurus. Of particular interest to hypotheses of tooth loss in sauropods is the recently discovered titanosaurian Bonitasaura, the dentary of which appears to have fewer alveoli than other titanosaurians and bears a highly vascularized, edentulous, possibly keratincovered shearing edge in its posterior half (Apesteguía, 2004; Gallina \& Apesteguía, 2011).

Nigersaurus also exhibits rostralization of the tooth row and an acuminate, edentulous margin of the dentary, which Sereno et al. (2007) suggest may have been associated with a keratinous sheath. Given that odontogenesis may be inhibited by the antagonistic influence of a keratinized oral appendage in taxa showing ontogenetic tooth reduction, we predict that the development of an edentulous shearing edge of the jaw in Bonitasaura and possibly Nigersaurus entailed progressive loss and/or anterior displacement of posterior alveoli through ontogeny (Wang et al., 2017b), hypotheses that can be tested by future discoveries of juvenile individuals.

\section{Ontogeny of endocranial soft tissues}

We are aware of no explicit statements for sauropods concerning the ontogeny of the brain or surrounding tissues (as approximated by physical or digital endocasts), which is unsurprising, given the paucity of well-preserved juvenile sauropod cranial material generally. That the system of large dural venous sinuses typical of most sauropods was well-developed in Bellusaurus and a juvenile Camarasaurus (CM 11338; Sereno et al., 2007; Witmer et al., 2008) indicates that elaboration of these sinuses occurred by relatively early stages of post-hatching development. The transverse ridge on the ventral surface of the parietal that divides the dural venous sinuses into anterior and posterior portions in Bellusaurus, Camarasaurus, and other early-branching macronarians is also present in adult Massospondylus, where it shows ontogenetic development, being incipiently developed or absent in more juvenile specimens (Chapelle, 2016: Fig. 2.20A,B; Chapelle \& Choiniere, 2018: Fig. 36). The absence of this partition of the dural venous sinuses in the non-neosauropod eusauropods Spinophorosaurus and Qijianglong may indicate loss of this ridge in non-macronarian sauropods, immaturity of the Spinophorosaurus and Qijianglong specimens, or convergent evolution of a complex endocranial ceiling in Massospondylus and macronarians. Regardless, the apparent loss of the transverse ridge in diplodocoids — or its independent gain in Massospondylus and macronarians - serves to highlight that sauropod

1538 endocranial anatomy is an under-leveraged source of phylogenetic information (Balanoff, Bever 
1539 \& Ikejiri, 2010). Ultimately, distinguishing the influences of ontogeny, convergence, and 1540 intraspecfic development on the distribution of the transverse ridge of the parietal endocranial 1541 surface, and on endocranial morphology more generally, will require the discovery of more

1542 sauropodomorph skulls and further study of taxa for which skulls from more than one

1543

1544

1545

1546

1547

1548

1549

1550

1551

1552

1553

1554

1555

1556

1557

1558

1559

1560

1561

1562

1563

1564

1565

1566

1567

1568

1569

1570

1571

1572

1573

1574

1575

1576

1577

1578

1579

1580

1581

1582

1583

1584

\section{Evolutionary heterochrony in sauropods}

Apart from possible variation in tooth count and our observation that the distance separating the supratemporal fenestrae diminished through ontogeny, few changes have been proposed to have occurred during the growth of the skull in Camarasaurus, and its skull has been suggested to have developed essentially isometrically (Ikejiri et al., 2005). In the absence of a more complete ontogenetic series or the application of quantitative approaches like geometric morphometrics to study shape variation, this assessment may be premature, though modest craniofacial remodeling was also suggested for Europasaurus on the basis of an apparent lack of dramatic ontogenetic change in the morphology and morphometry of cranial structures (Marpmann et al., 2014). Nevertheless, the acquisition in non-neosauropod eusauropods (e.g., Mamenchisaurus youngi) and basal macronarians (e.g., Camarasaurus) of a comparatively boxy, short-snouted skull with large orbits and small antorbital fenestrae (Rauhut et al., 2011) features that typically characterize juveniles of non-avian dinosaurs (Carpenter, Hirsch \& Horner, 1994; Varricchio, 1997; Salgado, Coria \& Chiappe, 2005; Bhullar et al., 2012; Foth, Hedrick \& Ezcurra, 2016) - suggests substantial paedomorphosis of some aspects of skull form along the stem leading to Neosauropoda, though a dense sampling of sauropod skulls has not been included in previous quantitative analyses of heterochrony in dinosaurs (Bhullar et al., 2012; Foth, Hedrick \& Ezcurra, 2016). This apparent transformation contrasts with that observed in non-avian theropod dinosaurs, where several lineages show evidence of peramorphic trends in the skull (Bhullar et al., 2012; Foth, Hedrick \& Ezcurra, 2016).

The origin and drivers of cranial paedomorphosis in sauropodomorph dinosaurs are incompletely understood. Eoraptor was suggested to have a paedomorphic skull (Bhullar et al., 2012), and a recent study found the skull of Massospondylus to be paedomorphic with respect to a hypothetical massopodan ancestor (Foth, Hedrick \& Ezcurra, 2016), though Massospondylus nevertheless shows significantly non-isometric growth through ontogeny, with heterochrony resulting in greater growth of bones of the snout than those of the braincase and orbit (Chapelle, 2016). From a presumably paedomorphic, somewhat Camarasaurus-like ancestor, some diplodocoids and advanced titanosauriforms evolved superficially convergent skull morphologies, broadly characterized by an elongate, horse-like rostrum, gracile mandibles, reduced and inclined adductor chambers, shortened tooth rows, and slender teeth (Upchurch, 1998, 1999; Chure et al., 2010; Button, Barrett \& Rayfield, 2017). It is not yet known whether these transitions involved element-specific developmental trajectories like those documented for Massospondylus (Chapelle, 2016), but these long-faced lineages did not re-invade the functional morphospace of their basal sauropodomorph predecessors (Button, Barrett \& Rayfield, 2017). Though it is beyond the scope of this review to summarize macroevolutionary trends in sauropod cranial morphology, we conclude our discussion of cranial ontogeny and evolutionary heterochrony by noting that several transformations of the skull hypothesized to occur during sauropod development - including extreme diminution of the skull relative to the postcranial skeleton, an increase in relative muzzle width, anterior displacement of the posterior end of the maxillary tooth row, and posterodorsal retraction of the nares (Table 5) - are recapitulations of 
1585 shape changes that occurred in the course of sauropodomorph evolution (Rauhut et al., 2011).

1586

1587

1588

1589

1590

1591

1592

1593

1594

1595

1596

1597

1598

1599

1600

1601

1602

1603

1604

1605

1606

1607

1608

1609

1610

1611

1612

1613

1614

1615

1616

1617

1618

1619

1620

1621

1622

1623

1624

1625

1626

1627

1628

1629

1630

\section{Phylogenetic affinities of Bellusaurus}

The phylogenetic position of Bellusaurus has been uncertain since its original, brief description over 20 years ago (Dong 1990). In pre-cladistic treatments, Bellusaurus was placed within the Brachiosauridae by Dong (1990), and was also suggested to have titanosaurian affinities owing to its procoelous anterior caudal vertebrae (Jacobs et al., 1993). More recently, phylogenetic analyses that include Bellusaurus have recovered the taxon just outside Neosauropoda (Wilson \& Upchurch, 2009; Mo, 2013; Royo-Torres \& Upchurch, 2012) or near the base of Macronaria (Upchurch et al., 2004; Carballido \& Sander, 2014). A revised phylogenetic hypothesis of Bellusaurus and other Shishugou Formation sauropods is beyond the scope of this study, and will be addressed elsewhere. Instead, we discuss some issues and cranial characters that are likely to be relevant in future phylogenetic studies that include Bellusaurus or other juvenile sauropod specimens as operational taxonomic units.

Previous studies of dinosaurs, synapsids, and whales indicate that juvenile specimens may be vulnerable to stemward slippage in phylogenetic analyses if they lack apomorphies that are acquired during ontogeny (e.g., Kammerer, 2010; Campione et al., 2013; Carballido \& Sander, 2014; Choiniere et al., 2013; Tsai \& Fordyce, 2014; Currie et al., 2016; Wang et al., 2017a). Notably, this phenomenon may be particularly pervasive in large-bodied lineages, where ontogenetic disparity is especially extreme and adult individuals have greater potential to accumulate "terminal" ontogenetic changes (Tsai \& Fordyce, 2014; Wang et al., 2017a). Several of the features hypothesized to vary ontogenetically in sauropods (Table 5) have been included in previous phylogenetic analyses and/or used to diagnose taxa. A deeply embayed orbital margin of the frontal, for example, may be a local autapomorphy of Europasaurus (Marpmann et al., 2014), but our survey suggests that the form of the lateral margin of the frontal can be ontogenetically variable, with more juvenile individuals showing a more concave margin (see above). However, the observation that a concave lateral margin of the frontal is homoplastically present in relatively adult skulls of several phylogenetically disparate groups of sauropodomorphs (Table 2; Tschopp, Mateus \& Benson, 2015) suggests that scoring juvenile taxa as unknown for this feature may risk erasing important synapomorphic information. Some previous authors (e.g., Currie et al., 2016) have cautioned that juvenile specimens should be scored as unknown ('?') for characters known to vary ontogenetically. We suggest that this approach should be considered just one of a handful of mutually informative approaches to including juvenile taxa in phylogenetic analyses, and that future studies should explore the effectiveness of applying phylogenetic methods that are known to be more robust to homoplasy than equal weights parsimony - specifically, implied weights parsimony (Goloboff, 1993; Goloboff et al., 2017) and Bayesian phylogenetic approaches with appropriate morphological models (Wright \& Hillis, 2014; Pyron, 2016; Puttick et al., 2017; but see Goloboff et al., 2017). The merits of implied weighting for accommodating ontogenetically variable characters, which are expected to be relatively homoplasious in matrices that include juvenile taxa, was discussed by Tschopp, Mateus \& Benson (2015), who also noted that the recovery of some juvenile sauropod specimens in well-defined clades and with adult specimens suggests that the influence of ontogenetically variable characters may be minimal in sauropods. Implied weighting and Bayesian approaches have the benefit of allowing all character data to be included, and may be especially well-suited to lineages for which information on ontogenetic variation is scant and ontogenetically variable features may not be readily recognizable as such. 
1631

1632

1633

1634

1635

1636

1637

1638

1639

1640

1641

1642

1643

1644

1645

1646

1647

1648

1649

1650

1651

1652

1653

1654

1655

1656

1657

1658

1659

1660

1661

1662

1663

1664

1665

1666

1667

1668

1669

1670

1671

1672

1673

1674

1675

1676

Bellusaurus exhibits several cranial characteristics that have been recovered as synapomorphies of Macronaria, Neosauropoda, or a slightly more inclusive group, including: subnarial foramen directed dorsally (Neosauropoda: Upchurch, 1998; Upchurch, Barrett \& Dodson, 2004); subnarial foramen within the external narial fossa (Macronaria: Upchurch, 1998); preantorbital opening in the maxilla (Neosauropoda: Wilson \& Sereno, 1998, Upchurch, Barrett \& Dodson, 2004; Neosauropoda + Jobaria: Wilson, 2002); lateral articulation of the ectopterygoid principally with the maxilla (Neosauropoda: Upchurch, 1998, Wilson \& Sereno, 1998, Upchurch, Barrett \& Dodson, 2004; Neosauropoda + Jobaria: Wilson, 2002); deep excavation in the posterior surface of the quadrate (Macronaria: Mannion et al., 2013); stepped dorsal margin of the palatine process of the pterygoid (Neosauropoda: Wilson, 2002); fewer than 18 dentary teeth (Macronaria: Wilson, 2002); and loss of denticles on the anterior and posterior margins of the crown (Neosauropoda: Wilson \& Sereno, 1998, Wilson, 2002; note that this is only true for the maxillary dentition of Bellusaurus). In addition, we add to this list the partial division of anterior and posterior portions of the dural venous expansion by a transverse ridge of the endocranial ceiling, which we suggest may constitute a synapomorphy of Macronaria that is subsequently diminished in some titanosauriforms (Wilson et al., 2009; Paulina Carabajal, 2012; Knoll et al., 2013; Sues et al., 2015), though additional sampling of sauropodomorph endocranial anatomy and a phylogenetic analysis including this character are necessary to test this hypothesis. Now that radiometric dating has placed Bellusaurus in the earliest Late Jurassic (Figure 2; see above), phylogenetic analyses recovering Bellusaurus as a basal macronarian imply a less drastic extension of the age of Neosauropoda than was inferred by earlier studies that considered the Shishugou Formation to be as old as Aalenian in age (Upchurch \& Barrett, 2005).

\section{CONCLUSION}

The abundance of cranial and postcranial material now assignable to Bellusaurus makes the taxon among the more completely known sauropods. The thorough description of the cranial anatomy of Bellusaurus presented here allows for a hypothesized reconstruction of the skull and provides new data that will facilitate the inclusion of Bellusaurus in analyses of sauropod phylogeny, cranial morphology, and ontogeny. Detailed comparisons to other sauropod taxa confirm that Bellusaurus is not a juvenile specimen of Klamelisaurus or other Middle-Late Jurassic Chinese sauropods, indicate that Bellusaurus is diagnosable by numerous unique autapomorphies from across the skull, and support previous phylogenetic hypotheses that recover Bellusaurus as an early-branching macronarian or close relative of Neosauropoda. We argue that phylogenetic analyses including Bellusaurus or other juvenile specimens should employ implied weights parsimony and Bayesian inference methods, as these approaches are known to be more robust to homoplasy than equal weights parsimony.

Sauropod skulls are rare, and ontogenetic variants of sauropod cranial material are rarer still. Nevertheless, our review of the current state of knowledge of sauropod cranial ontogeny identifies numerous transformations hypothesized to occur in the course of sauropod ontogeny that can be tested by future discoveries of sauropod skulls, and highlights several outstanding questions that can be addressed with the cranial material currently available. In particular, detailed morphometric analysis of the individual skull bones of specimens referred to Camarasaurus, as well as comparative studies of the endocranial anatomy of taxa for which numerous skulls are known (e.g., Camarasaurus, Moabosaurus, diplodocids), will aid in teasing apart the relative contributions of intraspecific variability and ontogeny to cranial variation in 
1677 sauropods. In addition, comparative histological and anatomical studies of sauropods with extant 1678 taxa that exhibit a parietal foramen associated with a photoreceptive pineal organ will aid in 1679 elucidating the developmental and functional significance of the midline aperture of the skull

\section{ACKNOWLEDGEMENTS}

This paper represents a portion of the doctoral thesis of AJM at the George Washington University. For their hospitality and access to specimens in their care, we wish to thank A. Henrici (CM), J. Choiniere (BPI), B. Britt \& R. Scheetz (BYU), J. Sertich (DMNH), A. Millhouse (USNM), R. Royo-Torres (CPT), Zheng F. \& Geng BH. (IVPP), M. Belinchón (MCNV), D. Schwarz-Wings \& T. Schossleitner (MB.R.), P. Sereno \& T. Keillor (University of Chicago), R. Irmis (UMNH), and Jiang S., Peng GZ, and Li F. (ZDM). We are grateful to L. Witmer for providing CT scans of Camarasaurus (CM 11338) and S. Poropat and B. Kear for scans of Euhelopus (PMU 24705). AJM is indebted to Wang S., Qin ZC., Zhou Y., Wang J., Liao JQ., and Li F. for their assistance and unflagging generosity during research trips to Beijing. We thank Feng Y. and Hou YM. for assistance with CT scanning and Wang HJ., Huo YL., Xiang LS., He SC., Li W., Yu T., and Cao RF. for collecting and preparing the fossils. We are grateful to J. Stiegler, K. Poole, D. White, and A. Ruebenstahl for helpful discussions. Thoughtful reviews by Emanuel Tschopp, an anonymous reviewer, and the editor improved an earlier version of this manuscript. 
1698

1699

1700

1701

1702

1703

1704

1705

1706

1707

1708

1709

1710

1711

1712

1713

1714

1715

1716

1717

1718

1719

1720

1721

1722

1723

1724

1725

1726

1727

1728

1729

1730

1731

1732

1733

1734

1735

1736

1737

1738

1739

1740

1741

1742

1743

Allain R., Aquesbi N. 2008. Anatomy and phylogenetic relationships of Tazoudasaurus naimi (Dinosauria, Sauropoda) from the late Early Jurassic of Morocco. Geodiversitas 30(2):345424.

Apesteguía S. 2004. Bonitasaura salgadoi gen. et sp. nov.: a beaked sauropod from the Late Cretaceous of Patagonia. Naturwissenschaften 91(10):493-497.

Balanoff AM., Rowe T. 2007. Osteological description of an embryonic skeleton of the extinct elephant bird, Aepyornis (Palaeognathae: Ratitae). Journal of Vertebrate Paleontology 27(sp9):1-53.

Balanoff AM., Bever GS., Ikejiri T. 2010. The braincase of Apatosaurus (Dinosauria: Sauropoda) based on computed tomography of a new specimen with comments on variation and evolution in sauropod neuroanatomy. American Museum Novitates: 1-32.

Baumel JJ., Witmer LM. 1993. Osteologia. - In: Baumel JJ., King AS., Breazile JE., Evans HE., Vanden Berge JC. (Eds.): Handbook of avian anatomy: Nomina Anatomica Avium. Publications of the Nuttall Ornithological Club 23:45-132.

Barrett PM., Upchurch P., Wang X-L. 2005. Cranial osteology of Lufengosaurus huenei Young (Dinosauria: Prosauropoda) from the Lower Jurassic of Yunnan, People's Republic of China. Journal of Vertebrate Paleontology 25(4):806-822.

Benton MJ., Csiki Z., Grigorescu D., Redelstorff R., Sander PM., Stein K., Weishampel DB. 2010. Dinosaurs and the island rule: The dwarfed dinosaurs from Haţeg Island.

Palaeogeography, Palaeoclimatology, Palaeoecology 293:3-4, 438-454. https://doi.org/10.1016/j.palaeo.2010.01.026

Berman DS., McIntosh JS. 1978. Skull and relationships of the Upper Jurassic sauropod Apatosaurus (Reptilia, Saurischia). Bulletin of the Carnegie Museum of Natural History 8:1-35.

Bever GS., Norell MA. 2009. The perinate skull of Byronosaurus (Troodontidae) with observations on the cranial ontogeny of paravian theropods. American Museum Novitates 3657:1-52.

Bever GS., Gauthier JA., Wagner GP. 2011. Finding the frame shift: digit loss, developmental variability, and the origin of the avian hand. Evolution \& Development 13(3):269-279.

Bhullar BAS., Marugán-Lobón J., Racimo F., Bever GS., Rowe TB., Norell MA., Abzhanov A. 2012. Birds have paedomorphic dinosaur skulls. Nature 487(7406):223-226.

Bonaparte JF. 1986. The dinosaurs (Carnosaurs, Allosaurids, Sauropods, Cetiosaurids) of the Middle Jurassic of Cerro Cóndor (Chubut, Argentina). In: Annales de Paléontologie (Vert.Invert.) 72(4):325-386. 
1744 Britt BB., Naylor BG. 1994. An embryonic Camarasaurus (Dinosauria, Sauropoda) from the

1745

1746

1747

1748

1749

1750

1751

1752

1753

1754

1755

1756

1757

1758

1759

1760

1761

1762

1763

1764

1765

1766

1767

1768

1769

1770

1771

1772

1773

1774

1775

1776

1777

1778

1779

1780

1781

1782

1783

1784

1785

1786

1787

1788

Upper Jurassic Morrison Formation (Dry Mesa Quarry, Colorado). In: Dinosaur eggs and babies, Carpenter K., Hirsch KF., Horner JR. (Eds.). 256-264.

Britt BB., Scheets RD., Whiting MF., Wilhite D. 2017. Moabosaurus utahensis, n. gen., n. sp., a new sauropod from the Early Cretaceous (Aptian) of North America. Contributions from the Museum of Paleontology, University of Michigan 32(11):189-243.

Button DJ., Rayfield EJ., Barrett PM. 2014. Cranial biomechanics underpins high sauropod diversity in resource-poor environments. Proceedings of the Royal Society B 281(1795): p. 20142114

Button DJ., Barrett PM., Rayfield EJ. 2017. Craniodental functional evolution in sauropodomorph dinosaurs. Paleobiology 43(3):435-462.

Calvo JO., Salgado L. 1995. Rebbachisaurus tessonei sp. nov. a new Sauropoda from the AlbianCenomanian of Argentina; new evidence on the origin of the Diplodocidae. Gaia 11:13-33.

Campione NE., Brink KS., Freedman EA., McGarrity CT., Evans DC. 2013. 'Glishades ericksoni', an indeterminate juvenile hadrosaurid from the Two Medicine Formation of Montana: implications for hadrosauroid diversity in the latest Cretaceous (CampanianMaastrichtian) of western North America. Palaeobiodiversity and Palaeoenvironments 93(1):65-75.

Carpenter K., Tidwell V. 2005. Reassessment of the Early Cretaceous sauropod Astrodon johnsoni Leidy 1865 (Titanosauriformes). In: Thunder-lizards, Tidwell V. Carpenter K. (Eds.). Bloomington and Indianapolis: Indiana University Press, 78-114.

Carpenter K., Hirsch KF., Horner JR. 1994. Summary and Prospectus. In: Dinosaur eggs and babies, Carpenter K., Hirsch KF., Horner JR. (Eds.). 366-370.

Chapelle KE. 2016. The cranial ontogeny of the basal sauropodomorph dinosaur Massospondylus carinatus. Unpublished PhD dissertation. Johannesburg: University of Witwatersrand.

Chapelle KE. Choiniere JN. 2018. A revised cranial description of Massospondylus carinatus Owen (Dinosauria: Sauropodomorpha) based on computed tomographic scans and a review of cranial characters for basal Sauropodomorpha. PeerJ 6:e4224.

Carballido JL., Pol D. 2010. The dentition of Amygdalodon patagonicus (Dinosauria: Sauropoda) and the dental evolution in basal sauropods. Comptes Rendus Palevol 9(3):8393.

Carballido JL., Sander PM. 2014. Postcranial axial skeleton of Europasaurus holgeri (Dinosauria, Sauropoda) from the Upper Jurassic of Germany: Implications for sauropod 
1789

1790

1791

1792

1793

1794

1795

1796

1797

1798

1799

1800

1801

1802

1803

1804

1805

1806

1807

1808

1809

1810

1811

1812

1813

1814

1815

1816

1817

1818

1819

1820

1821

1822

1823

1824

1825

1826

1827

1828

1829

1830

1831

1832

1833

ontogeny and phylogenetic relationships of basal Macronaria. Journal of Systematic

Palaeontology 12:3, 335-387. https://doi.org/10.1080/14772019.2013.764935

Carballido JL., Holwerda FM., Pol D., Rauhut OW. 2017. An Early Jurassic sauropod tooth from Patagonia (Cañadón Asfalto Formation): Implications for sauropod diversity. Publicación Electrónica de la Asociación Paleontológica Argentina 17(2).

Cerda IA., Chinsamy A., Pol D., Apaldetti C., Otero A., Powell JE., Martínez RN. 2017. Novel insight into the origin of the growth dynamics of sauropod dinosaurs. PLoS ONE 12(6):e0179707. https://doi. org/10.1371/journal.pone.0179707

Chatterjee S., Zheng Z. 2002. Cranial anatomy of Shunosaurus, a basal sauropod dinosaur from the Middle Jurassic of China. Zoological Journal of the Linnean Society 136(1):145-169.

Chiappe LM., Coria RA., Dingus L., Jackson F., Chinsamy A., Fox M. 1998. Sauropod dinosaur embryos from the Late Cretaceous of Patagonia. Nature 396:258-261.

Choiniere JN., Clark JM., Forster CA., Norell MA., Eberth DA., Erickson GM., Chu H., Xu X. 2013. A juvenile specimen of a new coelurosaur (Dinosauria: Theropoda) from the MiddleLate Jurassic Shishugou Formation of Xinjiang, People's Republic of China. Journal of Systematic Palaeontology. DOI: 10.1080/14772019.2013.781067.

Chow M., Rich TH. 1984. A New Triconodontan (Mammalia) from the Jurassic of China. Journal of Vertebrate Paleontology 3:226-231. DOI: 10.1126/science.93.2416.370.

Chure D., Britt BB., Whitlock JA., Wilson JA. 2010. First complete sauropod dinosaur skull from the Cretaceous of the Americas and the evolution of sauropod dentition. Naturwissenschaften 97(4):379-391.

Clark JM., Xu X., Eberth DA., Forster CA., Malkus M., Hemming S., Hernandez R. 2006. The Middle To Late Jurassic Terrestrial Transition: New Discoveries From the Shishugou Formation, Xinjiang, China. Ninth International Symposium On Mesozoic Terrestrial Ecosystems and Biota, 26-28.

Currie PJ., Holmes RB., Ryan MJ., Coy C. 2016. A juvenile chasmosaurine ceratopsid (Dinosauria, Ornithischia) from the Dinosaur Park Formation, Alberta, Canada. Journal of Vertebrate Paleontology 36(2):e1048348.

Curry, KA. 1999. Ontogenetic histology of Apatosaurus (Dinosauria: Sauropoda): New insights on growth rates and longevity. Journal of Vertebrate Paleontology 19(4):654-665.

Curry Rogers K., Forster CA. 2004. The skull of Rapetosaurus krausei (Sauropoda: Titanosauria) from the Late Cretaceous of Madagascar. Journal of vertebrate Paleontology 24(1):121-144. 
1834 Curry Rogers K, Erickson GM. 2005. Sauropod Histology. In: The Sauropods: Evolution and

1835

1836

1837

1838

1839

1840

1841

1842

1843

1844

1845

1846

1847

1848

1849

1850

1851

1852

1853

1854

1855

1856

1857

1858

1859

1860

1861

1862

1863

1864

1865

1866

1867

1868

1869

1870

1871

1872

1873

1874

1875

1876

1877

1878

1879
Paleobiology, Curry Rogers KA, Wilson J. (Eds.). Berkeley, Los Angeles, and London:

University of California Press, 303-326.

Curry Rogers K., Wilson JA. 2014. Vahiny depereti, gen. et sp. nov., a new titanosaur (Dinosauria, Sauropoda) from the Upper Cretaceous Maevarano Formation, Madagascar. Journal of Vertebrate Paleontology 34(3):606-617.

Dal Sasso C., Maganuco S. 2011. Scipionyx samniticus (Theropoda: Compsognathidae) from the Lower Cretaceous of Italy: osteology, ontogenetic assessment, phylogeny, soft tissue anatomy, taphonomy and paleobiology. Memorie della Societa Italiana di Scienze Naturali e del Museo Civico di Storia Naturale 37(1), 282pp.

D’Emic MD. 2013. Revision of the sauropod dinosaurs of the Lower Cretaceous Trinity Group, southern USA, with the description of a new genus. Journal of Systematic

Palaeontology 11(6):707-726.

De Pinna MC. 1991. Concepts and tests of homology in the cladistic paradigm. Cladistics 7(4):367-394.

Dong Z. 1990. Sauropoda from the Kelameili Region of the Junggar Basin, Xinjiang Autonomous Region. Vertebrata Palasiatica 28:43-58.

Dong Z-M., Zhou S., Zhang Y. 1983. Dinosaurs from the Jurassic of Sichuan. Palaeontologica Sinica 162:1-136.

Eberth DA., Brinkman DB., Chen P-J., Yuan F-T., Wu S-Z., Li G., Cheng X-S. 2001. Sequence stratigraphy, paleoclimate patterns, and vertebrate fossil preservation in Jurassic-Cretaceous strata of the Junggar Basin, Xinjiang Autonomous Region, People's Republic of China. Canadian Journal of Earth Sciences 38:1627-1644.

Eberth DA., Xu X., Clark JM. 2010. Dinosaur Death Pits from the Jurassic of China. Palaios 25:112-125. DOI: 10.2110/palo.2009.p09-028r.

Edinger T. 1955. The size of the parietal foramen and organ in reptiles. Bulletin of the Museum of Comparative Zoology 114:3-34.

Fiorillo AR. 1998. Dental micro wear patterns of the sauropod dinosaurs Camarasaurus and Diplodocus: Evidence for resource partitioning in the late Jurassic of North America. Historical Biology 13(1):1-16.

Foth C., Hedrick BP., Ezcurra MD. 2016. Cranial ontogenetic variation in early saurischians and the role of heterochrony in the diversification of predatory dinosaurs. PeerJ, 4:e1589.

Gallina PA., Apesteguía S. 2011. Cranial anatomy and phylogenetic position of the titanosaurian sauropod Bonitasaura salgadoi. Acta Palaeontologica Polonica 56(1):45-60. 
1880

1881

1882

1883

1884

1885

1886

1887

1888

1889

1890

1891

1892

1893

1894

1895

1896

1897

1898

1899

1900

1901

1902

1903

1904

1905

1906

1907

1908

1909

1910

1911

1912

1913

1914

1915

1916

1917

1918

1919

1920

1921

1922

1923

1924

1925

Galton PM. 1985. Cranial anatomy of the prosauropod dinosaur Plateosaurus from the Knollenmergel (Middle Keuper, Upper Triassic) of Germany. II. All the cranial material and details of soft-part anatomy. Geologica et Palaeontologica 19:119-159.

García RA. 2007. Consideraciones sobre la fenestra preantorbital en embriones de dinosaurios saurópodos del Cretácico de Patagonia. Ameghiniana 44(2):467-471.

García RA., Cerda IA. 2010. Dentition and histology in titanosaurian dinosaur embryos from Upper Cretaceous of Patagonia, Argentina. Palaeontology 53(2):335-346.

García RA., Salgado L., Coria RA., Chiappe LM. 2010. Osteología embrionaria de saurópodos titanosaurios de Neuquén (Argentina): aspectos ontogenéticos y evolutivos. Ameghiniana 47(4):409-430.

Gilmore CW. 1925. A nearly complete articulated skeleton of Camarasaurus, a saurischian from the Dinosaur National Monument, Utah. Memoirs of the Carnegie Museum 10:347-384.

Goloboff PA. 1993. Estimating character weights during tree search. Cladistics 9(1):83-91.

Goloboff PA., Torres A., Arias JS. 2017. Weighted parsimony outperforms other methods of phylogenetic inference under models appropriate for morphology. Cladistics.

Grellet-Tinner G., Sim CM., Kim DH., Trimby P., Higa A., An SL., Oh HS., Kim T., Kardjilov N. 2011. Description of the first lithostrotian titanosaur embryo in ovo with Neutron characterization and implications for lithostrotian Aptian migration and dispersion. Gondwana Research 20(2-3):621-629.

Han F-L., Forster CA., Clark JM., Xu X. 2015. Cranial anatomy of Yinlong downsi (Ornithischia: Ceratopsia) from the Upper Jurassic Shishugou Formation of Xinjiang, China. Journal of Vertebrate Paleontology:e1029579. DOI: 10.1080/02724634.2015.1029579.

Harris JD. 2006. The Significance of Suuwassea emilieae (Dinosauria: Sauropoda) for flagellicaudatan intrarelationships and evolution. Journal of Systematic Palaeontology 4:185-198. DOI: $10.1017 /$ S1477201906001805.

He X., Li K., Cai K. 1988. The Middle Jurassic Dinosaur Fauna from Dashanpu, Zigong, Sichuan, Vol. IV. Sauropod Dinosaurs (2), Omeisaurus Tianfuensis. Chengdu: Sichuan Scientific and Technological Publishing House.

Holland WJ. 1924. The skull of Diplodocus. Memoirs of the Carnegie Museum 9:379-403.

Holwerda FM., Pol D., Rauhut OWM. 2015. Using Dental Enamel Wrinkling to Define Sauropod Tooth Morphotypes from the Cañadón Asfalto Formation, Patagonia, Argentina. PLoS ONE 10(2): e0118100. doi:10.1371/journal.pone.0118100 
1926

1927

1928

1929

1930

1931

1932

1933

1934

1935

1936

1937

1938

1939

1940

1941

1942

1943

1944

1945

1946

1947

1948

1949

1950

1951

1952

1953

1954

1955

1956

1957

1958

1959

1960

1961

1962

1963

1964

1965

1966

1967

1968

1969

1970

1971

Huene F von. 1932. Die fossil Reptil-Ordnung Saurischia, ihre Entwicklung und Geschichte. Monographien zur Geologie und Palaeontologie 1(4):1-361.

Ikejiri T. 2004. Anatomy of Camarasaurus lentus (Dinosauria: Sauropoda) from the Morrison Formation (Late Jurassic), Thermopolis, central Wyoming, with determination and interpretation of ontogenetic, sexual dimorphic, and individual variation in the genus. Master Thesis, Fort Hays State University, Kansas. UMI pp.

Ikejiri T. 2005. Distribution and Biochronology of Camarasaurus (Dinosauria, Sauropoda) From the Jurassic Morrison Formation of the Rocky Mountain Region. New Mexico Geological Society, 56th Field Conference Guidebook, Geology of the Chama Basin:367-379.

Ikejiri T, Tidwell V, Trexler DL. 2005. New adult specimens of Camarasaurus lentus highlight ontogenetic variation within the species. In: Thunder-lizards: the sauropodomorph dinosaurs. Bloomington: Indiana University Press, 154-179.

Jacobs L., Winkler DA., Downs WR., Gomani EM. 1993. New material of an Early Cretaceous titanosaurid saurepod dinosaur from Malawi. Palaeontology 36:523-523.

Janensch W. 1935-1936. Die Schädel der Sauropoden Brachiosaurus, Barosaurus und Dicraeosaurus aus den Tendaguru-schichten Deutsch-Ostafrikas. Palaeontographica 2:145298.

Kammerer CF. 2011. Systematics of the anteosauria (Therapsida: Dinocephalia). Journal of Systematic Palaeontology 9(2):261-304.

Knoll F, Schwarz-Wings D. 2009. Palaeoneuroanatomy of Brachiosaurus. Annales de paléontologie 95(3):165-175.

Knoll F., Witmer LM., Ortega F., Ridgely RC., Schwarz-Wings D. 2012. The Braincase of the Basal Sauropod Dinosaur Spinophorosaurus and 3D Reconstructions of the Cranial Endocast and Inner Ear. PLoS ONE 7(1): e30060. doi:10.1371/journal.pone.0030060

Knoll F., Ridgely RC., Ortega F., Sanz JL., Witmer LM. 2013. Neurocranial osteology and neuroanatomy of a Late Cretaceous titanosaurian sauropod from Spain (Ampelosaurus sp.). PLoS One 8(1):e54991.

Läng E. Mahammed F. 2010. New anatomical data and phylogenetic relationships of Chebsaurus algeriensis (Dinosauria, Sauropoda) from the Middle Jurassic of Algeria. Historical Biology 22(1-3):142-164.

Li K., Liu J., Yang C., Hu F. 2011. Dinosaur assemblages from the Middle Jurassic Shaximiao Formation and Chuanjie Formation in the Sichuan-Yunnan Basin, China. Volumina Jurassica 9:21-42. 
1972 Madsen JH, McIntish JS, Berman DS. 1995. Skull and atlas-axis complex of the Upper Jurassic

1973

1974

1975

1976

1977

1978

1979

1980

1981

1982

1983

1984

1985

1986

1987

1988

1989

1990

1991

1992

1993

1994

1995

1996

1997

1998

1999

2000

2001

2002

2003

2004

2005

2006

2007

2008

2009

2010

2011

2012

2013

2014

2015

2016 sauropod Camarasaurus Cope (Reptilia: Saurischia). Bulletin of the Carnegie Museum of Natural History 31:1-115.

Mannion PD., Upchurch P., Carrano MT., Barrett PM. 2011. Testing the effect of the rock record on diversity: A multidisciplinary approach to elucidating the generic richness of sauropodomorph dinosaurs through time. Biological Reviews 86:157-181. DOI: 10.1111/j.1469-185X.2010.00139.x.

Mannion PD., Upchurch P., Barnes RN., Mateus O. 2013. Osteology of the Late Jurassic Portuguese sauropod dinosaur Lusotitan atalaiensis (Macronaria) and the evolutionary history of basal titanosauriforms. Zoological Journal of the Linnean Society 168(1):98-206.

Mannion PD., Allain R., Moine O. 2017. The earliest known titanosauriform sauropod dinosaur and the evolution of Brachiosauridae. PeerJ 5:e3217.

Marpmann JS., Carballido JL., Sander PM., Knötschke N. 2014. Cranial anatomy of the Late Jurassic dwarf sauropod Europasaurus holgeri (Dinosauria, Camarasauromorpha): ontogenetic changes and size dimorphism. Journal of Systematic Palaeontology. https://doi.org/10.1080/14772019.2013.875074

Marsh OC. 1878. Principal characters of American Jurassic dinosaurs. Pt. I. American Journal of Science 3(16):411-416.

Marsh OC. 1884. Principal characters of American Jurassic dinosaurs. Part VII. On the Diplodocidae, a new family of the Sauropoda. American Journal of Science (Series 3) 27:161-167.

Marsh OC. 1891. The Gigantic Ceratopsidae, or Horned Dinosaurs, of North America. Geological Magazine 8(6):241-248.

Martin-Rolland V. 1999. Les Sauropodes chinois. Revue de Paléobiologie 18:287-315.

Martínez RDF., Lamanna MC., Novas FE., Ridgely RC., Casal GA., Martínez JE., Vita JR., Witmer LM. 2016. A basal lithostrotian titanosaur (Dinosauria: Sauropoda) with a complete skull: Implications for the evolution and paleobiology of titanosauria. PLOS ONE 11:1-82. DOI: 10.1371/journal.pone.0151661.

Mateus O., Mannion PD., Upchurch P. 2014. Zby atlanticus, a new turiasaurian sauropod (Dinosauria, Eusauropoda) from the Late Jurassic of Portugal. Journal of Vertebrate Paleontology 34(3):618-634.

McIntosh JS, Miles CA, Cloward KA, Parker JR. 1996. A new nearly complete skeleton of Camarasaurus. Bulletin of the Gunma Museum of Natural History 1:1-87. 
2017 Mo, J. 2013. Topics in Chinese Dinosaur Paleontology: Bellusaurus sui. Zhengzhou: Henan

Nowinski A. 1971. Nemegtosaurus mongoliensis n. gen., n. sp., (Sauropoda) from the uppermost Cretaceous of Mongolia. Palaeontologica Polonica 25:57-81.

Ouyang H. 1989. A new sauropod dinosaur from Dashanpu, Zigong County, Sichuan Province (Abrosaurus dongpoensis gen. et sp. nov.). Newsletter of the Zigong Dinosaur Museum 2:10-14.

Ouyang H., Ye Y. 2002. The first mamenchisaurian skeleton with complete skull: Mamenchisaurus youngi. Chengdu: Sichuan Science and Technology Press.

Paul GS. 2010. The Princeton Field Guide to Dinosaurs. New Jersey: Princeton University Press.

Paulina Carabajal A. 2012. Neuroanatomy of titanosaurid dinosaurs from the Upper Cretaceous of Patagonia, with comments on endocranial variability within Sauropoda. The Anatomical Record 295(12):2141-2156.

Paulina Carabajal A., Carballido JL., Currie PJ. 2014. Braincase, neuroanatomy, and neck posture of Amargasaurus cazaui (Sauropoda, Dicraeosauridae) and its implications for understanding head posture in sauropods. Journal of Vertebrate Paleontology 34(4):870882.

Poropat SF., Kear BP. 2013. Photographic atlas and three-dimensional reconstruction of the holotype skull of Euhelopus zdanskyi with description of additional cranial elements. PLoS ONE 8(11):e79932.

Porter WR. 2015. Physiological Implications of Dinosaur Cephalic Vascular Systems. Unpublished PhD dissertation. Athens: Ohio University. 433pp.

Powell JE. 1992. Osteología de Saltasaurus Loricatus (Sauropoda-Titanosauridae) del Cretácico Superior argentino. In: Los dinosaurios y su entorno biótico II. Curso de Paleontología, 10 a 12 de julio de 1990: Actas (pp. 165-230). Instituto Juan de Valdés.

Prieto-Márquez A., Norell MA. 2011. Redescription of a nearly complete skull of Plateosaurus (Dinosauria: Sauropodomorpha) from the Late Triassic of Trossingen (Germany). American Museum Novitates 3727:1-58.

Puttick MN., O'Reilly JE., Tanner AR., Fleming JF., Clark J., Holloway L., Lozano-Fernandez J., Parry LA., Tarver JE., Pisani D, Donoghue PC. Uncertain-tree: discriminating among competing approaches to the phylogenetic analysis of phenotype data. Proceedings of the Royal Society B 284(1846):p. 20162290. 
2061 Pyron RA. 2016. Novel approaches for phylogenetic inference from morphological data and

2062

2063

2064

2065

2066

2067

2068

2069

2070

2071

2072

2073

2074

2075

2076

2077

2078

2079

2080

2081

2082

2083

2084

2085

2086

2087

2088

2089

2090

2091

2092

2093

2094

2095

2096

2097

2098

2099

2100

2101

2102

2103

2104

2105 total-evidence dating in squamate reptiles (lizards, snakes, and amphisbaenians). Systematic biology 66(1):38-56.

Rauhut OW., Fechner R., Remes K., Reis K. 2011. How to get big in the Mesozoic: the evolution of the sauropodomorph body plan. Biology of the sauropod dinosaurs: Understanding the life of giants, 119-149.

Remes K., Ortega F., Fierro I., Joger U., Kosma R., Ferrer JMM., Ide OA., Maga A. 2009. A new basal sauropod dinosaur from the Middle Jurassic of Niger and the early evolution of Sauropoda. PLoS One 4(9):e6924.

Royo-Torres R., Upchurch P. 2012. The cranial anatomy of the sauropod Turiasaurus riodevensis and implications for its phylogenetic relationships. Journal of Systematic Palaeontology 10:553-583.

Royo-Torres R., Upchurch P., Kirkland JI., DeBlieux DD., Foster JR., Cobos A., Alcalá L. 2017. Descendants of the Jurassic turiasaurs from Iberia found refuge in the Early Cretaceous of western USA. Scientific Reports 7(1):14311.

Russell DA., Zheng Z. 1993. A large mamenchisaurid from the Junggar Basin, Xinjiang, People's Republic of China. Canadian Journal of Earth Sciences 30:2082-2095.

Salgado L. 1999. The macroevolution of the Diplodocimorpha (Dinosauria; Sauropoda): a developmental model. Ameghiniana 36(2):203-216.

Salgado L., Bonaparte JF. 1991. Un nuevo sauropodo Dicraeosauridae, Amargasaurus cazaui gen. et sp. nov., de la Formacion La Amarga, Neocomiano de la Provincia del Neuquén, Argentina. Ameghiniana 28(3-4): 333-346.

Salgado L., Calvo JO. 1992. Cranial osteology of Amargasurus cazaui Salgado \& Bonaparte (Sauropoda, Dicraeosuridae) from the Neocomian of Patagonia. Ameghiniana 29(4):337346.

Salgado L., Coria RA., Chiappe, LM. 2005. Osteology of the sauropod embryos from the Upper Cretaceous of Patagonia. Acta Palaeontologica Polonica 50(1):79-92.

Sampson SD., Witmer LM. 2007. Craniofacial anatomy of Majungasaurus crenatissimus (Theropoda: Abelisauridae) from the late Cretaceous of Madagascar. Journal of Vertebrate Paleontology 27(sp8):32-102.

Sander PM., Mateus O., Laven T., Knötschke N. 2006. Bone histology indicates insular dwarfism in a new Late Jurassic sauropod dinosaur. Nature 441(8):739-741. 
2106 Sander PM., Klein N., Stein K., Wings O. 2011. Sauropod Bone Histoloy and Its Implications

2107

2108

2109

2110

2111

2112

2113

2114

2115

2116

2117

2118

2119

2120

2121

2122

2123

2124

2125

2126

2127

2128

2129

2130

2131

2132

2133

2134

2135

2136

2137

2138

2139

2140

2141

2142

2143

2144

2145

2146

2147

2148

2149

2150

2151

for Sauropd Biology. In: Biology of the Sauropod Dinosaurs: Understanding the Life of Giants, Klein N., Remes K., Gee CT., Sander PM. (Eds.). Bloomington and Indianapolis: Indiana University Press, 276-302.

Schwarz D., Ikejiri T., Breithaupt BH., Sander PM., Klein N. 2007. A nearly complete skeleton of an early juvenile diplodocid (Dinosauria: Sauropoda) from the Lower Morrison Formation (Late Jurassic) of north central Wyoming and its implications for early ontogeny and pneumaticity in sauropods. Historical Biology 19(3):225-253.

Seeley HG. 1887. The classification of the Dinosauria. Geological Magazine 3:562.

Sekiya T. 2011. Re-examination of Chuanjiesaurus anaensis (Dinosauria: Sauropoda) from the Middle Jurassic Chuanjie Formation, Lufeng County, Yunnan Province, Southwest China. Memoir of the Fukui Prefectural Dinosaur Museum 10:1-54.

Sereno PC., Wilson JA. 2005. Structure and evolution of a sauropod tooth battery. In: The Sauropods: Evolution and Paleobiology. Berkeley: University of California Press, 157-177.

Sereno PC., Wilson JA., Witmer LM., Whitlock JA., Maga A., Ide O., Rowe TA. 2007. Structural extremes in a Cretaceous dinosaur. PLoS One 2(11):e1230.

Sereno PC., Martínez RN., Alcober OA. 2012. Osteology of Eoraptor lunensis (Dinosauria, Sauropodomorpha). Journal of Vertebrate Paleontology 32(sup1):83-179.

Snively E., Russell AP. 2007. Functional variation of neck muscles and their relation to feeding style in Tyrannosauridae and other large theropod dinosaurs. The Anatomical Record 290(8):934-957.

Sues HD., Averianov A., Ridgely RC., Witmer LM. 2015. Titanosauria (Dinosauria, Sauropoda) from the Upper Cretaceous (Turonian) Bissekty Formation of Uzbekistan. Journal of Vertebrate Paleontology 35(1):e889145.

Tang F, Jin X, Kang X., Zhang G. 2001. Omeisaurus maoianus: A Complete Sauropoda from Jingyan, Sichuan. Research Works of Natural Museum of Zhejiang.

Tsai CH., Fordyce RE. 2014. Juvenile morphology in baleen whale phylogeny. Naturwissenschaften 101(9):765-769.

Tschopp E., Mateus O. 2013. The skull and neck of a new flagellicaudatan sauropod from the Morrison Formation and its implication for the evolution and ontogeny of diplodocid dinosaurs. Journal of Systematic Palaeontology 11(7):853-888.

Tschopp E., Mateus O. 2017. Osteology of Galeamopus pabsti sp. nov. (Sauropoda: Diplodocidae), with implications for neurocentral closure timing, and the cervico-dorsal transition in diplodocids. PeerJ 5:e3179. 
2152

2153

2154

2155

2156

2157

2158

2159

2160

2161

2162

2163

2164

2165

2166

2167

2168

2169

2170

2171

2172

2173

2174

2175

2176

2177

2178

2179

2180

2181

2182

2183

2184

2185

2186

2187

2188

2189

2190

2191

2192

2193

2194

2195

2196

Tschopp E., Mateus O., Benson RBJ. 2015. A specimen-level phylogenetic analysis and taxonomic revision of Diplodocidae (Dinosauria, Sauropoda). PeerJ 3:e857. DOI: $10.7717 /$ peerj.857.

Tsuihiji T. 2005. Homologies of the Transversospinalis Muscles in the Anterior Presacral Region of Sauria (Crown Diapsida). Journal of Morphology 263(2):151-178.

Tsuihiji T. 2010. Reconstructions of the axial muscle insertions in the occipital region of dinosaurs: evaluations of past hypotheses on Marginocephalia and Tyrannosauridae using the Extant Phylogenetic Bracket approach. The Anatomical Record 293(8):1360-1386.

Tütken T., Pfretzschner H-U., Vennemann TW., Sun G., Wang YD. 2004. Paleobiology and skeletochronology of Jurassic dinosaurs: implications from the histology and oxygen isotope compositions of bones. Palaeogeography, Palaeoclimatology, Palaeoecology 206:217-238.

Upchurch P. 1995. The Evolutionary History of Sauropod Dinosaurs. Philosophical Transactions of the Royal Society B: Biological Sciences 349:365-390. DOI: 10.1098/rstb.1995.0125.

Upchurch P. 1998. The phylogenetic relationships of sauropod dinosaurs. Zoological Journal of the Linnean Society 124:43-103.

Upchurch P. 1999. The phylogenetic relationships of the Nemegtosauridae (Saurischia, Sauropoda). Journal of Vertebrate Paleontology 19(1):106-125.

Upchurch P., Barrett PM. 2005. Phylogenetic and Taxic Perspectives on Sauropod Diversity. In: The Sauropods: Evolution and Paleobiology, Curry Rogers KA, Wilson J. (Eds.). Berkeley, Los Angeles, and London: University of California Press, 104-124.

Upchurch P., Barrett PM., Dodson P. 2004. Sauropoda. In: The Dinosauria, Weishampel DB, Dodson P, Osmolska H (Eds). Berkeley: University of California Press, 259-322.

Upchurch P., Barrett PM., Zhao X-J., Xu X. 2007. A re-evaluation of Chinshakiangosaurus chunghoensis Ye vide Dong 1992 (Dinosauria, Sauropodomorpha): Implications for cranial evolution in basal sauropod dinosaurs. Geological Magazine 144:247-262. DOI: $10.1017 / \mathrm{S} 0016756806003062$.

Varricchio D. 1997. Growth and embryology. In: Encyclopedia of Dinosaurs, Currie PJ., Padian K. (Eds). San Diego: Academic Press, 282-288.

Wang S., Stiegler J., Amiot R., Wang X., Du G-H., Clark JM., Xu X. 2017a. Extreme Ontogenetic Changes in a Ceratosaurian Theropod. Current Biology 27:144-148. 
2197 Wang S., Stiegler J., Wu P., Chuong C.M., Hu D., Balanoff A., Zhou Y. Xu X. 2017b.

2198 Heterochronic truncation of odontogenesis in theropod dinosaurs provides insight into the

2199

2200

2201

2202

2203

2204

2205

2206

2207

2208

2209

2210

2211

2212

2213

2214

2215

2216

2217

2218

2219

2220

2221

2222

2223

2224

2225

2226

2227

2228

2229

2230

2231

2232

2233

2234

2235

2236

2237

2238

2239 macroevolution of avian beaks. Proceedings of the National Academy of Sciences, p.201708023.

Wedel MJ. 2003. The evolution of vertebral pneumaticity in sauropod dinosaurs. Journal of Vertebrate Paleontology 23(2):344-357.

Wedel MJ., Taylor M. 2013. Neural Spine Bifurcation in Sauropod Dinosaurs of the Morrison Formation : Ontogenetic and Phylogenetic Implications. Palarch's Journal of Vertebrate Palaeontology 10(1):1-34.

White TE. 1958. The braincase of Camarasaurus lentus (Marsh). Journal of Paleontology 32(3):477-494.

Whitlock JA. 2011a. A phylogenetic analysis of Diplodocoidea (Saurischia: Sauropoda). Zoological Journal of the Linnean Society 161:872-915. DOI: 10.1111/j.10963642.2010.00665.x.

Whitlock JA. 2011b. Inferences of diplodocoid (Sauropoda: Dinosauria) feeding behavior from snout shape and microwear analyses. PLoS One 6(4):e18304.

Whitlock JA., Wilson JA., Lamanna MC. 2010. Description of a nearly complete juvenile skull of Diplodocus (Sauropoda: Diplodocoidea) from the Late Jurassic of North America. Journal of Vertebrate Paleontology 30(2): 442-457.

Wiersma K., Sander PM. 2016. The dentition of a well-preserved specimen of Camarasaurus sp.: implications for function, tooth replacement, soft part reconstruction, and food intake. PalZ 91(1):145-161.

Wilson JA. 2002. Sauropod dinosaur phylogeny: critique and cladistic analysis. Zoological Journal of the Linnean Society 136:215-275. DOI: 10.1046/j.1096-3642.2002.00029.x.

Wilson JA. 2005. Redescription of the Mongolian sauropod Nemegtosaurus mongoliensis Nowinski (Dinosauria: Saurischia) and comments on Late Cretaceous sauropod diversity. Journal of Systematic Palaeontology 3(3):283-318. DOI: 10.1017/S1477201905001628.

Wilson JA., Sereno PC. 1998. Early evolution and higher-level phylogeny of sauropod dinosaurs. Journal of Vertebrate Paleontology 18:1-68.

Wilson JA., Upchurch P. 2009. Redescription and reassessment of the phylogenetic affinities of Euhelopus zdanskyi (dinosauria: Sauropoda) from the Early Cretaceous of China. Journal of Systematic Palaeontology 7:199-239. DOI: 10.1017/S1477201908002691. 
2241 Wilson JA., Malkani MS., Gingerich PD. 2005. A sauropod braincase from the Pab Formation

2242

2243

2244

2245

2246

2247

2248

2249

2250

2251

2252

2253

2254

2255

2256

2257

2258

2259

2260

2261

2262

2263

2264

2265

2266

2267

2268

2269

2270

2271

2272

2273

2274

2275

2276

2277

2278

2279

2280

2281

2282

2283

2284

2285

2286
(Upper Cretaceous, Maastrichtian) of Balochistan, Pakistan. Gondwana Geological Magazine 8:101-109.

Wilson JA., Pol D., Zaher H. 2016. The skull of Tapuiasaurus macedoi (Dinosauria: Sauropoda), a basal titanosaur from the Early Cretaceous of Brazil. Zoological Journal of the Linnean Society. https://doi.org/10.1111/zoj.12420

Wilson JA., D’Emic MD., Curry Rogers KA., Mohabey DM., Sen S. 2009. Reassessment of the sauropod dinosaur Jainosaurus (="Antarctosaurus") septentrionalis from the Upper Cretaceous of India. Contributions from the Museum of Paleontology, University of Michigan 32(2):17-40.

Witmer LM., Ridgely RC. 2009. New insights into the brain, braincase, and ear region of tyrannosaurs (Dinosauria, Theropoda), with implications for sensory organization and behavior. The Anatomical Record 292(9):1266-1296.

Witmer LM., Ridgely RC., Dufeau DL., Semones MC. 2008. Using CT to peer into the past: 3D visualization of the brain and ear regions of birds, crocodiles, and nonavian dinosaurs. In: Anatomical Imaging. Tokyo: Springer, 67-87.

Woodruff DC., Fowler DW. 2012. Ontogenetic influence on neural spine bifurcation diplodocoidea (dinosauria: Sauropoda): A critical phylogenetic character. Journal of Morphology 273:754-764. DOI: 10.1002/jmor.20021.

Woodruff DC., Foster JR. 2017. The first specimen of Camarasaurus (Dinosauria: Sauropoda) from Montana: The northernmost occurrence of the genus. PLoS ONE 12. DOI: 10.1371/journal.pone.0177423.

Wright AM., Hillis DM. 2014. Bayesian analysis using a simple likelihood model outperforms parsimony for estimation of phylogeny from discrete morphological data. PLoS One 9(10):e109210.

Xing L., Miyashita T., Currie PJ., You H., Zhang J., Dong Z. 2015a. A new basal eusauropod from the Middle Jurassic of Yunnan, China, and faunal compositions and transitions of Asian sauropodomorph dinosaurs. Acta Palaeontologica Polonica 60:145-154. DOI: 10.4202/app.2012.0151.

Xing L., Miyashita T., Zhang J., Li D., Ye Y., Sekiya T., Wang F., Currie PJ. 2015b. A new sauropod dinosaur from the late Jurassic of China and the diversity, distribution, and relationships of mamenchisaurids. Journal of Vertebrate Paleontology 35:37-41. DOI: 10.1080/02724634.2014.889701.

Yates AM. 2007. The first complete skull of the Triassic dinosaur Melanorosaurus Haughton (Sauropodomorpha: Anchisauria). Special Papers in Palaeontology 77:9-55. 
2287 Ye Y., Ouyang H., Fu Q-M. 2001. New material of Mamenchisaurus hochuanensis from Zigong, 2288 2289

2290

2291

2292

2293

2294

2295

2296

2297

2298

2299 Sichuan. Vertebrata PalAsiatica 39(4):266-271.

Ye Y., Gao Y., Jiang S. 2005. A new genus of sauropod from Zigong, Sichuan. Vertebrata PalAsiatica 43(3):175-181.

Young CC. 1937. A New Dinosaurian from Sinkiang. National Geological Survey of China.

Zhang Y., Li K. 1998. A new species of sauropod dinosaur from the Upper Jurassic of Sichuan Basin, China. Journal of Chengdu University of Technology 25(1):61-70.

Zhao X. 1993. A new Middle Jurassic sauropod subfamily (Klamelisaurinae subfam. nov.) from Xinjiang Autonomous Region, China. Vertebrata Palasiatica 31:132-138. 


\section{Table 1 (on next page)}

Measurements $(\mathrm{mm})$ of the cranial material of Bellusaurus.

Underlined values indicate minimum lengths, reflecting incomplete preservation; italicized values are estimations. 


\begin{tabular}{|c|c|c|c|}
\hline Element & Measurement & Specimen & Value \\
\hline \multirow[t]{5}{*}{ Maxilla } & Length along ventral margin & IVPP V8299 & $\underline{46.6}$ \\
\hline & & IVPP V17768.1 & 98.8 \\
\hline & & IVPP V17768.3 & $\underline{83.4}$ \\
\hline & $\begin{array}{l}\text { Height of body below ventralmost point of } \\
\text { antorbital fenestra }\end{array}$ & IVPP V17768.1 & 26.6 \\
\hline & & IVPP V17768.3 & $\underline{17.4}$ \\
\hline \multirow[t]{2}{*}{ Nasal } & Anteroposterior length along midline & IVPP V17768.4 & $\underline{65}$ \\
\hline & Maximum width & IVPP V17768.4 & $\underline{29.8}$ \\
\hline \multirow[t]{11}{*}{ Frontal } & $\begin{array}{c}\text { Greatest anteroposterior length, along } \\
\text { interfrontal suture }\end{array}$ & IVPP V17768.5 & 48.7 \\
\hline & & IVPP V17768.6 & $\underline{41.2}$ \\
\hline & & IVPP V17768.7 & $\underline{43.6}$ \\
\hline & $\begin{array}{l}\text { Greatest transverse width, measured from } \\
\text { interfrontal suture to lateralmost extent } \\
\text { dorsal surface of process for postorbital }\end{array}$ & IVPP V17768.5 & 49.4 \\
\hline & & IVPP V17768.6 & 48.8 \\
\hline & & IVPP V17768.7 & 54.5 \\
\hline & $\begin{array}{c}\text { Combined breadth anteriorly of prefrontal } \\
\text { and nasal articulations }\end{array}$ & IVPP V17768.5 & 32.5 \\
\hline & & IVPP V17768.7 & 41.2 \\
\hline & $\begin{array}{l}\text { Anteroposterior diameter of frontoparietal } \\
\text { fenestra }\end{array}$ & IVPP V17768.5 & 10.7 \\
\hline & & IVPP V17768.6 & 10.5 \\
\hline & & IVPP V17768.7 & 10.9 \\
\hline \multirow[t]{3}{*}{ Parietal } & Anteroposterior length along midline & IVPP V17768.5 & 24 \\
\hline & & IVPP V17768.6 & 28.5 \\
\hline & & IVPP V17768.7 & 24.9 \\
\hline
\end{tabular}




\begin{tabular}{|c|c|c|c|}
\hline Element & Measurement & Specimen & Value \\
\hline & $\begin{array}{l}\text { Minimum transverse width at } \\
\text { supratemporal fenestra }\end{array}$ & IVPP V17768.5 & 17 \\
\hline & & IVPP V17768.6 & 18 \\
\hline & & IVPP V17768.7 & 22 \\
\hline & $\begin{array}{l}\text { Transverse width of supratemporal } \\
\text { fenestra }\end{array}$ & IVPP V17768.5 & 27.5 \\
\hline & & IVPP V17768.6 & 28.7 \\
\hline & & IVPP V17768.7 & $\underline{19}$ \\
\hline & $\begin{array}{l}\text { Anteroposterior width of supratemporal } \\
\text { fenestra }\end{array}$ & IVPP V17768.5 & $\underline{18.6}$ \\
\hline & & IVPP V17768.6 & $\underline{19.6}$ \\
\hline & & IVPP V17768.7 & $\underline{15}$ \\
\hline Squamosal & Maximum dorsoventral height & IVPP V17768.8 & 49.5 \\
\hline Quadrate & Maximum dorsoventral height & IVPP V17768.9 & 63.8 \\
\hline \multirow[t]{5}{*}{ Parabasisphenoid } & $\begin{array}{l}\text { Length of basipterygoid process along } \\
\text { medial edge }\end{array}$ & IVPP V8299 & 19.4 \\
\hline & $\begin{array}{l}\text { Proximal anteroposterior breadth of } \\
\text { basipterygoid process }\end{array}$ & IVPP V8299 & 13.9 \\
\hline & $\begin{array}{l}\text { Proximal transverse breadth of } \\
\text { basipterygoid process }\end{array}$ & IVPP V8299 & 6.4 \\
\hline & $\begin{array}{l}\text { Distal anteroposterior breadth of } \\
\text { basipterygoid process }\end{array}$ & IVPP V8299 & 11.9 \\
\hline & $\begin{array}{c}\text { Distal transverse breadth of basipterygoid } \\
\text { process }\end{array}$ & IVPP V8299 & 7 \\
\hline \multirow[t]{2}{*}{ Angular } & Anteroposterior length & IVPP V17768.12 & 117.8 \\
\hline & Maximum dorsoventral height & IVPP V17768.12 & 18.6 \\
\hline
\end{tabular}




\section{Table 2 (on next page)}

Form of orbital margin of the frontal in various sauropodomorphs.

"Stage" refers to the approximate ontogenetic stage of the specimen; taxa were coarsely binned into early juvenile, late juvenile or adult categories, based on gross indicators of skeletal maturity (e.g., bone texture; neurocentral fusion). Where measurements were taken in person with calipers, rather than from publications or photographs, they are provided, in millimeters. Abbreviations: Ad, adult; BM, basal Macronaria; BS, non-sauropod Sauropodomorpha; DC, Diplodocoidea; EJuv, early juvenile; LJuv, late juvenile; SA, nonneosauropod Sauropoda; TF, Titanosauriformes. 


\begin{tabular}{|c|c|c|c|c|c|c|c|c|}
\hline Taxon & Specimen & Source & $\begin{array}{l}\text { Transverse width } \\
\text { across } \\
\text { articulations for } \\
\text { the nasal and } \\
\text { prefrontal } \\
\text { (X) }\end{array}$ & $\begin{array}{c}\text { Greatest } \\
\text { transverse width } \\
\text { of the frontal in } \\
\text { dorsal view } \\
\text { (where it reaches } \\
\text { the postorbital) } \\
\text { (Y) }\end{array}$ & $\mathbf{X} / \mathbf{Y}$ & $\begin{array}{c}\text { Form of } \\
\text { orbital } \\
\text { margin in } \\
\text { dorsal view }\end{array}$ & Clade & Stage \\
\hline Dicraeosaurus & $\begin{array}{c}\text { MB.R.233 } \\
6\end{array}$ & $\begin{array}{c}\text { Janensch, } \\
\text { 1935-36: } \\
\text { Fig. } 97\end{array}$ & - & - & 0.97 & concave & $\mathrm{DC}$ & LJuv \\
\hline Kaatedocus siberi & SMA 0004 & $\begin{array}{l}\text { Tschopp, } \\
\text { Mateus \& } \\
\text { Benson, } \\
\text { 2015: Fig. } 7\end{array}$ & - & - & 0.93 & straight & $\mathrm{DC}$ & $\begin{array}{l}\text { LJuv or } \\
\text { Ad }\end{array}$ \\
\hline Camarasaurus & $\begin{array}{c}\text { UMNH } \\
\text { VP } 5668\end{array}$ & pers. obs. & - & - & 0.92 & straight & $\mathrm{BM}$ & ?Ad \\
\hline Camarasaurus & CM 11338 & pers. obs. & - & - & 0.90 & concave & $\mathrm{BM}$ & EJuv \\
\hline
\end{tabular}




\begin{tabular}{|c|c|c|c|c|c|c|c|c|}
\hline Taxon & Specimen & Source & $\begin{array}{l}\text { Transverse width } \\
\text { across } \\
\text { articulations for } \\
\text { the nasal and } \\
\text { prefrontal } \\
\text { (X) }\end{array}$ & $\begin{array}{l}\text { Greatest } \\
\text { transverse width } \\
\text { of the frontal in } \\
\text { dorsal view } \\
\text { (where it reaches } \\
\text { the postorbital) } \\
\text { (Y) }\end{array}$ & $\mathbf{X} / \mathbf{Y}$ & $\begin{array}{c}\text { Form of } \\
\text { orbital } \\
\text { margin in } \\
\text { dorsal view }\end{array}$ & Clade & Stage \\
\hline Qijianglong & $\begin{array}{l}\text { QJGPM } \\
1001\end{array}$ & $\begin{array}{c}\text { Xing et al., } \\
\text { 2015b: Fig. } \\
2\end{array}$ & - & - & 0.88 & concave & SA & Ad \\
\hline Nemegtosaurus & $\begin{array}{c}\text { Z. PAL } \\
\text { MgD-I/9 }\end{array}$ & $\begin{array}{c}\text { Wilson, } \\
\text { 2005: Fig. } 7\end{array}$ & - & - & 0.87 & straight & $\mathrm{TF}$ & ?Ad \\
\hline Spinophorosaurus & $\begin{array}{c}\text { GCP-CV- } \\
4229\end{array}$ & $\begin{array}{l}\text { Knoll et al., } \\
\text { 2012: Fig. } 3\end{array}$ & - & - & 0.84 & straight & SA & LJuv \\
\hline Shunosaurus & ZDM 5009 & pers. obs. & 63 & 75 & 0.84 & straight & SA & ?Ad \\
\hline
\end{tabular}




\begin{tabular}{|c|c|c|c|c|c|c|c|c|}
\hline Taxon & Specimen & Source & $\begin{array}{l}\text { Transverse width } \\
\text { across } \\
\text { articulations for } \\
\text { the nasal and } \\
\text { prefrontal } \\
\text { (X) }\end{array}$ & $\begin{array}{c}\text { Greatest } \\
\text { transverse width } \\
\text { of the frontal in } \\
\text { dorsal view } \\
\text { (where it reaches } \\
\text { the postorbital) } \\
\text { (Y) }\end{array}$ & $\mathbf{X} / \mathbf{Y}$ & $\begin{array}{c}\text { Form of } \\
\text { orbital } \\
\text { margin in } \\
\text { dorsal view }\end{array}$ & Clade & Stage \\
\hline Tornieria & $\begin{array}{c}\text { MB.R.238 } \\
6\end{array}$ & pers. obs. & 84 & 100 & 0.84 & straight & $\mathrm{DC}$ & Ad \\
\hline Giraffatitan & $\begin{array}{c}\text { MB.R.218 } \\
0.22\end{array}$ & pers. obs. & 109 & 130 & 0.84 & straight & $\mathrm{TF}$ & Ad \\
\hline Galeamopus pabsti & SMA 0011 & $\begin{array}{l}\text { Tschopp, } \\
\text { Mateus \& } \\
\text { Benson, } \\
\text { 2015: Fig. } 7\end{array}$ & - & - & 0.83 & concave & $\mathrm{DC}$ & LJuv \\
\hline cf. Diplodocus & $\begin{array}{c}\text { USNM } \\
2673\end{array}$ & pers. obs. & - & - & 0.82 & concave & $\mathrm{DC}$ & $\begin{array}{l}\text { LJuv or } \\
\text { Ad }\end{array}$ \\
\hline
\end{tabular}




\begin{tabular}{|c|c|c|c|c|c|c|c|c|}
\hline Taxon & Specimen & Source & $\begin{array}{l}\text { Transverse width } \\
\text { across } \\
\text { articulations for } \\
\text { the nasal and } \\
\text { prefrontal } \\
\text { (X) }\end{array}$ & $\begin{array}{l}\text { Greatest } \\
\text { transverse width } \\
\text { of the frontal in } \\
\text { dorsal view } \\
\text { (where it reaches } \\
\text { the postorbital) } \\
\text { (Y) }\end{array}$ & $\mathbf{X} / \mathbf{Y}$ & $\begin{array}{c}\text { Form of } \\
\text { orbital } \\
\text { margin in } \\
\text { dorsal view }\end{array}$ & Clade & Stage \\
\hline Abydosaurus & $\begin{array}{l}\text { DINO } \\
39727\end{array}$ & pers. obs. & - & - & 0.82 & straight & $\mathrm{TF}$ & $\begin{array}{l}\text { LJuv or } \\
\text { Ad }\end{array}$ \\
\hline Apatosaurus & CM 11162 & $\begin{array}{l}\text { Tschopp, } \\
\text { Mateus \& } \\
\text { Benson, } \\
\text { 2015: Fig. } 7\end{array}$ & - & - & 0.80 & concave & $\mathrm{DC}$ & Ad \\
\hline Limaysaurus & $\begin{array}{c}\text { MUCPV- } \\
205\end{array}$ & $\begin{array}{c}\text { Calvo \& } \\
\text { Salgado } \\
\text { 1995: Fig. } 3\end{array}$ & - & - & 0.77 & straight & $\mathrm{DC}$ & ?Ad \\
\hline Bellusaurus & $\begin{array}{c}\text { IVPP } \\
\text { V17768.7 }\end{array}$ & pers. obs. & - & - & 0.76 & concave & ?BM & EJuv \\
\hline
\end{tabular}




\begin{tabular}{|c|c|c|c|c|c|c|c|c|}
\hline Taxon & Specimen & Source & $\begin{array}{l}\text { Transverse width } \\
\text { across } \\
\text { articulations for } \\
\text { the nasal and } \\
\text { prefrontal } \\
\text { (X) }\end{array}$ & $\begin{array}{l}\text { Greatest } \\
\text { transverse width } \\
\text { of the frontal in } \\
\text { dorsal view } \\
\text { (where it reaches } \\
\text { the postorbital) } \\
\text { (Y) }\end{array}$ & $\mathbf{X} / \mathbf{Y}$ & $\begin{array}{c}\text { Form of } \\
\text { orbital } \\
\text { margin in } \\
\text { dorsal view }\end{array}$ & Clade & Stage \\
\hline Nigersaurus & $\begin{array}{c}\text { MNBH } \\
\text { GAD512 }\end{array}$ & $\begin{array}{l}\text { Tschopp, } \\
\text { Mateus \& } \\
\text { Benson, } \\
\text { 2015: Fig. } 7\end{array}$ & - & - & 0.76 & convex & $\mathrm{DC}$ & Ad \\
\hline Jobaria & $\begin{array}{c}\text { MNBH } \\
\text { TIG } 4\end{array}$ & pers. obs. & - & - & 0.74 & straight & SA & Ad \\
\hline cf. Diplodocus & CM 3452 & $\begin{array}{l}\text { Berman \& } \\
\text { McIntosh, } \\
\text { 1978: Fig. } 3\end{array}$ & - & - & 0.74 & concave & $\mathrm{DC}$ & ?LJuv \\
\hline Lufengosaurus & IVPP V15 & $\begin{array}{c}\text { Barrett, } \\
\text { Upchurch \& } \\
\text { Wang, 2005: } \\
\text { Fig. } 3\end{array}$ & - & - & 0.74 & concave & $\mathrm{BS}$ & ?Ad \\
\hline
\end{tabular}




\begin{tabular}{|c|c|c|c|c|c|c|c|c|}
\hline Taxon & Specimen & Source & $\begin{array}{l}\text { Transverse width } \\
\text { across } \\
\text { articulations for } \\
\text { the nasal and } \\
\text { prefrontal } \\
\text { (X) }\end{array}$ & $\begin{array}{l}\text { Greatest } \\
\text { transverse width } \\
\text { of the frontal in } \\
\text { dorsal view } \\
\text { (where it reaches } \\
\text { the postorbital) } \\
\text { (Y) }\end{array}$ & $\mathbf{X} / \mathbf{Y}$ & $\begin{array}{c}\text { Form of } \\
\text { orbital } \\
\text { margin in } \\
\text { dorsal view }\end{array}$ & Clade & Stage \\
\hline Europasaurus & $\begin{array}{c}\mathrm{DFMMh} / \mathrm{F} \\
\text { V } 389\end{array}$ & $\begin{array}{c}\text { Marpmann } \\
\text { et al,. } 2014: \\
\text { Fig. } 6\end{array}$ & - & - & 0.73 & concave & $\begin{array}{l}\mathrm{BM} \text { or } \\
\mathrm{TF}\end{array}$ & EJuv \\
\hline Europasaurus & $\begin{array}{c}\mathrm{DFMMh} / \mathrm{F} \\
\mathrm{V} 162\end{array}$ & $\begin{array}{c}\text { Marpmann } \\
\text { et al,. 2014: } \\
\text { Fig. } 6\end{array}$ & - & - & 0.72 & concave & $\begin{array}{l}\mathrm{BM} \text { or } \\
\mathrm{TF}\end{array}$ & Ejuv \\
\hline Daanosaurus & $\begin{array}{l}\text { ZDM } 0193 \\
\quad \text { (left) }\end{array}$ & pers. obs. & 30 & 42 & 0.71 & concave & ?SA & EJuv \\
\hline Massospondylus & $\mathrm{BP} / \mathrm{I} / 4779$ & pers. obs. & 22 & 31 & 0.71 & concave & $\mathrm{BS}$ & $\begin{array}{l}\text { LJuv or } \\
\text { Ad }\end{array}$ \\
\hline
\end{tabular}




\begin{tabular}{|c|c|c|c|c|c|c|c|c|}
\hline Taxon & Specimen & Source & $\begin{array}{l}\text { Transverse width } \\
\text { across } \\
\text { articulations for } \\
\text { the nasal and } \\
\text { prefrontal } \\
\text { (X) }\end{array}$ & $\begin{array}{l}\text { Greatest } \\
\text { transverse width } \\
\text { of the frontal in } \\
\text { dorsal view } \\
\text { (where it reaches } \\
\text { the postorbital) } \\
\text { (Y) }\end{array}$ & $\mathbf{X} / \mathbf{Y}$ & $\begin{array}{c}\text { Form of } \\
\text { orbital } \\
\text { margin in } \\
\text { dorsal view }\end{array}$ & Clade & Stage \\
\hline $\begin{array}{c}\text { Mamenchisaurus } \\
\text { hochuanensis }\end{array}$ & ZDM 0126 & $\begin{array}{l}\text { Ye et al,. } \\
\text { 2001: Plate } \\
1.2\end{array}$ & - & - & 0.69 & concave & SA & Ad \\
\hline Bellusaurus & $\begin{array}{c}\text { IVPP } \\
\text { V17768.5 }\end{array}$ & pers. obs. & 33 & 49 & 0.67 & concave & ?BM & EJuv \\
\hline Daanosaurus & $\begin{array}{l}\text { ZDM } 0193 \\
\text { (right) }\end{array}$ & pers. obs. & 28 & 43 & 0.65 & concave & ?SA & EJuv \\
\hline Massospondylus & $\mathrm{BP} / \mathrm{I} / 4934$ & pers. obs. & 24 & 38 & 0.63 & concave & $\mathrm{BS}$ & Ad \\
\hline
\end{tabular}




\begin{tabular}{|c|c|c|c|c|c|c|c|c|}
\hline Taxon & Specimen & Source & $\begin{array}{l}\text { Transverse width } \\
\text { across } \\
\text { articulations for } \\
\text { the nasal and } \\
\text { prefrontal } \\
\text { (X) }\end{array}$ & $\begin{array}{c}\text { Greatest } \\
\text { transverse width } \\
\text { of the frontal in } \\
\text { dorsal view } \\
\text { (where it reaches } \\
\text { the postorbital) } \\
\text { (Y) }\end{array}$ & $\mathbf{X} / \mathbf{Y}$ & $\begin{array}{c}\text { Form of } \\
\text { orbital } \\
\text { margin in } \\
\text { dorsal view }\end{array}$ & Clade & Stage \\
\hline Europasaurus & $\begin{array}{c}\mathrm{DFMMh} / \mathrm{F} \\
\mathrm{V} 552\end{array}$ & $\begin{array}{c}\text { Marpmann } \\
\text { et al,. 2014: } \\
\text { Fig. } 6\end{array}$ & - & - & 0.61 & concave & $\begin{array}{c}\text { BM or } \\
\text { TF }\end{array}$ & Ad \\
\hline
\end{tabular}




\section{Table 3(on next page)}

Measurements (mm) of the teeth of Bellusaurus sui.

Underlined values indicate minimum lengths, reflecting incomplete preservation; italicized values are estimations. 


\begin{tabular}{|c|c|c|c|c|c|}
\hline Specimen & $\begin{array}{c}\text { Total } \\
\text { apicobasal } \\
\text { height of } \\
\text { crown + root }\end{array}$ & $\begin{array}{c}\text { Total } \\
\text { apicobasal } \\
\text { height of } \\
\text { crown }\end{array}$ & $\begin{array}{l}\text { Maximum } \\
\text { mesiodistal } \\
\text { width of } \\
\text { crown }\end{array}$ & $\begin{array}{l}\text { Mesiodistal } \\
\text { width of } \\
\text { crown at its } \\
\text { base }\end{array}$ & $\begin{array}{c}\text { Slenderness } \\
\text { index (crown } \\
\text { height / max. } \\
\text { breadth) }\end{array}$ \\
\hline $\begin{array}{l}\text { IVPP } \\
\text { V8299.3 }\end{array}$ & $\underline{21.1}$ & $\underline{18.8}$ & 8.5 & - & - \\
\hline $\begin{array}{l}\text { IVPP } \\
\text { V8299.4 }\end{array}$ & $\underline{17.9}$ & $\underline{17.9}$ & 8.8 & - & - \\
\hline $\begin{array}{l}\text { IVPP } \\
\text { V8299.6 }\end{array}$ & $\underline{21.8}$ & $\underline{21.8}$ & $\underline{9.5}$ & - & - \\
\hline $\begin{array}{l}\text { IVPP } \\
\text { V8299.7 }\end{array}$ & $\underline{18.9}$ & $\underline{18.9}$ & $\underline{8.1}$ & - & - \\
\hline $\begin{array}{l}\text { IVPP } \\
\text { V17768.12 }\end{array}$ & $\underline{20.5}$ & 16.6 & 7.8 & 5.1 & 2.1 \\
\hline $\begin{array}{l}\text { IVPP } \\
\text { V17768.13 }\end{array}$ & $\underline{38.0}$ & 20.9 & 8.2 & 6.3 & 2.5 \\
\hline $\begin{array}{l}\text { IVPP } \\
\text { V17768.14 }\end{array}$ & $\underline{31.7}$ & 19.7 & 8.6 & 5.6 & 2.3 \\
\hline $\begin{array}{l}\text { IVPP } \\
\text { V17768.15 }\end{array}$ & 13.7 & $\underline{13.7}$ & - & - & - \\
\hline $\begin{array}{l}\text { IVPP } \\
\text { V17768.16 }\end{array}$ & $\underline{12.7}$ & 11.4 & 5.9 & 4.7 & 1.9 \\
\hline $\begin{array}{l}\text { IVPP } \\
\text { V17768.17 }\end{array}$ & $\underline{32.0}$ & 16.6 & $\underline{7.5}$ & 5.7 & - \\
\hline $\begin{array}{l}\text { IVPP } \\
\text { V17768.18 }\end{array}$ & $\underline{14.4}$ & 11.1 & 6.5 & 5.4 & 1.7 \\
\hline $\begin{array}{l}\text { IVPP } \\
\text { V17768.19 }\end{array}$ & $\underline{21.3}$ & 8.2 & 6.1 & 4.6 & 1.3 \\
\hline $\begin{array}{l}\text { IVPP } \\
\text { V17768.20 }\end{array}$ & $\underline{19.8}$ & $\underline{17.5}$ & 7.5 & - & - \\
\hline $\begin{array}{l}\text { IVPP } \\
\text { V17768.21 }\end{array}$ & 32.1 & 13.0 & 6.4 & 5.2 & 2.0 \\
\hline
\end{tabular}




\section{Table 4 (on next page)}

Sauropod taxa for which unambiguously juvenile cranial material is known.

Taxa for which adult cranial material is also known are indicated with an asterisk. 


\begin{tabular}{|c|c|c|}
\hline Taxon & Material & Key References \\
\hline \multicolumn{3}{|c|}{ Non-neosauropods } \\
\hline Patagosaurus* & Mandible & Bonaparte, 1986 \\
\hline Chebsaurus & Premaxilla, basicranium, surangular & Läng \& Mahammed, 2010 \\
\hline Daanosaurus & $\begin{array}{c}\text { Maxilla, frontal, parietal, quadrate, } \\
\text { otoccipital }\end{array}$ & Ye, Gao \& Jiang., 2005 \\
\hline Moabosaurus* & Braincase & Britt et al., 2017 \\
\hline \multicolumn{3}{|c|}{ Macronaria } \\
\hline Bellusaurus & $\begin{array}{l}\text { Maxilla, nasal, frontal, parietal, } \\
\text { squamosal, quadrate, pterygoid, } \\
\text { otoccipital, basisphenoid, dentary, angular, } \\
\text { teeth }\end{array}$ & Dong, 1990; this study \\
\hline Camarasaurus* & Complete skull; isolated premaxilla & $\begin{array}{l}\text { Gilmore, 1925; Britt \& } \\
\text { Naylor, } 1994\end{array}$ \\
\hline Europasaurus* & $\begin{array}{l}\text { Nearly complete skull elements from } \\
\text { numerous individuals }\end{array}$ & Marpmann et al., 2014 \\
\hline $\begin{array}{c}\text { Auca Mahuevo } \\
\text { titanosaurian }\end{array}$ & Largely complete embryonic skulls & $\begin{array}{c}\text { Salgado et al., 2005; García et } \\
\text { al., 2010; García \& Cerda, } \\
2010\end{array}$ \\
\hline $\begin{array}{l}\text { Lithostrotia } \\
\text { indet. }\end{array}$ & Partial embryonic skull & Grellet-Tinner et al., 2011 \\
\hline Rapetosaurus* & $\begin{array}{l}\text { Quadrate, pterygoid, partial braincase, } \\
\text { surangular, angular }\end{array}$ & Curry Rogers \& Forster, 2004 \\
\hline Vahiny* & Basioccipital & Curry Rogers \& Wilson, 2014 \\
\hline Saltasaurus* & Frontal & Powell, 1992 \\
\hline “Astrodon" & $\begin{array}{l}\text { Maxilla, fragmentary pterygoid partial } \\
\text { braincase elements, dentary, teeth }\end{array}$ & $\begin{array}{c}\text { Carpenter \& Tidwell, 2005; } \\
\text { D’Emic, } 2013\end{array}$ \\
\hline \multicolumn{3}{|c|}{ Diplodocoidea } \\
\hline cf. Diplodocus* & Largely complete skull & $\begin{array}{l}\text { Whitlock, Wilson \& } \\
\text { Lamanna, } 2010\end{array}$ \\
\hline
\end{tabular}




\section{Table 5 (on next page)}

Hypothesized transformations in the course of cranial ontogeny in sauropods.

This list is not exhaustive, and emphasizes ontogenetic hypotheses that are particular to sauropods and can be made for more than one taxon. 


\begin{tabular}{|c|c|c|c|}
\hline $\begin{array}{l}\text { Hypothesized } \\
\text { transformation }\end{array}$ & $\begin{array}{l}\text { Taxa providing } \\
\text { evidence }\end{array}$ & Sources & Comments \\
\hline $\begin{array}{l}\text { Extreme decrease in } \\
\text { relative skull size }\end{array}$ & Sauropodomorpha & $\begin{array}{l}\text { Ikejiri, 2004; } \\
\text { Rauhut et al., } \\
\text { 2011; this } \\
\text { study }\end{array}$ & $\begin{array}{l}\text { While relative skull size } \\
\text { decreases through ontogeny } \\
\text { in many vertebrates, the } \\
\text { exceptional diminution of } \\
\text { skull size on the } \\
\text { evolutionary line leading to } \\
\text { Eusauropoda (Rauhut et al. } \\
\text { 2011) indicates that negative } \\
\text { allometry of the skull with } \\
\text { respect to the postcranial } \\
\text { skeleton in sauropods was } \\
\text { especially extreme }\end{array}$ \\
\hline $\begin{array}{l}\text { Increasingly fused } \\
\text { interfrontal and } \\
\text { interparietal sutures }\end{array}$ & Diplodocoidea & $\begin{array}{l}\text { Salgado, 1999; } \\
\text { Whitlock, } \\
\text { Wilson \& } \\
\text { Lamanna, } \\
\text { 2010; Tschopp } \\
\text { \& Mateus, } \\
\text { 2013; } \\
\text { Tschopp, } \\
\text { Mateus \& } \\
\text { Benson, 2015 }\end{array}$ & - \\
\hline $\begin{array}{c}\text { Decrease in relative } \\
\text { anteroposterior width of } \\
\text { nasal process of premaxilla }\end{array}$ & $\begin{array}{l}\text { Camarasaurus; } \\
\text { Europasaurus }\end{array}$ & $\begin{array}{l}\text { Britt \& Naylor, } \\
\text { 1994; } \\
\text { Marpmann et } \\
\text { al., } 2014\end{array}$ & - \\
\hline $\begin{array}{l}\text { Stepped margin of the } \\
\text { muzzle becomes more } \\
\text { distinct }\end{array}$ & $\begin{array}{l}\text { Camarasaurus; } \\
\text { Shunosaurus }\end{array}$ & $\begin{array}{l}\text { Britt \& Naylor, } \\
\text { 1994; Wilson } \\
\text { \& Sereno, } \\
1998\end{array}$ & $\begin{array}{l}\text { This hypothesized } \\
\text { transformation does not } \\
\text { apply to taxa lacking a } \\
\text { stepped muzzle (e.g., } \\
\text { diplodocids) }\end{array}$ \\
\hline $\begin{array}{l}\text { Muzzle increases in } \\
\text { relative width }\end{array}$ & $\begin{array}{l}\text { cf. Diplodocus; } \\
\text { Camarasaurus; } \\
\text { Europasaurus }\end{array}$ & $\begin{array}{l}\text { Whitlock, } \\
\text { Wilson \& } \\
\text { Lamanna, } \\
\text { 2010; } \\
\text { Whitlock, } \\
\text { 2011b; } \\
\text { Marpmann et } \\
\text { al., } 2014\end{array}$ & - \\
\hline
\end{tabular}




\begin{tabular}{|c|c|c|c|}
\hline $\begin{array}{l}\text { Hypothesized } \\
\text { transformation }\end{array}$ & $\begin{array}{c}\text { Taxa providing } \\
\text { evidence }\end{array}$ & Sources & Comments \\
\hline $\begin{array}{l}\text { Muzzle transitions from } \\
\text { rounded and narrow to } \\
\text { square and blunt }\end{array}$ & Diplodocinae & $\begin{array}{l}\text { Whitlock, } \\
\text { Wilson \& } \\
\text { Lamanna, } \\
\text { 2010; Tschopp } \\
\text { \& Mateus, } \\
2013\end{array}$ & $\begin{array}{l}\text { In addition to general } \\
\text { widening of the muzzle, the } \\
\text { anterior, tooth-bearing region } \\
\text { of diplodocids transitions } \\
\text { from transversely narrow and } \\
\text { rounded to square and blunt. } \\
\text { This transition has been } \\
\text { suggested to signify niche } \\
\text { partitioning between } \\
\text { juveniles and adults, and is } \\
\text { thus far hypothesized only } \\
\text { for diplodocids, or possibly } \\
\text { Diplodocoidea generally }\end{array}$ \\
\hline Elongation of the snout & $\begin{array}{l}\text { Theropoda; } \\
\text { Massospondylus; } \\
\text { cf. Diplodocus; } \\
\text { Titanosauria }\end{array}$ & $\begin{array}{l}\text { Varricchio, } \\
\text { 1997; Salgado, } \\
\text { Coria \& } \\
\text { Chiappe, 2005; } \\
\text { Whitlock, } \\
\text { Wilson \& } \\
\text { Lamanna, } \\
\text { 2010; García } \\
\text { et al. 2010; } \\
\text { Chapelle, 2016 }\end{array}$ & $\begin{array}{l}\text { Such a transformation is } \\
\text { typical of theropods and } \\
\text { basal sauropodomorphs. } \\
\text { However, rostral elongation } \\
\text { was diminished in } \\
\text { eusauropods, followed by } \\
\text { subsequent elongation of the } \\
\text { rostrum in diplodocoids and } \\
\text { some advanced } \\
\text { titanosauriforms (see } \\
\text { Discussion) }\end{array}$ \\
\hline $\begin{array}{l}\text { Posterodorsal retraction of } \\
\text { the external nares }\end{array}$ & Titanosauria & $\begin{array}{l}\text { Salgado, Coria } \\
\text { \& Chiappe, } \\
\text { 2005; Garcia } \\
\text { \& Cerda, } 2010\end{array}$ & - \\
\hline $\begin{array}{l}\text { Reduction of the maxillary } \\
\text { process of the jugal }\end{array}$ & Titanosauria & $\begin{array}{l}\text { Salgado, Coria } \\
\text { \& Chiappe, } \\
2005\end{array}$ & - \\
\hline
\end{tabular}




\begin{tabular}{|c|c|c|c|}
\hline $\begin{array}{l}\text { Hypothesized } \\
\text { transformation }\end{array}$ & $\begin{array}{l}\text { Taxa providing } \\
\text { evidence }\end{array}$ & Sources & Comments \\
\hline $\begin{array}{l}\text { Decreasing participation of } \\
\text { jugal in ventral margin of } \\
\text { the skull }\end{array}$ & $\begin{array}{l}\text { Europasaurus; } \\
\text { Titanosauria }\end{array}$ & $\begin{array}{l}\text { Marpmann et } \\
\text { al., 2014; } \\
\text { Salgado, Coria } \\
\text { \& Chiappe, } \\
\text { 2005; García } \\
\text { et al., } 2010\end{array}$ & $\begin{array}{l}\text { The presence of a free ventral } \\
\text { edge of the jugal in adult } \\
\text { Europasaurus, though } \\
\text { reduced from the juvenile } \\
\text { condition, is hypothesized to } \\
\text { reflect paedomorphosis. The } \\
\text { jugal has a large participation } \\
\text { in the ventral margin of the } \\
\text { skull in embryonic } \\
\text { titanosaurians, a character } \\
\text { otherwise absent in } \\
\text { sauropods more derived than } \\
\text { Shunosaurus, with the } \\
\text { exception of Europasaurus, } \\
\text { Giraffatitan, and } \\
\text { Malawisaurus (Royo-Torres } \\
\text { \& Upchurch 2012) }\end{array}$ \\
\hline $\begin{array}{l}\text { Frontal becomes relatively } \\
\text { wider and less elongate }\end{array}$ & $\begin{array}{l}\text { Diplodocidae; } \\
\text { Europasaurus; } \\
\text { Titanosauria }\end{array}$ & $\begin{array}{l}\text { García et al., } \\
\text { 2010; Tschopp } \\
\text { \& Mateus, } \\
\text { 2013; this } \\
\text { study }\end{array}$ & $\begin{array}{l}\text { The observation that the } \\
\text { frontal is relatively longer } \\
\text { anteroposteriorly in the } \\
\text { paedomorphic Europasaurus, } \\
\text { embryonic titanosaurians, } \\
\text { and some juvenile sauropods } \\
\text { (Bellusaurus, Daanosaurus) } \\
\text { than is typical for sauropods } \\
\text { suggests that this feature may } \\
\text { vary ontogenetically }\end{array}$ \\
\hline $\begin{array}{l}\text { Decrease in depth of orbital } \\
\text { rim penetration of the } \\
\text { frontal (in dorsal view), } \\
\text { perhaps with concomitant } \\
\text { increase in width of frontal, } \\
\text { including articulations with } \\
\text { prefrontal and nasal }\end{array}$ & $\begin{array}{c}\text { Europasaurus; } \\
\text { Bellusaurus; } \\
\text { Daanosaurus; } \\
\text { Titanosauria; } \\
\text { possibly cf. } \\
\text { Diplodocus }\end{array}$ & $\begin{array}{l}\text { Marpmann et } \\
\text { al., 2014; } \\
\text { Chiappe et al., } \\
\text { 1998; Garcia } \\
\text { et al., 2010; } \\
\text { Whitlock, } \\
\text { Wilson \& } \\
\text { Lamanna, } \\
\text { 2010; this } \\
\text { study }\end{array}$ & See Discussion \\
\hline $\begin{array}{l}\text { Decrease in distance } \\
\text { separating the } \\
\text { supratemporal fenestrae }\end{array}$ & $\begin{array}{l}\text { Europasaurus; } \\
\text { Camarasaurus }\end{array}$ & $\begin{array}{l}\text { Marpmann et } \\
\text { al., 2014; this } \\
\text { study }\end{array}$ & - \\
\hline
\end{tabular}




\begin{tabular}{|c|c|c|c|}
\hline $\begin{array}{l}\text { Hypothesized } \\
\text { transformation }\end{array}$ & $\begin{array}{l}\text { Taxa providing } \\
\text { evidence }\end{array}$ & Sources & Comments \\
\hline $\begin{array}{l}\text { Decrease in relative size of } \\
\text { supratemporal fenestrae }\end{array}$ & Titanosauria & $\begin{array}{l}\text { Salgado, Coria } \\
\text { \& Chiappe, } \\
2005\end{array}$ & $\begin{array}{l}\text { The supratemporal fenestra is } \\
\text { well-developed in } \\
\text { titanosaurian embryos but is } \\
\text { reduced in more adult } \\
\text { titanosaurian skulls, } \\
\text { suggesting ontogenetic } \\
\text { reduction of this aperture in } \\
\text { titanosaurians }\end{array}$ \\
\hline $\begin{array}{l}\text { Opening or closure of } \\
\text { frontal/frontoparietal/pariet } \\
\text { al fenestra? }\end{array}$ & $\begin{array}{l}\text { Camarasaurus; } \\
\text { Europasaurus; } \\
\text { Apatosaurus; } \\
\text { Titanosauria }\end{array}$ & $\begin{array}{l}\text { Salgado, Coria } \\
\text { \& Chiappe, } \\
\text { 2005; } \\
\text { Balanoff, } \\
\text { Bever \& } \\
\text { Ikejiri, 2010; } \\
\text { Marpmann et } \\
\text { al., 2014; } \\
\text { Woodruff \& } \\
\text { Foster, 2017; }\end{array}$ & See Discussion \\
\hline $\begin{array}{l}\text { Increasingly large } \\
\text { separation between } \\
\text { squamosal and } \\
\text { quadratojugal }\end{array}$ & Flagellicaudata & $\begin{array}{l}\text { Whitlock, } \\
\text { Wilson \& } \\
\text { Lamanna, } \\
\text { 2010; Tschopp } \\
\text { \& Mateus, } \\
2013\end{array}$ & $\begin{array}{l}\text { Flagellicaudatans lack } \\
\text { contact between the } \\
\text { squamosal and quadratojugal, } \\
\text { while these two elements are } \\
\text { nearly touching in a juvenile } \\
\text { diplodocid (CM 11255), } \\
\text { suggesting this feature may } \\
\text { vary ontogenetically. } \\
\text { Notably, embryonic } \\
\text { titanosaurians lack the } \\
\text { squamosal-quadratojugal } \\
\text { articulation present in more } \\
\text { adult titanosaurians (Salgado, } \\
\text { Coria \& Chiappe, 2005), } \\
\text { possibly indicating lineage- } \\
\text { specific ontogenetic } \\
\text { trajectories. }\end{array}$ \\
\hline $\begin{array}{l}\text { Increasing depth of } \\
\text { quadrate fossa }\end{array}$ & Europasaurus & $\begin{array}{l}\text { Marpmann et } \\
\text { al., } 2014\end{array}$ & $\begin{array}{l}\text { This mirrors a phylogenetic } \\
\text { increase in the depth of this } \\
\text { fossa in Sauropodomorpha } \\
\text { (reversed in Flagellicaudata) }\end{array}$ \\
\hline
\end{tabular}




\begin{tabular}{|c|c|c|c|}
\hline $\begin{array}{l}\text { Hypothesized } \\
\text { transformation }\end{array}$ & $\begin{array}{c}\text { Taxa providing } \\
\text { evidence }\end{array}$ & Sources & Comments \\
\hline $\begin{array}{l}\text { Increasing development of } \\
\text { tooth-like process on body } \\
\text { of pterygoid }\end{array}$ & Europasaurus & $\begin{array}{l}\text { Marpmann et } \\
\text { al., } 2014\end{array}$ & - \\
\hline $\begin{array}{c}\text { Increasing depth of } \\
\text { basipterygoid fossa of the } \\
\text { pterygoid }\end{array}$ & Europasaurus & $\begin{array}{l}\text { Marpmann et } \\
\text { al., } 2014\end{array}$ & - \\
\hline $\begin{array}{c}\text { Crista interfenestralis } \\
\text { ossifies }\end{array}$ & $\begin{array}{l}\text { Apatosaurus; } \\
\text { Nebulasaurus; } \\
\text { Bellusaurus }\end{array}$ & $\begin{array}{l}\text { Balanoff, } \\
\text { Bever \& } \\
\text { Ikejiri, 2010; } \\
\text { Xing et al., } \\
\text { 2015a; this } \\
\text { study }\end{array}$ & - \\
\hline $\begin{array}{l}\text { Ossification of bony } \\
\text { septum dividing the optic } \\
\text { (CN II) foramen into } \\
\text { separate foramina }\end{array}$ & $\begin{array}{c}\text { Europasaurus; } \\
\text { basal } \\
\text { sauropodomorphs }\end{array}$ & $\begin{array}{l}\text { Marpmann et } \\
\text { al., } 2014\end{array}$ & $\begin{array}{l}\text { The presence of a single } \\
\text { optic foramen in basal } \\
\text { sauropodomorphs and } \\
\text { apparent reversion to the } \\
\text { plesiomorphic state in } \\
\text { Europasaurus suggests } \\
\text { ontogenetic ossification of } \\
\text { this septum }\end{array}$ \\
\hline $\begin{array}{l}\text { Closure of external } \\
\text { mandibular fenestra }\end{array}$ & Titanosauria & $\begin{array}{l}\text { Salgado, Coria } \\
\text { \& Chiappe, } \\
\text { 2005; García } \\
\text { et al., } 2010\end{array}$ & $\begin{array}{l}\text { An external mandibular } \\
\text { fenestra is absent in } \\
\text { neosauropods, with the } \\
\text { exception of Nigersaurus } \\
\text { (Sereno et al. 1999, 2007). } \\
\text { Appearance of this feature in } \\
\text { embryonic titanosaurians } \\
\text { suggests it is lost over the } \\
\text { course of ontogeny, though } \\
\text { without adult representatives } \\
\text { of the Auca Mahuevo } \\
\text { titanosaurian, this remains } \\
\text { speculative }\end{array}$ \\
\hline $\begin{array}{l}\text { Decrease in relative size of } \\
\text { surangular foramen }\end{array}$ & Rapetosaurus & $\begin{array}{l}\text { Curry Rogers } \\
\& \text { Forster, } \\
2004\end{array}$ & - \\
\hline
\end{tabular}




\begin{tabular}{|c|c|c|c|}
\hline $\begin{array}{l}\text { Hypothesized } \\
\text { transformation }\end{array}$ & $\begin{array}{c}\text { Taxa providing } \\
\text { evidence }\end{array}$ & Sources & Comments \\
\hline $\begin{array}{l}\text { Displacement anteriorly of } \\
\text { the posterior extent of the } \\
\text { maxillary tooth row }\end{array}$ & $\begin{array}{c}\text { Diplodocinae; } \\
\text { Titanosauria }\end{array}$ & $\begin{array}{l}\text { Salgado, Coria } \\
\text { \& Chiappe, } \\
\text { 2005; García } \\
\text { \& Cerda, } \\
\text { 2010; García } \\
\text { et al., 2010; } \\
\text { Whitlock, } \\
\text { Wilson \& } \\
\text { Lamanna, } \\
\text { 2010; Tschopp } \\
\text { \& Mateus, } \\
2013\end{array}$ & - \\
\hline $\begin{array}{l}\text { Decrease in number of } \\
\text { teeth? }\end{array}$ & $\begin{array}{l}\text { Camarasaurus; } \\
\text { Bonitasaura; } \\
\text { Diplodocidae }\end{array}$ & this study & See Discussion \\
\hline
\end{tabular}

1

2 


\section{Figure 1}

Reconstruction of the skull of Bellusaurus sui from the Middle-Late Jurassic Shishugou Formation of Xinjiang, China.

This reconstruction is a composite based on isolated holotypic and referred material. (A)

Right lateral view. (B) Dorsal view. Holotypic elements are indicated in blue and referred elements are in green. 
A

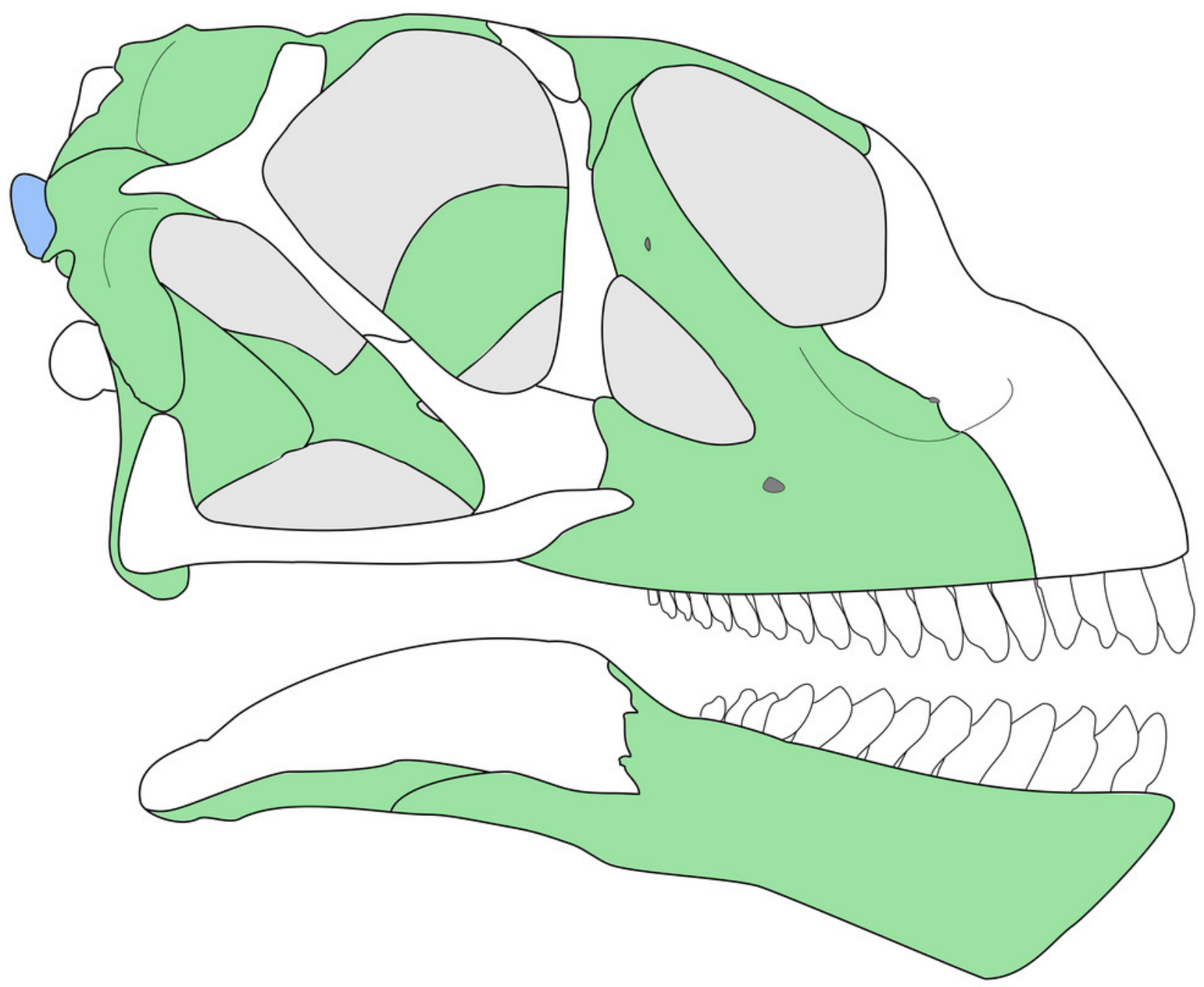

B

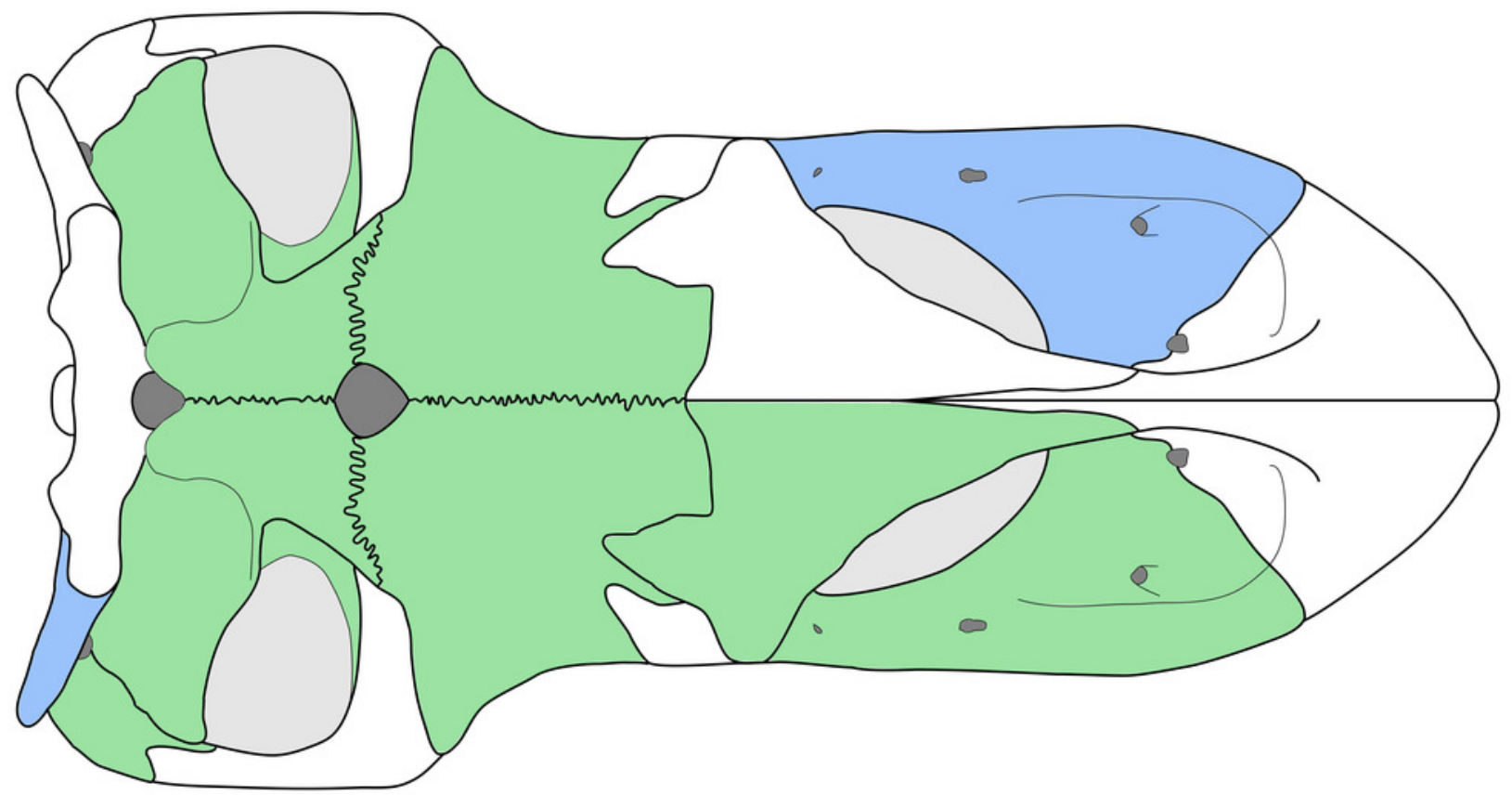


Figure 2

Stratigraphic position of sauropods from the Middle-Late Jurassic Shishugou Formation of Xinjiang, China.

Composite section based on local sections at Jiangjunmiao, Konglonggou, and Wucaiwan. Radiometric dates are from Wucaiwan only. Copyright by David Eberth, modified with permission.
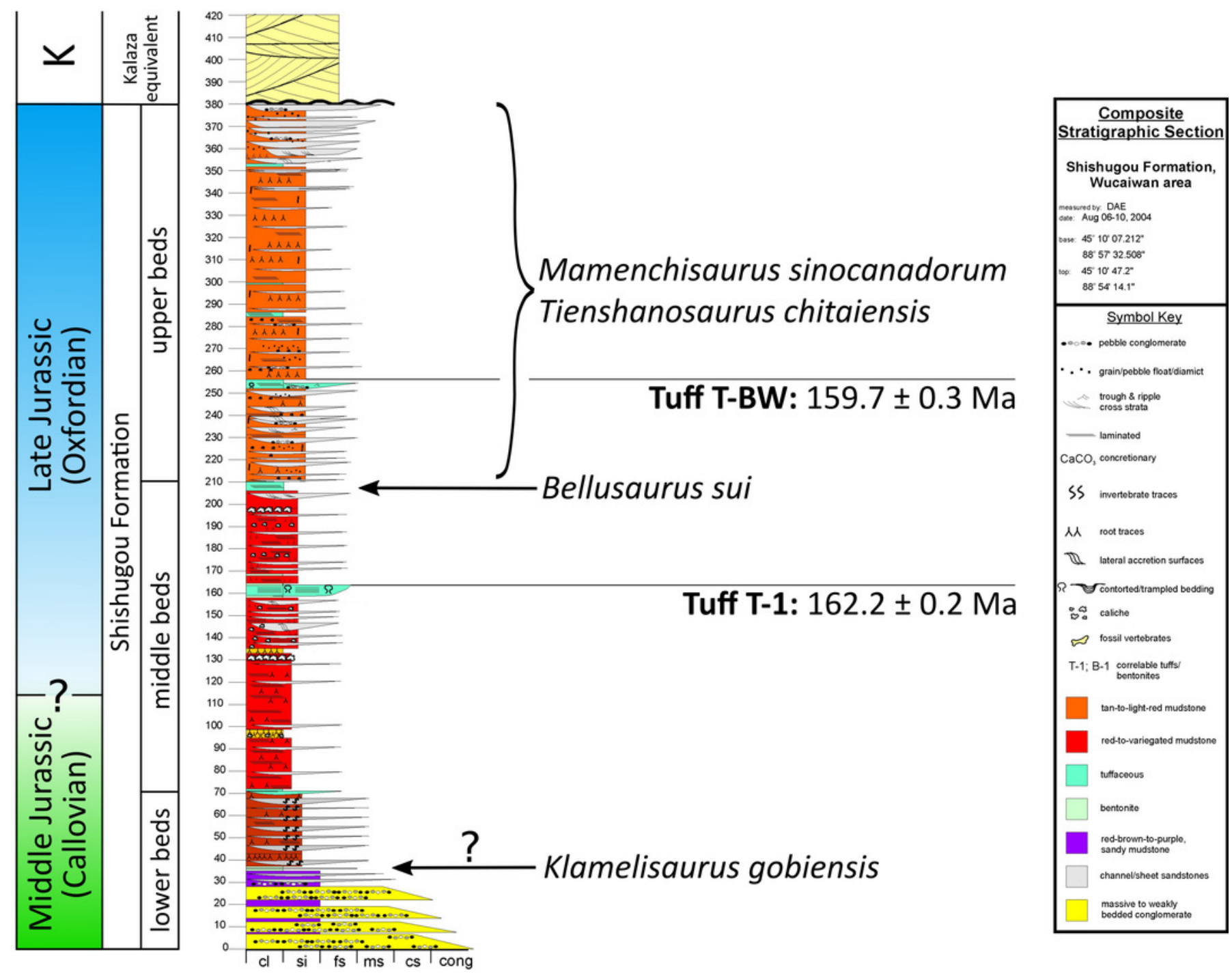
Figure 3

Bellusaurus sui, holotype left maxilla (IVPP V8299.5).

(A) Lateral view. (B) Medial view. (C) Dorsal view. (D) Ventral view. (E) Anterior view. (F) Posterior view. Abbreviations: amf, anterior maxillary foramen; asp, ascending process of the maxilla; nf, narial fossa; snf, maxillary portion of the subnarial foramen. Scale bar $=3$ $\mathrm{cm}$.

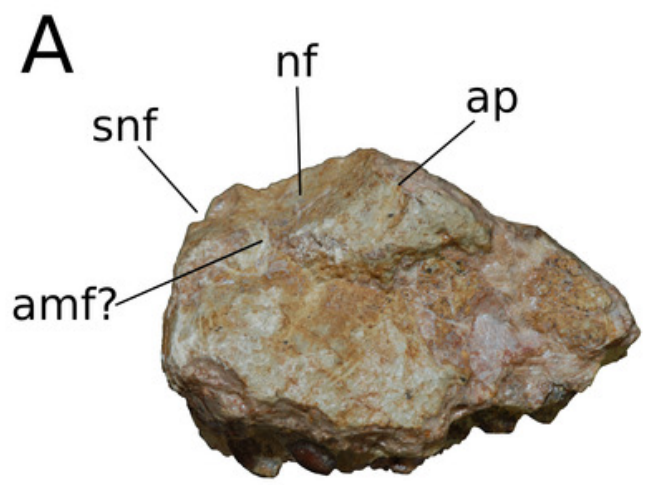

B

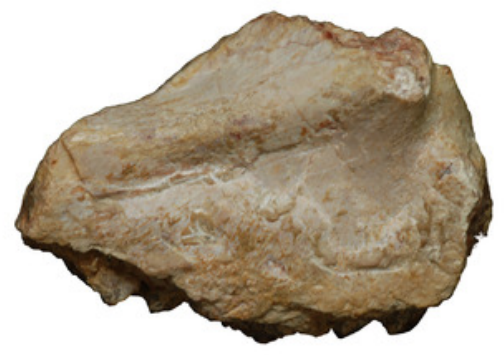

C

D
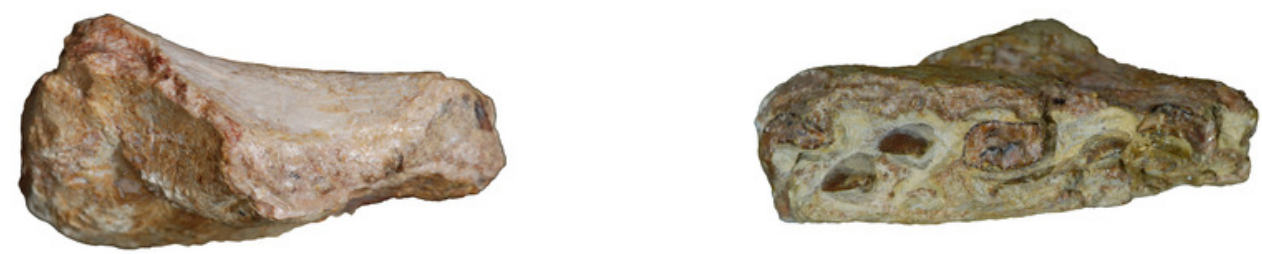

$\mathrm{E}$

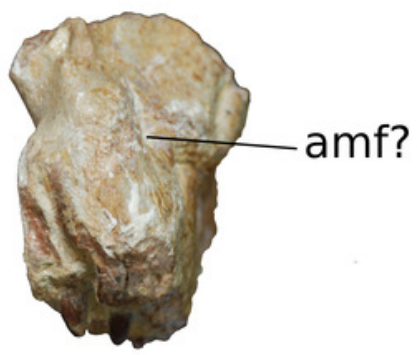

$\mathrm{F}$

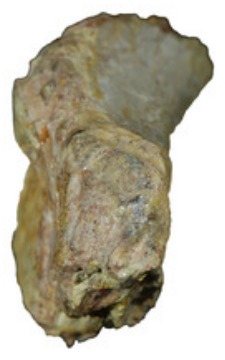




\section{Figure 4}

Bellusaurus sui, right maxilla (IVPP V17768.1).

(A) Lateral view. (B) Dorsal view. (C) Medial view. (D) Anterior view. (E) Posterior view emphasizing articulations of the posterior portion of the maxilla. Abbreviations: aof, antorbital fenestra; asp, ascending process; ef, ectopterygoid facet; et, erupting tooth; jf, jugal facet; Ip, lacrimal process; nf, narial fossa; pf, palatine facet; qjf, quadratojugal facet; $\mathbf{r t}$, replacement tooth; snf, maxillary portion of the subnarial foramen. Scale bar $=3 \mathrm{~cm}$.

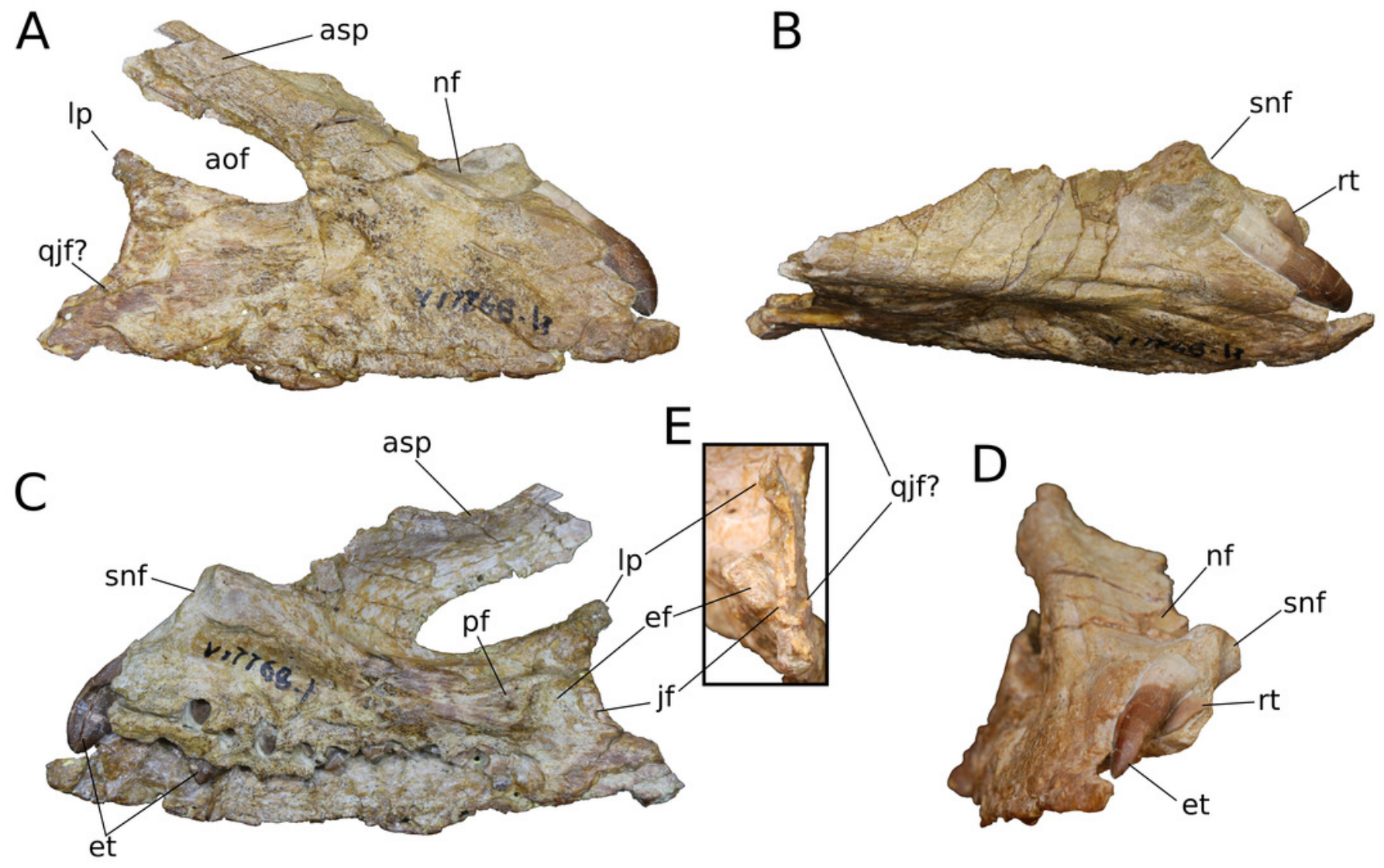




\section{Figure 5}

Bellusaurus sui, right maxilla (IVPP V17768.2).

(A) Lateral view. (B) Medial view. (C) Anterior view. (D) Dorsal view. Abbreviations: aof, antorbital fenestra; asp, ascending process; gdmp, groove for the dorsal maxillary process of the premaxilla; nf, narial fossa; nfo, neurovascular foramen; pmp, premaxillary process; snf, maxillary portion of the subnarial foramen; wt, wart-like tuberosities. Asterisk denotes an autapomorphy. Scale bar $=3 \mathrm{~cm}$.

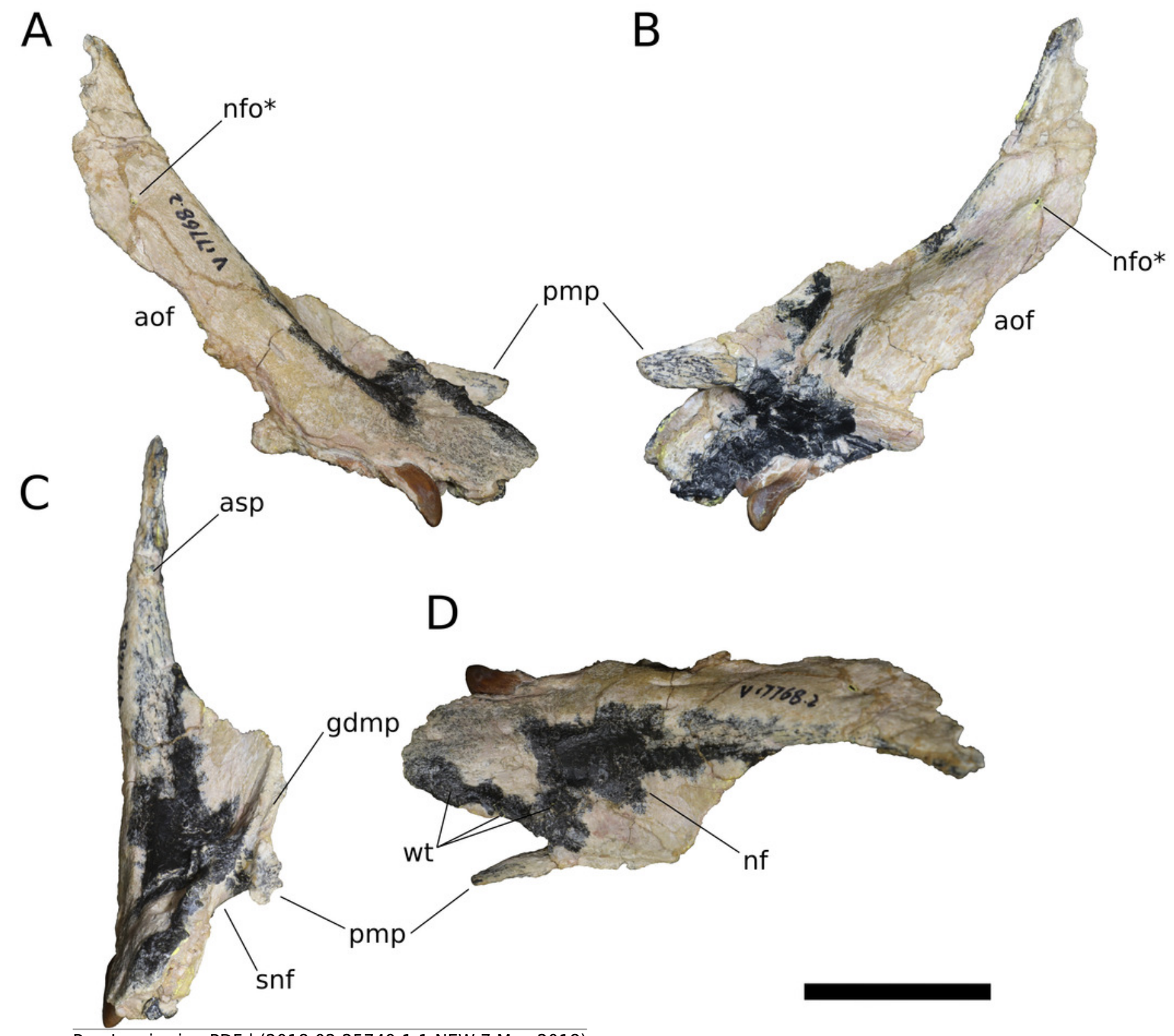




\section{Figure 6}

Bellusaurus sui, right maxilla (IVPP V17768.3).

(A) Lateral view. (B) Medial view. (C) Dorsal view. (D) Anterior view. Abbreviations: al, alveolus; amf, anterior maxillary foramen; aof, antorbital fenestra; asp, ascending process; ef, ectopterygoid facet; Ip, lacrimal process; paf, posterior alveolar foramen; paof, preantorbital foramen; pmp, premaxillary process; qjf, quadratojugal facet; snf, maxillary portion of the subnarial foramen. Scale bar $=3 \mathrm{~cm}$.

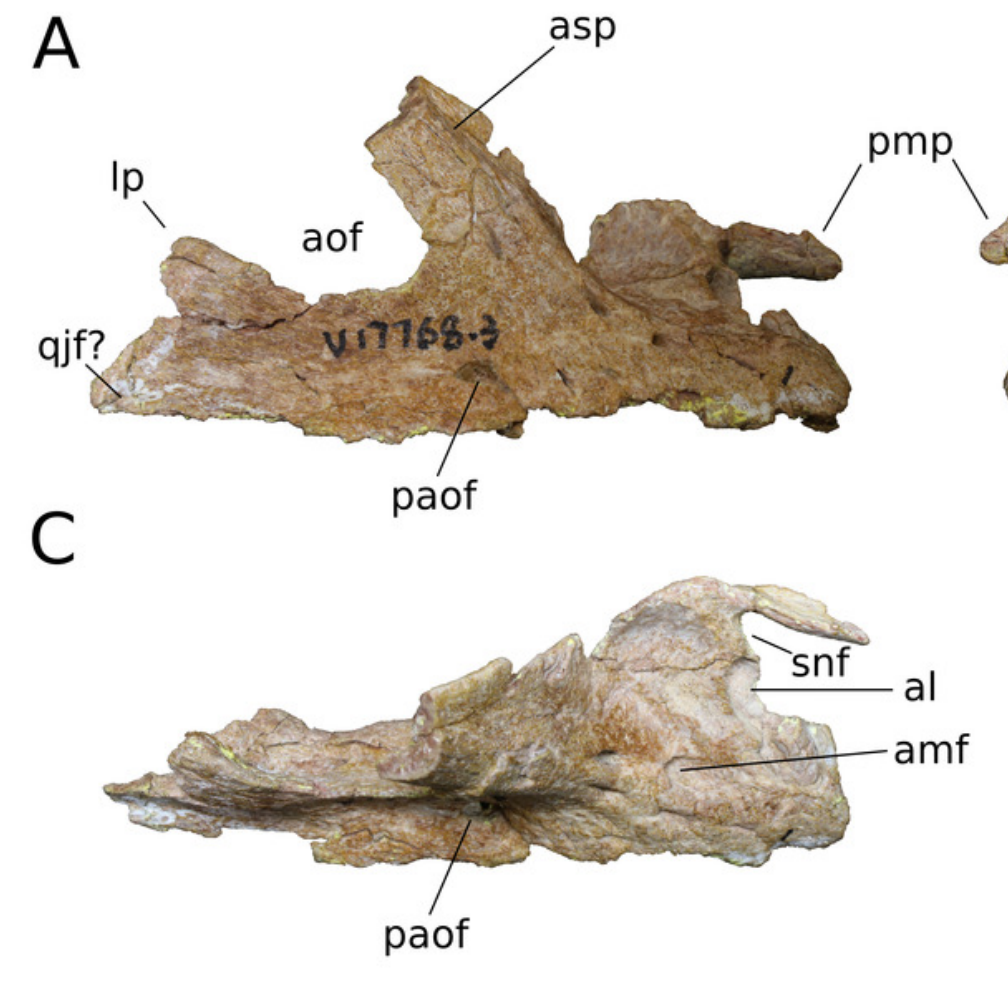

B

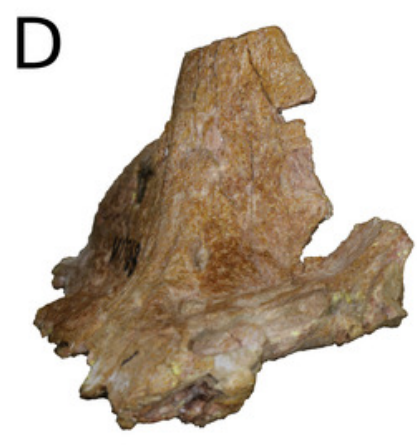




\section{Figure 7}

Maxillary neurovasculature and replacement teeth in Bellusaurus sui.

Major maxillary neurovasculature channels indicated in red; replacement teeth indicated in orange. (A) Right maxilla (IVPP V17768.1) in lateral view. (B) Right maxilla (IVPP V17768.3) in lateral view. (C) Transparent rendering of right maxilla (IVPP V17768.1) in lateral view. (D) Transparent rendering of right maxilla (IVPP V17768.3) in lateral view. amf, anterior maxillary foramen; paof, preantorbital foramen. Not to scale.
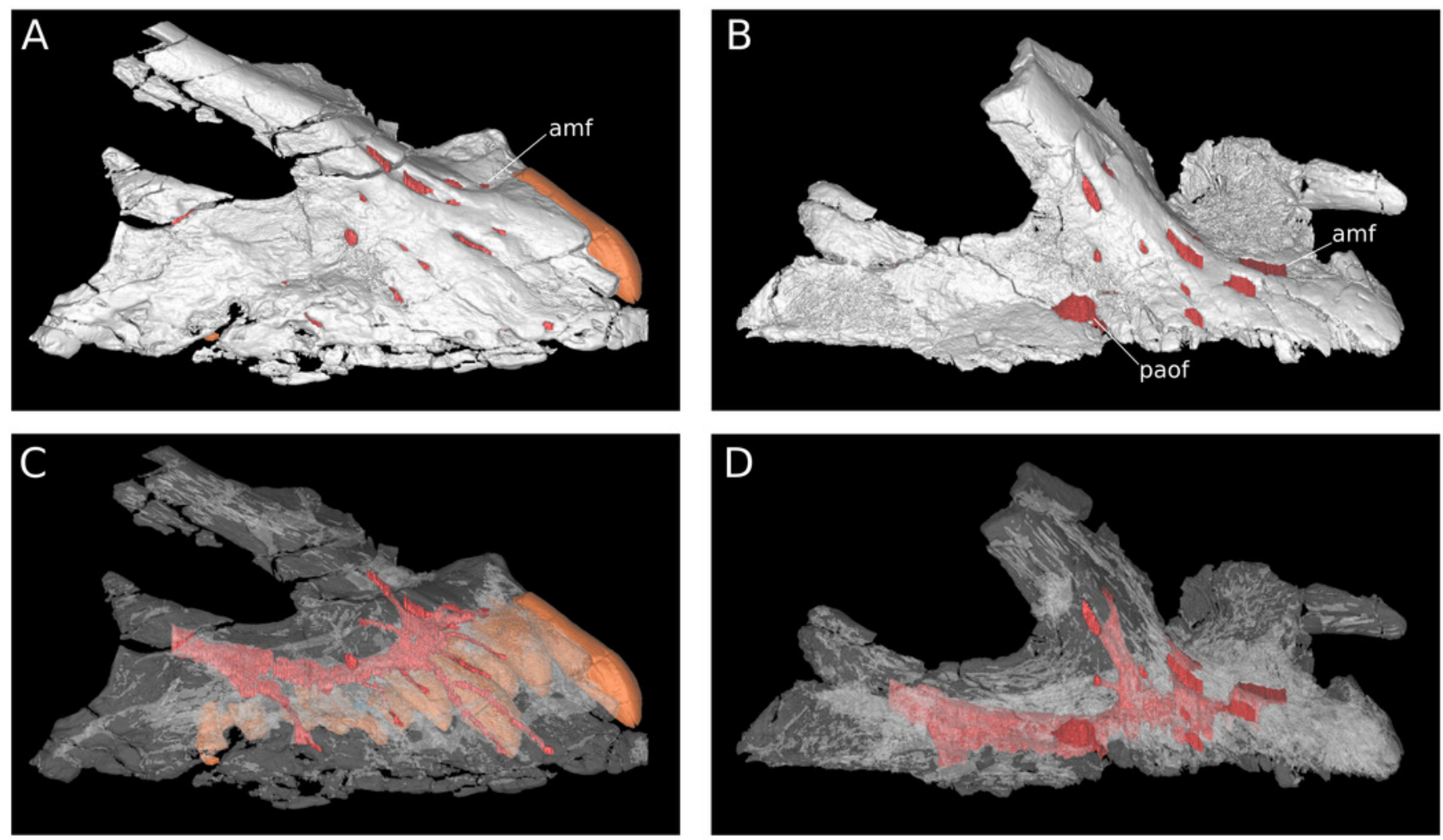
Figure 8

Bellusaurus sui, right nasal (IVPP V17768.4).

(A) Dorsal view. (B) Lateral view. (C) Medial view. (D) Ventral view. Abbreviations: cc, crista cranii; gnp, groove for the nasal process of the premaxilla; nc, nasal cavity; oc, orbital cavity; pmp, premaxillary process; vlp, ventrolateral process. Scale bar $=3 \mathrm{~cm}$.

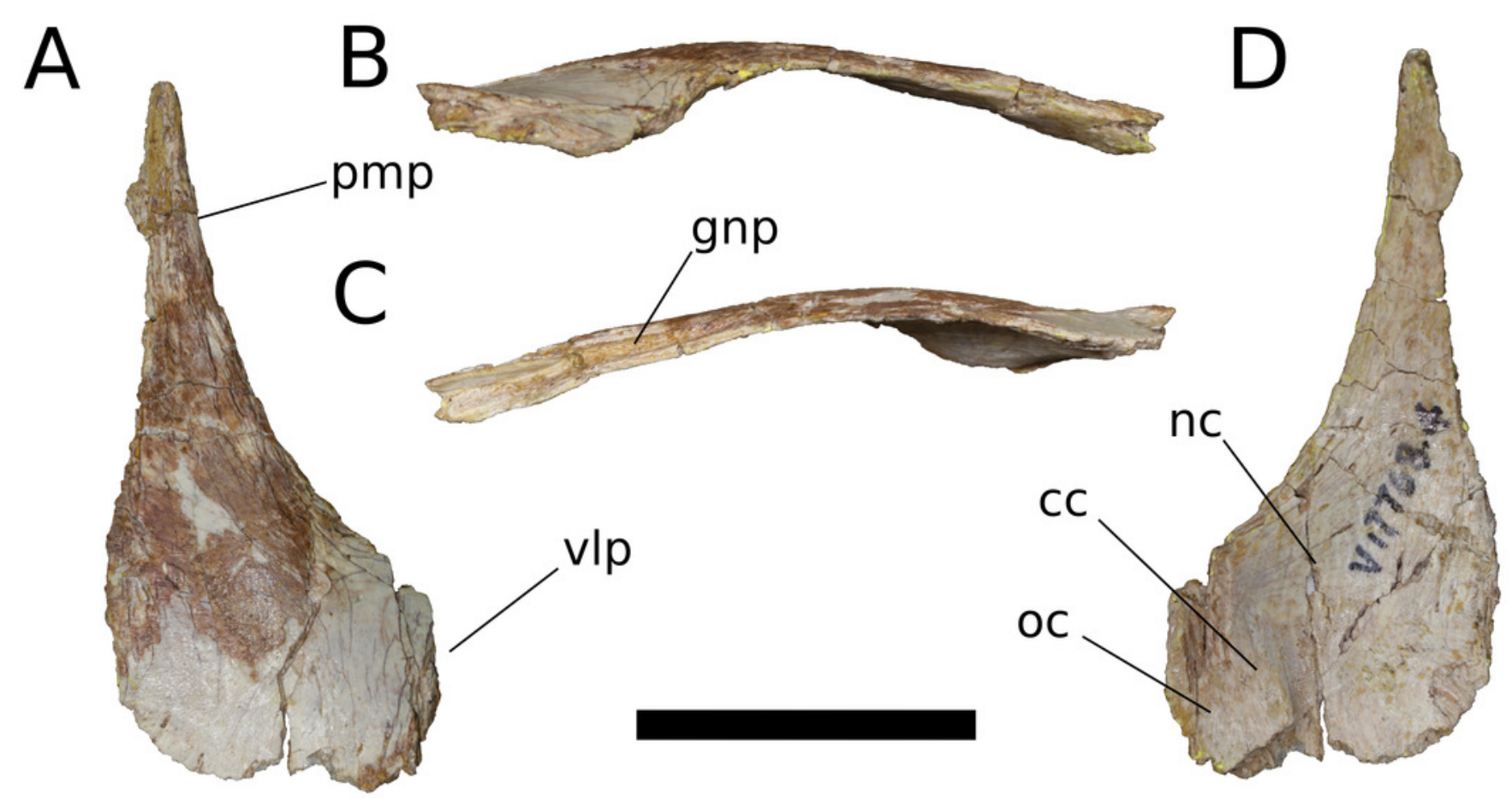




\section{Figure 9}

Bellusaurus sui, right frontal and parietal (IVPP V17768.5).

(A) Dorsal view. (B) Ventral view. (C) Posterior view. (D) Lateral view. (E) Medial view.

Abbreviations: cc, crista cranii; dv, diploic vein impressions; dvsf, fossa associated with dural venous sinuses; fpf, frontoparietal fenestra; fps, frontal-parietal suture; Isa, laterosphenoid articular surface; naf, nasal facet; nc, nasal cavity; oc, orbital cavity; pof, postorbital facet; ppf, postparietal foramen; prf, prefrontal facet; sf, squamosal facet; sof, frontal portion of the supraorbital foramen; stf, supratemporal fenestra; tr, transverse ridge separating anterior and posterior compartments of the dural venous sinuses. Scale bar $=3$ $\mathrm{cm}$. 

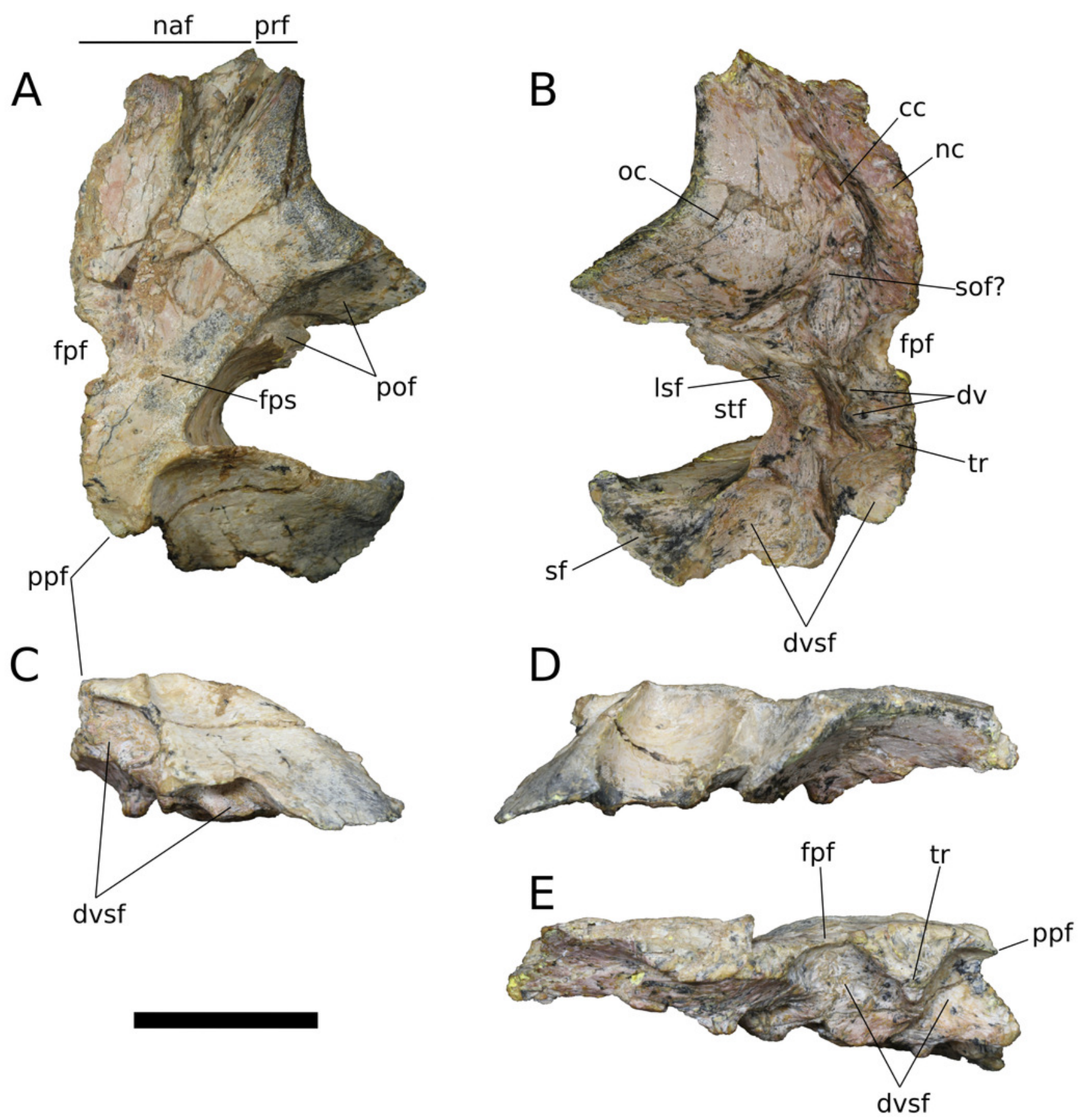


\section{Figure 10}

Bellusaurus sui, left frontal and parietal (IVPP V17768.6).

(A) Dorsal view. (B) Ventral view. (C) Posterior view. (D) Lateral view. (E) Medial view.

Abbreviations: cc, crista cranii; dvsf, fossa associated with dural venous sinuses; fpf, frontoparietal fenestra; fps, frontal-parietal suture; Isa, laterosphenoid articular surface; pof, postorbital facet; sf, squamosal facet; stf, supratemporal fenestra; tr, transverse ridge separating anterior and posterior compartments of the dural venous sinuses. Scale bar $=3$ $\mathrm{cm}$. 
A

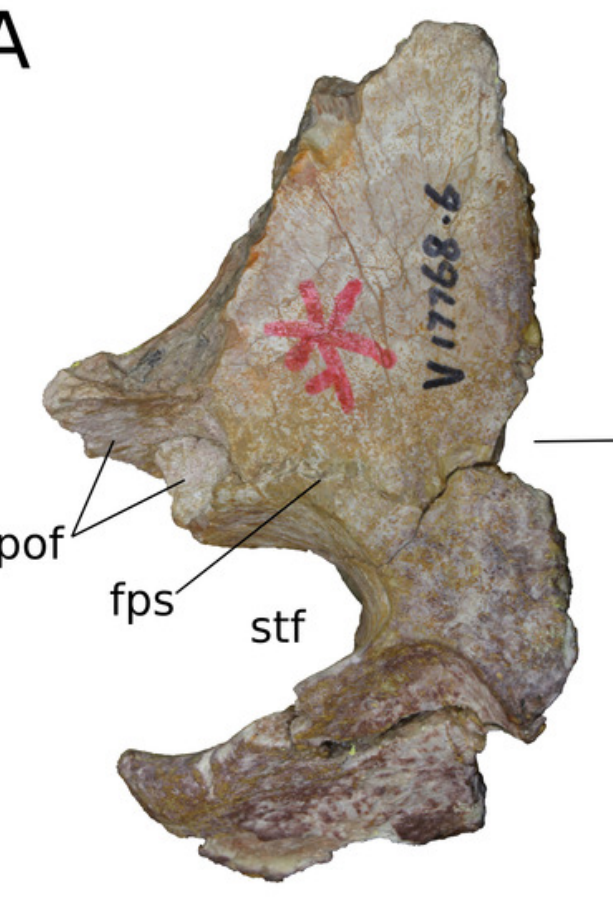

C

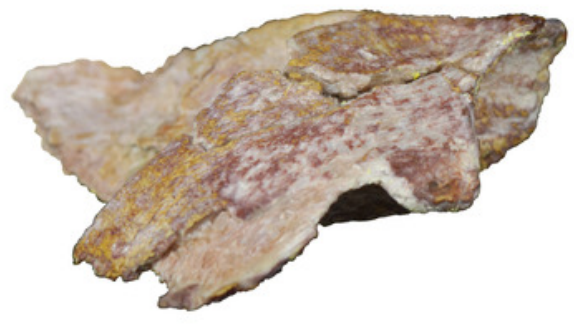

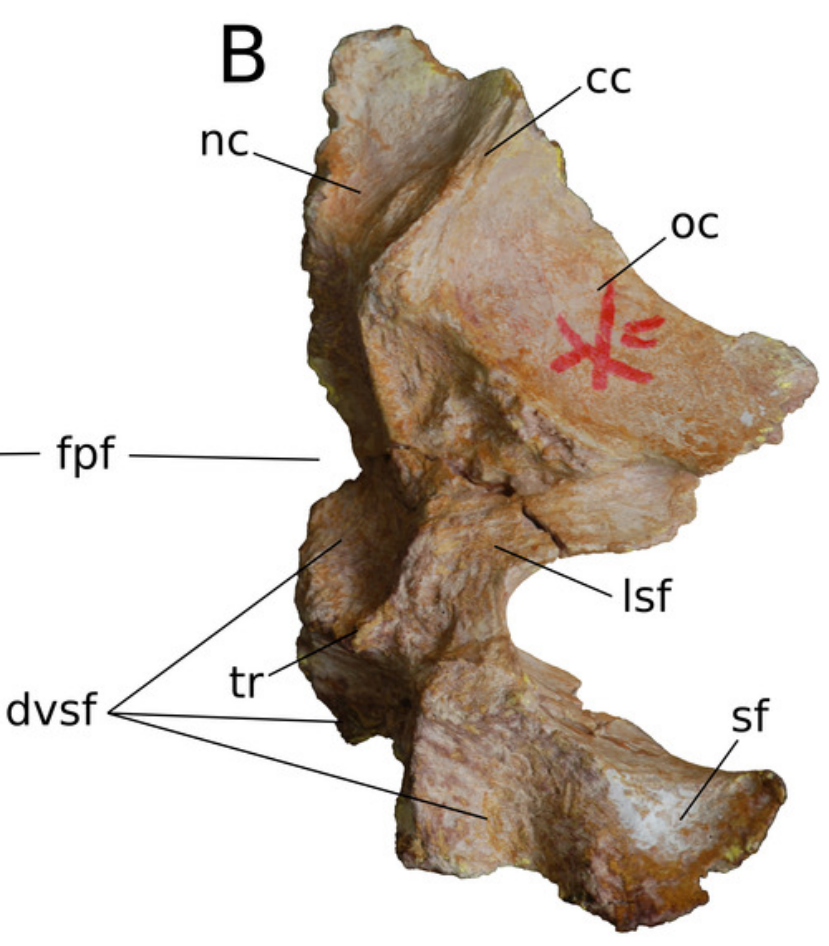

D

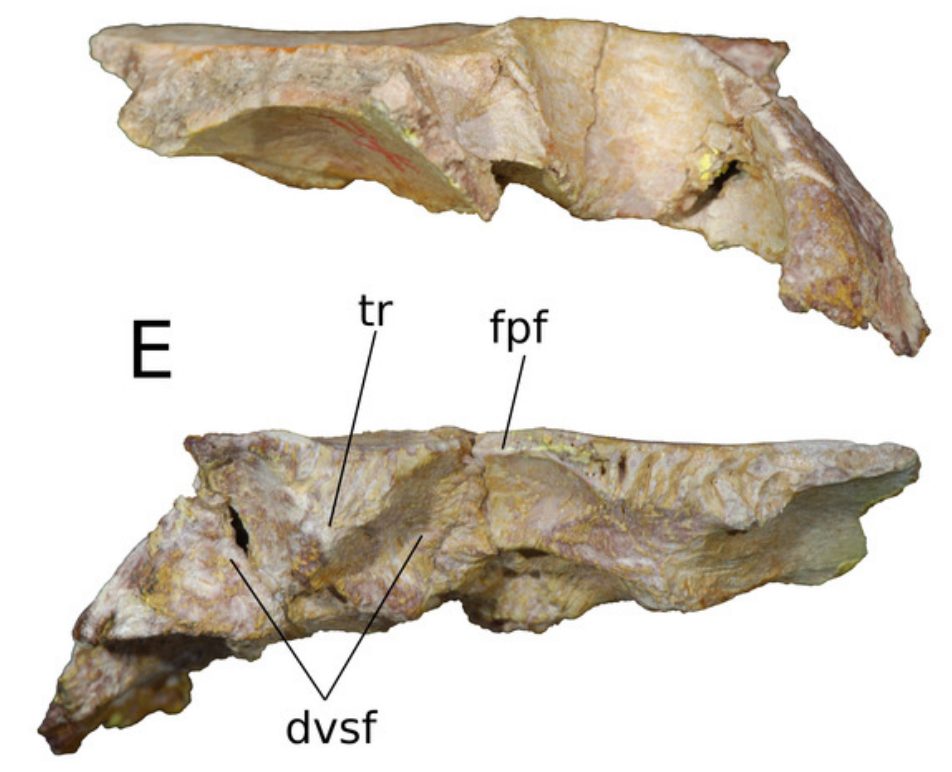




\section{Figure 11}

Bellusaurus sui, left frontal and parietal (IVPP V17768.7).

(A) Dorsal view. (B) Ventral view. (C) Posterior view. (D) Lateral view. (E) Medial view. Abbreviations: cc, crista cranii; dvsf, fossa associated with dural venous sinuses; fpf, frontoparietal fenestra; fps, frontal-parietal suture; Isa, laterosphenoid articular surface; naf, nasal facet; pof, postorbital facet; ppf, postparietal foramen; prf, prefrontal facet; stf, supratemporal fenestra; $\mathbf{t r}$, transverse ridge separating anterior and posterior compartments of the dural venous sinuses. Scale bar $=3 \mathrm{~cm}$. 


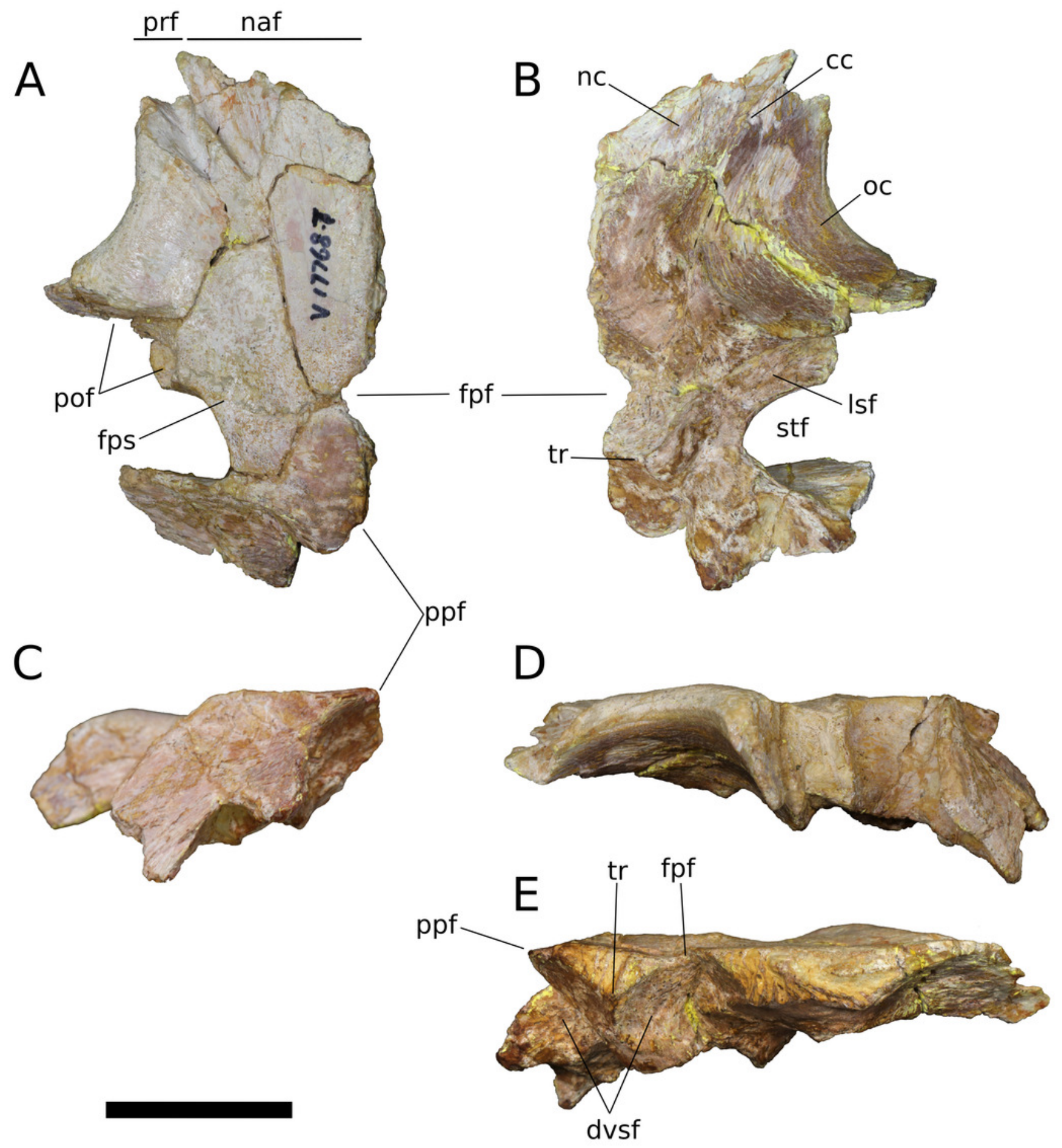




\section{Figure 12}

Bellusaurus sui, right squamosal (IVPP V17768.8).

(A) Dorsal view. (B) Lateral view. (C) Posterior view. (D) Anterior view. (E) Medial view. (F) Ventral view. Abbreviations: ap, anterior process; dmp, dorsomedial process; Ino, lateral notch; Itp, laterotemporal fenestra; mno, medial notch; parf, parietal facet; pof, postorbital facet; popf, paroccipital process facet; pp, posterior process; ptf, squamosal portion of the posttemporal foramen; vp, ventral process. Asterisk denotes an autapomorphy. Scale bar = $3 \mathrm{~cm}$.
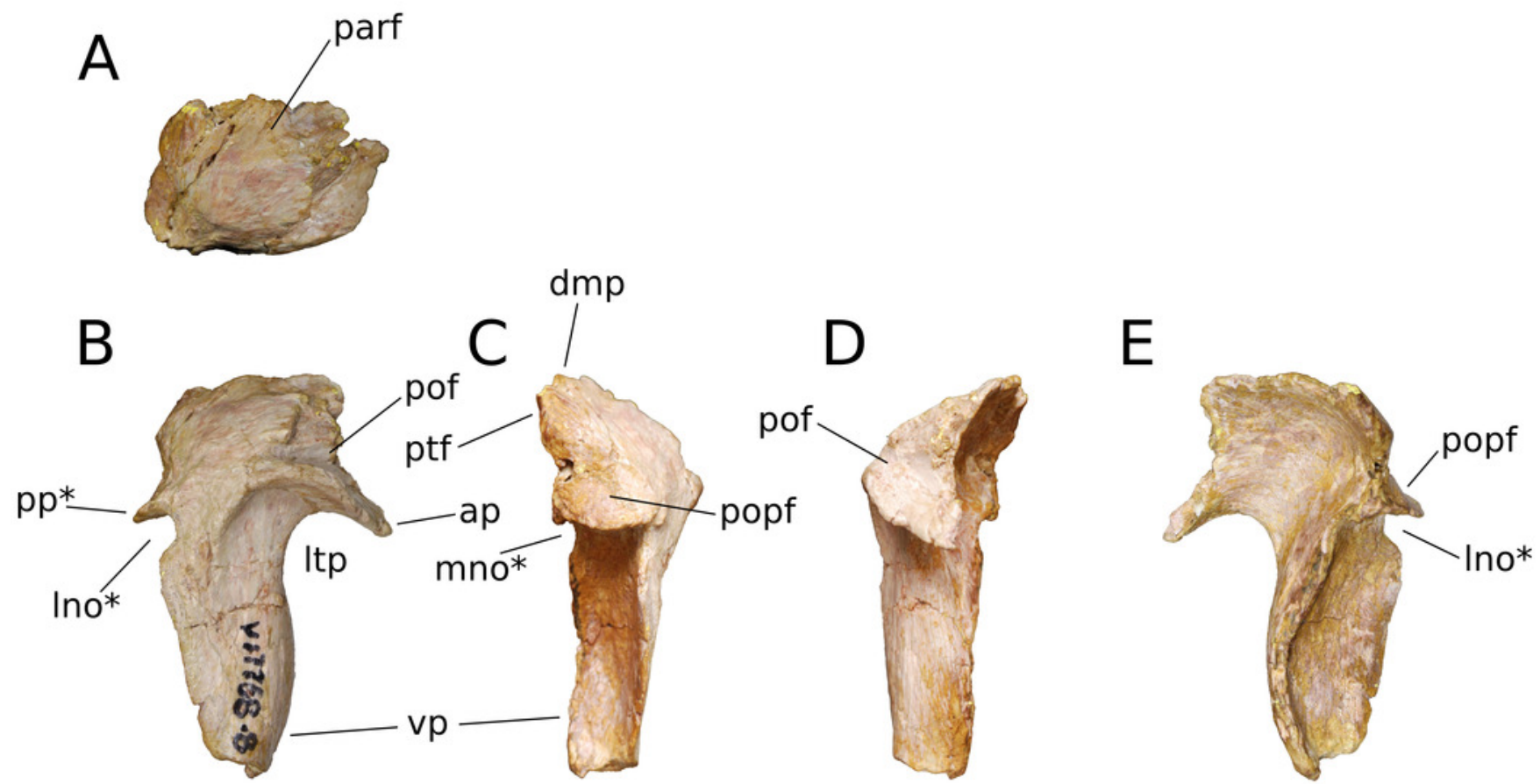

$\mathrm{F}$

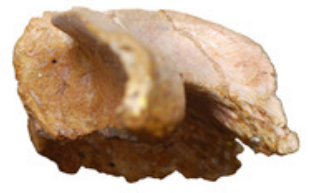




\section{Figure 13}

Bellusaurus sui, right quadrate (IVPP V17768.9).

(A) Lateral view. (B) Anterior view. (C) Posterior view. (D) Medial view. (E) Ventral view.

Abbreviations: amc, anteromedial concavity; ptw, pterygoid wing; qf, quadrate fossa; qjf, quadratojugal facet. Asterisk denotes an autapomorphy. Scale bar $=3 \mathrm{~cm}$.

A

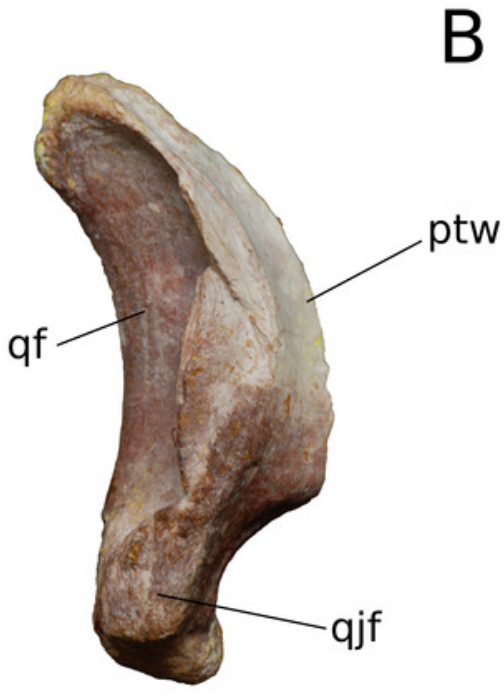

$\mathrm{E}$

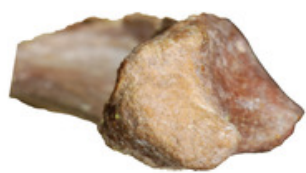

C

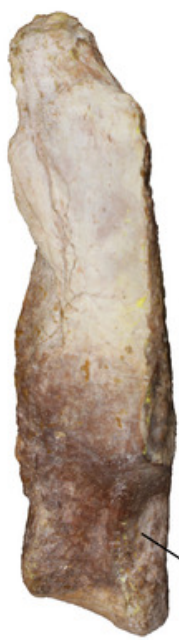

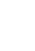
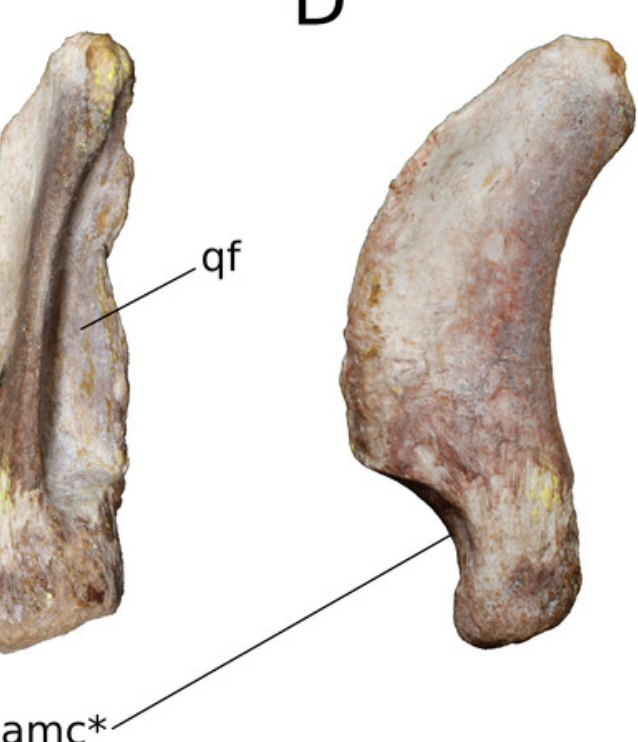


\section{Figure 14}

Bellusaurus sui, right pterygoid (IVPP V17768.10).

(A) Lateral view. (B) Medial view. (C) Dorsal view. (D) Ventral view. (E) Anterior view. (F) Posterior view. Grayed out areas are supporting matrix. Abbreviations: bps, socket for the basipterygoid process; ds, dorsal shelf of the quadrate process; ef, ectopterygoid facet; gr, groove; ptt, pterygoid trough; qp, quadrate process; ri, ridge; tp, transverse process; vp, vomerine process. Asterisk denotes an autapomorphy. Scale bar $=3 \mathrm{~cm}$. 


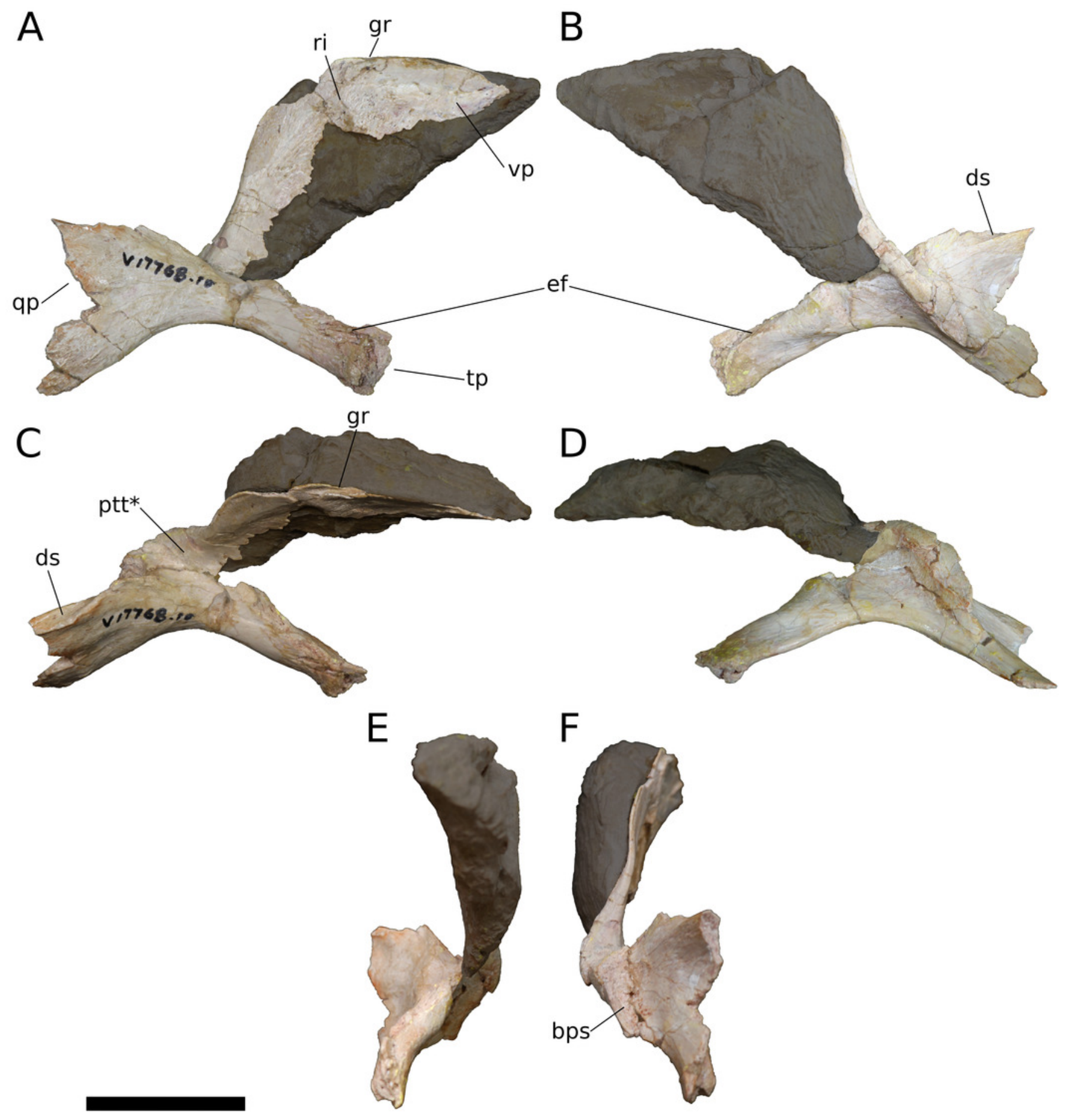




\section{Figure 15}

Bellusaurus sui, holotype right otoccipital (IVPP V8299.1).

(A) Posterior view. (B) Anterior view. (C) Dorsal view. (D) Ventral view. (E) Lateral view. (F) Medial view. Abbreviations: aoc, area of the atlanto-occipital capsule; ci, crista interfenestralis; $\mathbf{f m}$, otoccipital margin of the foramen magnum; $\mathbf{m f}$, metotic foramen; pra, prootic articular surface; pop, paroccipital process; prof, proatlantal facet; sf, squamosal articular facet. Scale bar $=3 \mathrm{~cm}$. 


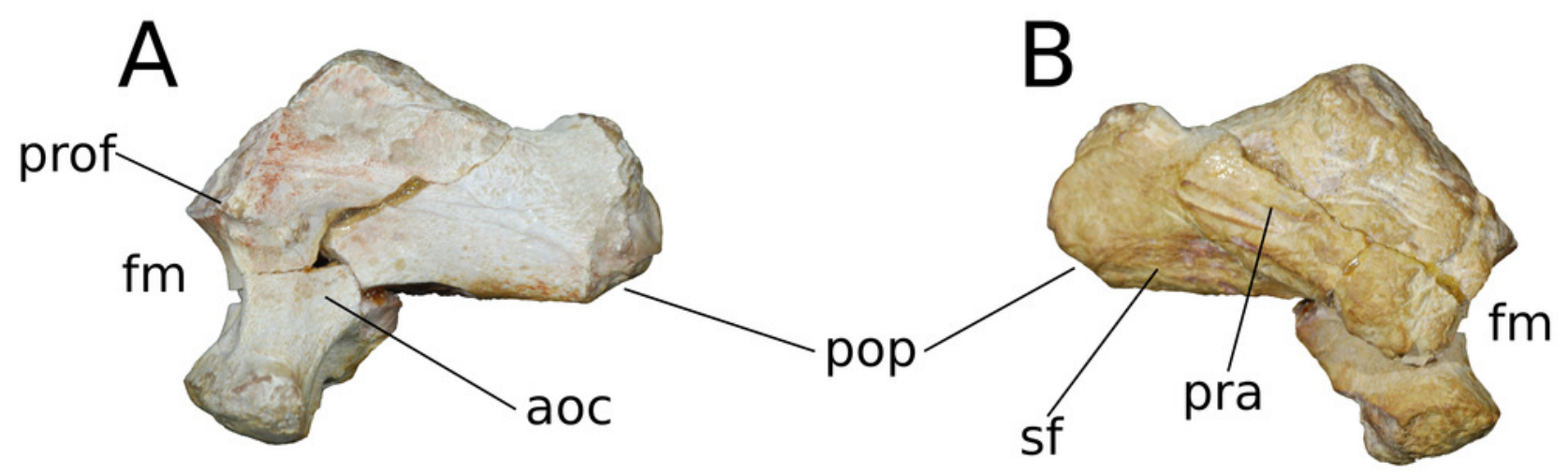

C

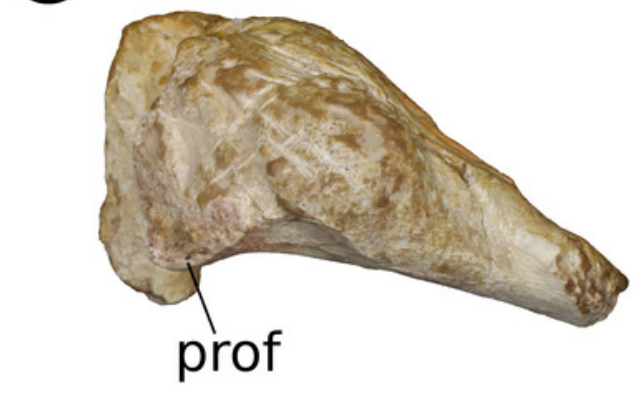

D

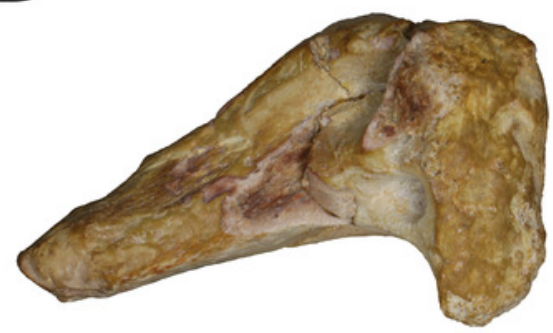

E

F
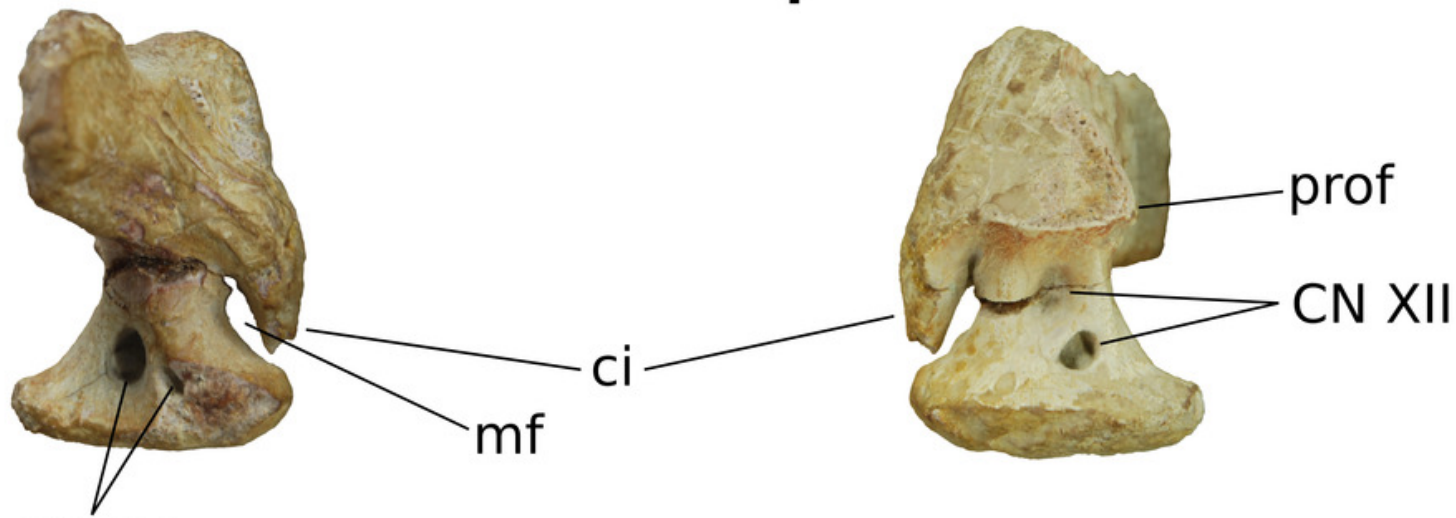

CN XII 


\section{Figure 16}

Bellusaurus sui, holotype parabasisphenoid (IVPP V8299.2).

(A) Dorsal view. (B) Anterior view. (C) Right lateral view. (D) Left lateral view. (E) Posterior view. (F) Ventral view. Abbreviations: bpp, basipterygoid process; bt, basisphenoid portion of basal tubera; cv, crista ventrolateralis; dos, dorsum sellae; fo, foramen; icf, internal carotid foramen; st, sella turcica; su, sagittal sulcus separating basal tubera. Scale bar = 3 $\mathrm{cm}$.

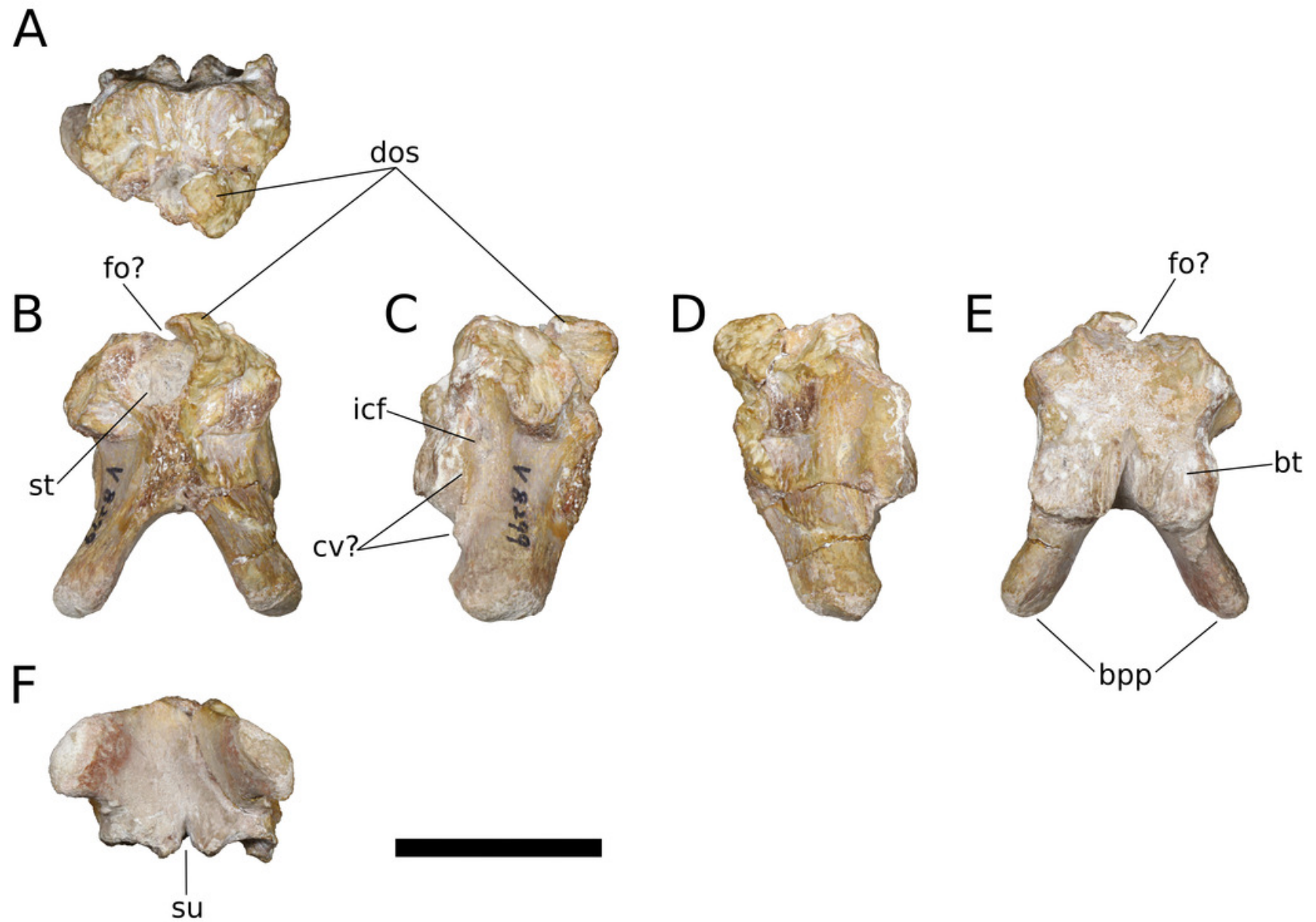




\section{Figure 17}

Bellusaurus sui, left dentary (IVPP V17768.11).

(A) Lateral view. (B) Medial view. (C) Ventral view. (D) Dorsal view. (E) Close up of dentary teeth. Abbreviations: dr, dorsal ramus; Mg, Meckelian groove; vr, ventral ramus. Scale bar $=3 \mathrm{~cm}(\mathrm{~A}-\mathrm{D})$ and $1 \mathrm{~cm}(\mathrm{E})$.

A

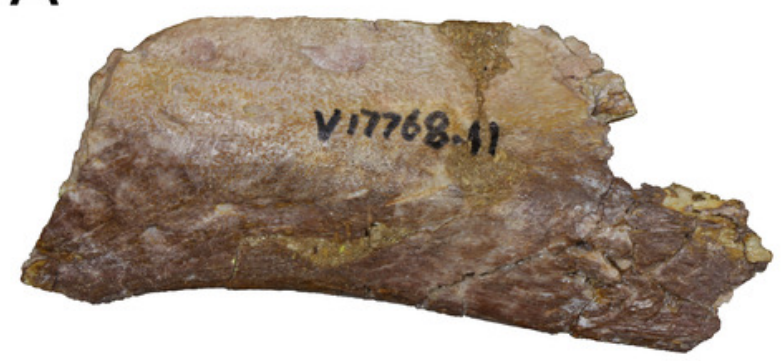

B

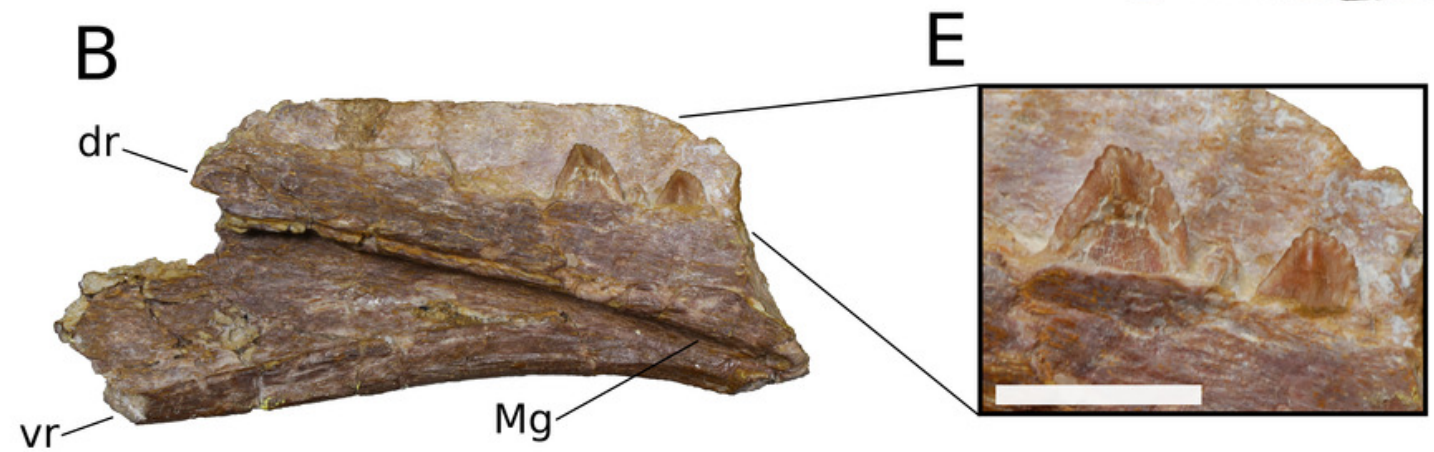

$\mathrm{E}$

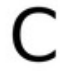

$\mathrm{D}$

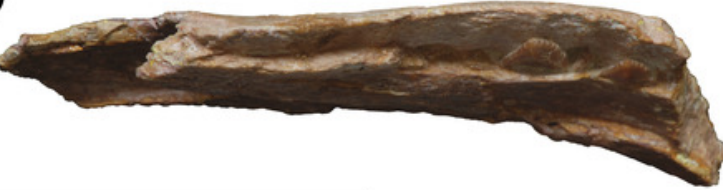




\section{Figure 18}

Bellusaurus sui, right angular (IVPP V17768.12).

(A) Lateral view. (B) Medial view. (C) Dorsal view. (D) Ventral view. Abbreviations: add, floor of the adductor chamber; spf, splenial facet; paa, prearticular facet. Scale bar $=3 \mathrm{~cm}$.

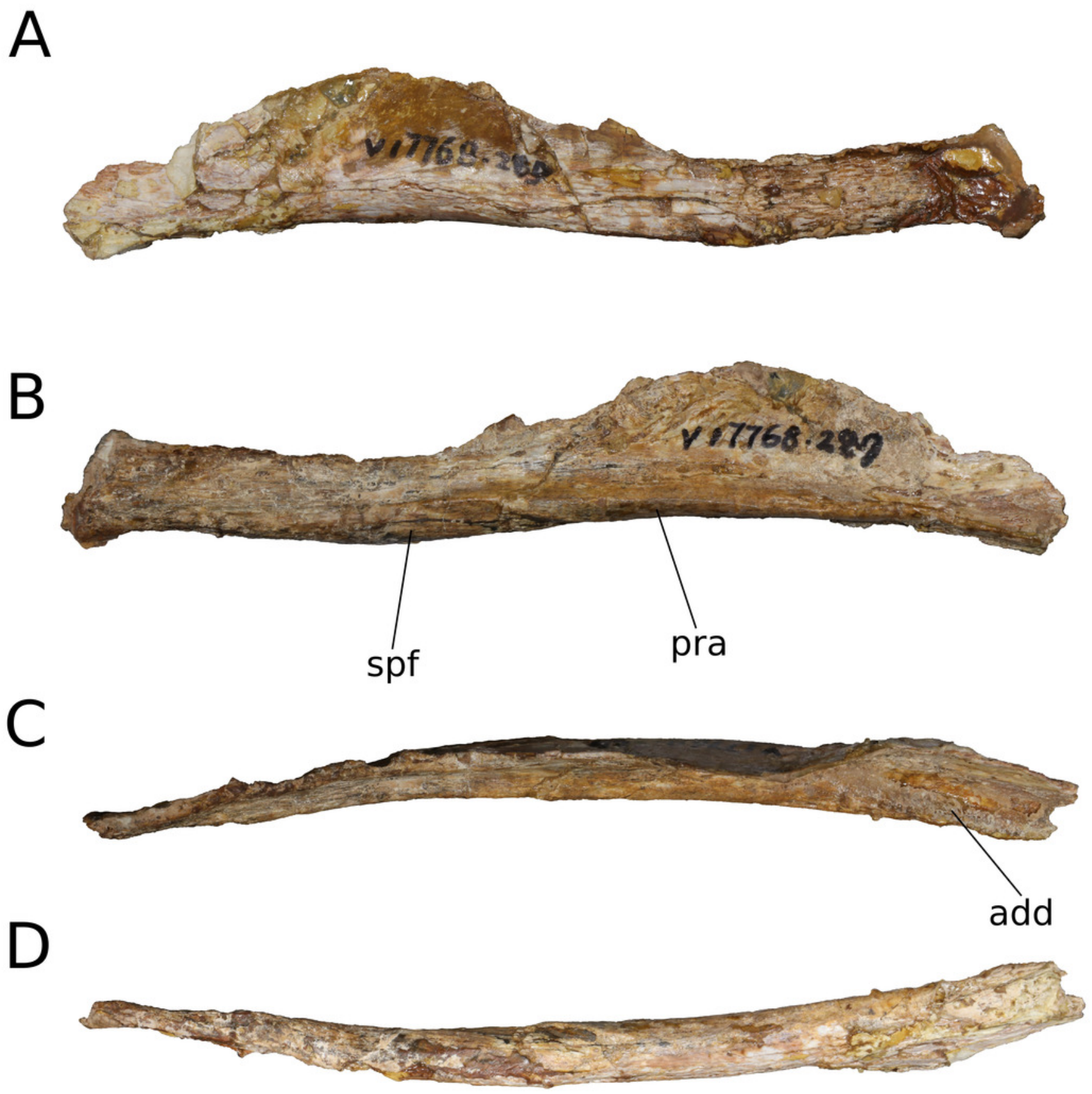


Figure 19

Bellusaurus sui, holotype isolated teeth (IVPP V8299.3, V8299.4, V8299.6, V8299.7).

( $A, E, I, M)$ Lingual views. (B, F,J,N) Labial views. (C,G,K,O) Mesial views. (D,H,L,P) Distal views. (A-D) IVPP V8299.3. (E-H) IVPP V8299.4. (I-L) IVPP V8299.6. (M-P) IVPP V8299.7. Scale bar = $3 \mathrm{~cm}$.

A
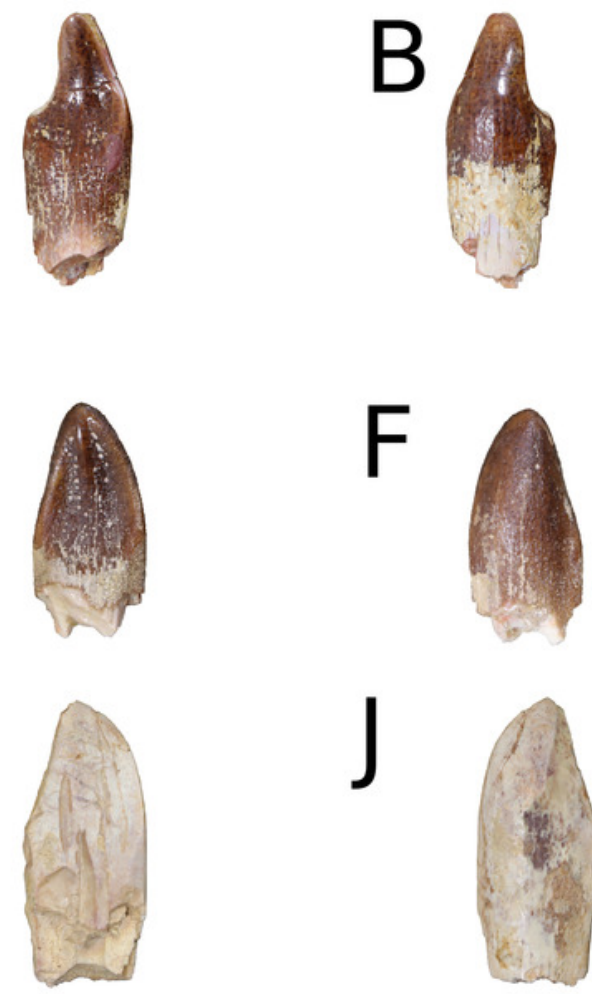

J

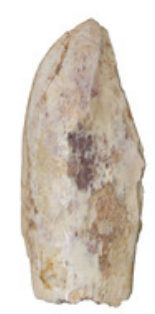

M

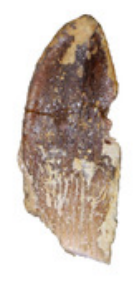

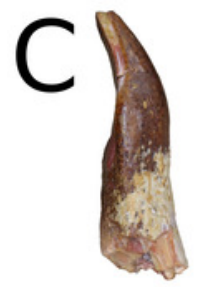
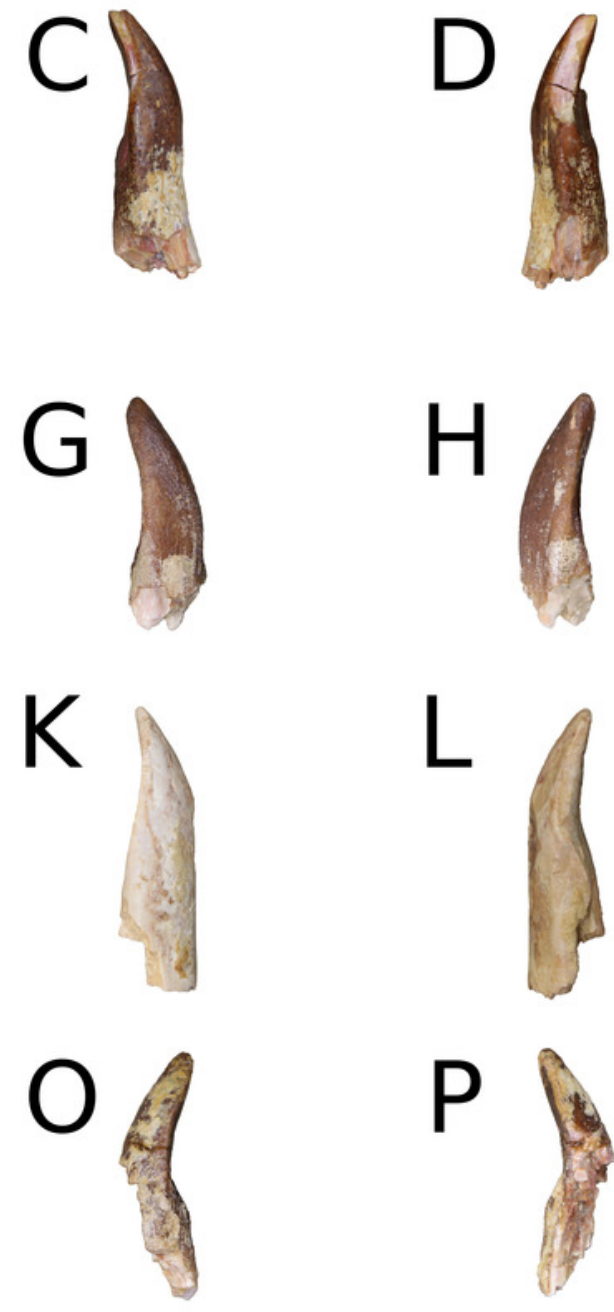


\section{Figure 20}

Bellusaurus sui, referred isolated teeth (IVPP V17768.12-21).

( $A, E, J, M, Q, U, Y, C C, G G, K K)$ Lingual views. (B,F,J,N,R,V,Z,DD,HH,LL) Labial views.

(C,G,K,O,S,W,AA,EE,II,MM) Mesial views. (D,H,L,P,T,X,BB,FF,JJ,NN) Distal views. (A-D) IVPP

V17768.12. (E-H) IVPP V17768.13. (I-L) IVPP V17768.14. (M-P) IVPP V17768.15. (Q-T) IVPP

V17768.16. (U-X) IVPP V17768.17. (Y-BB) IVPP V17768.18. (CC-FF) IVPP V17768.19. (GG-J))

IVPP V17768.20. (KK-NN) IVPP V17768.21. Scale bar $=3 \mathrm{~cm}$. 
A 9
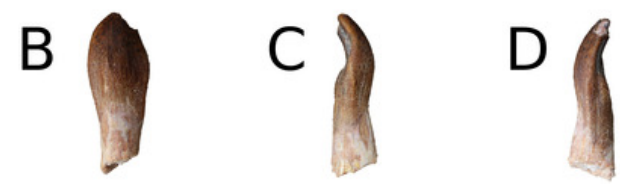

E
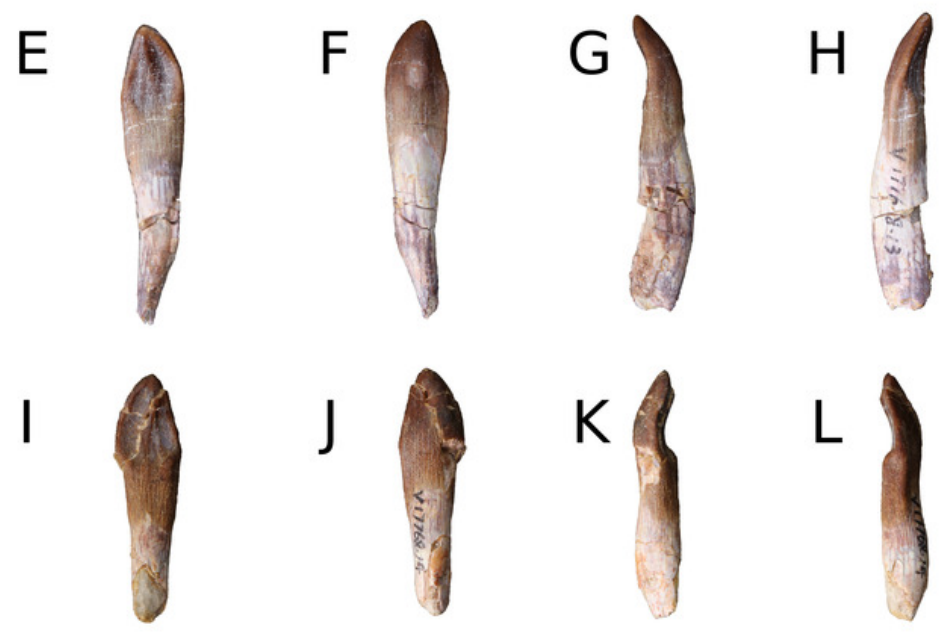

$M$
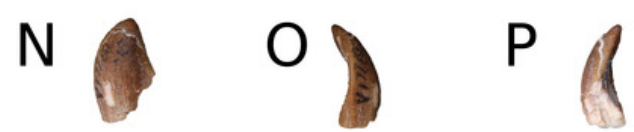

Q 8

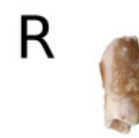

$\mathrm{S}$

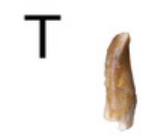

U
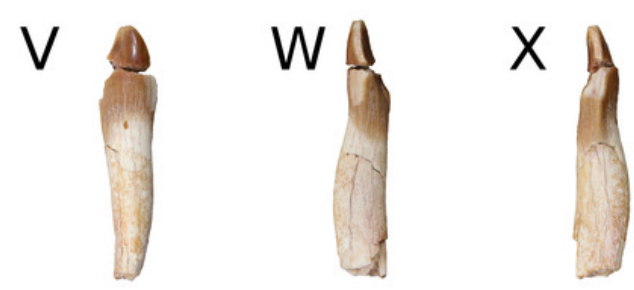

Y 8

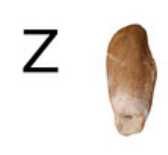

AA) $B B$

CC ?
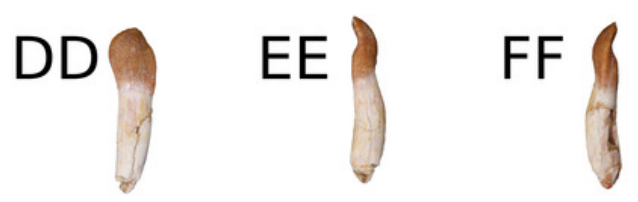

GG
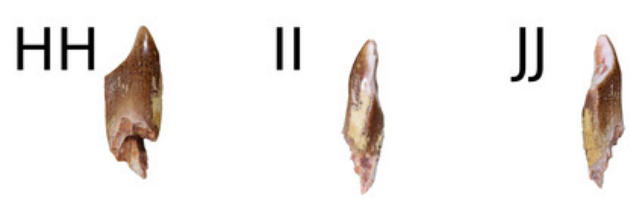

KK
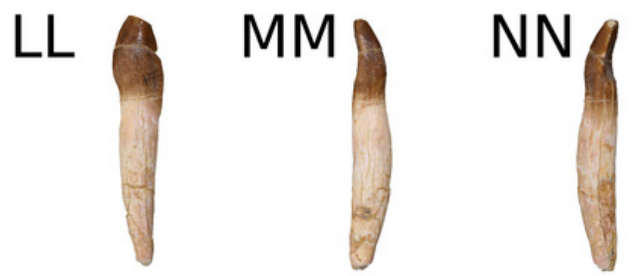


\section{Figure 21}

Bellusaurus sui, replacement teeth of the right maxilla (IVPP V17768.1).

Orange indicates the first generation of replacement teeth, blue indicates the second generation of replacement teeth, and red denotes neurovasculature. Numbers denote alveolus position. paf, posterior alveolar foramen. 


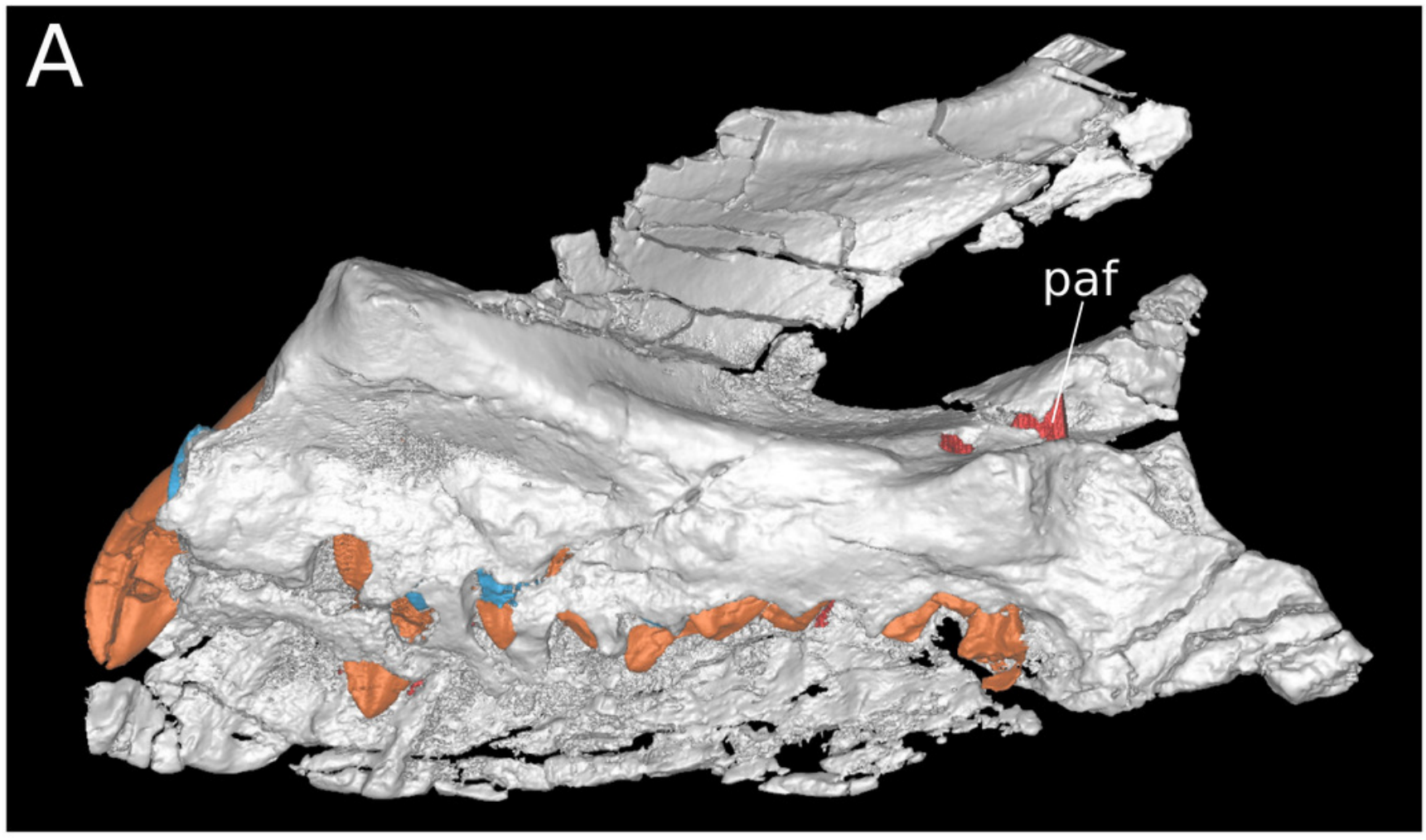

\section{B}

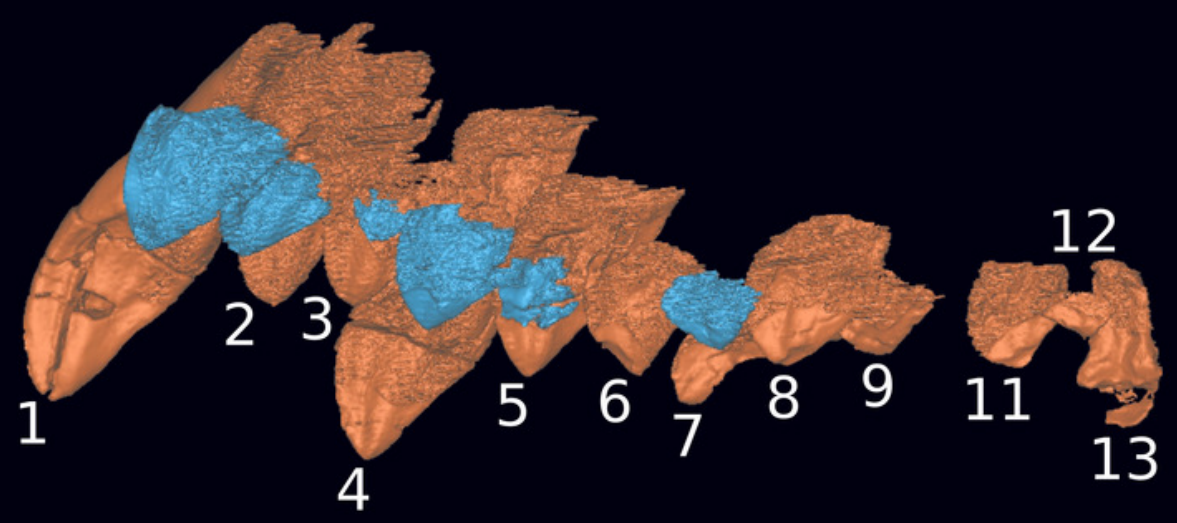

